Anhang 



\section{Zeittafel 1964}

3. Januar

12. Januar

15./16. Januar

20. Januar

21. Januar

27. Januar

27. bis 29. Januar

1. Februar

8. Februar

14./15. Februar

16. Februar

18. Februar

19. Februar

24. Februar

27. Februar

29. Februar

2. März
Deutschland-Initiative der Bundesregierung

Proklamation der Volksrepublik Sansibar nach einem Militärputsch gegen Sultan Ben Abdullah und Premierminister Hamadi

\section{Besuch des Bundeskanzlers Erhard in London}

Erklärung der Bundesregierung über die Erforschung und Ausbeutung des Festlandsockels in der Nordsee

Konferenz der 18-Mächte-Abrüstungskommission in Genf: Vorschlag des amerikanischen Präsidenten Johnson zu einem kontrollierten Einfrieren („freeze") der strategischen Kernwaffenträger

Aufnahme diplomatischer Beziehungen zwischen Frankreich und der Volksrepublik China

Besuch des Bundeskanzlers Erhard in Rom

Sowjetische Protestnote gegen die angebliche Produktion von Trägerraketen in der Bundesrepublik

Eröffnung einer Botschaft der DDR in der Republik Sansibar

Besuch des Bundeskanzlers Erhard in Paris

Wahl des Regierenden Bürgermeisters von Berlin, Brandt, zum Vorsitzenden der SPD

Antwort des Bundeskanzlers Erhard auf den Vorschlag des sowjetischen Ministerpräsidenten Chruschtschow vom 31. Dezember 1963 über einen Gewaltverzicht in territorialen Streitfragen

Erklärung der Bundesregierung über die Einstellung der Entwicklungshilfe an Ceylon als Reaktion auf die Umwandlung der Handelsvertretung der DDR in ein Generalkonsulat

Erklärung des Auswärtigen Amts über die Nichtaufnahme diplomatischer Beziehungen zur Volksrepublik Sansibar

Abbruch der Passierschein-Gespräche mit der DDR

Polnisches Memorandum über das Einfrieren der nuklearen Rüstung in Mitteleuropa (Gomulka-Plan)

Gründung des Deutschen Instituts für Entwicklungspolitik in Berlin (West) 
2./3. März

6. März

7. März

9./10. März

11. März

18. März

19. März

23. März

27. März

8. April

16. April

20. April

23./24. April

27. April

1. Mai

4. bis 6. Mai

4. Mai
Besuch des Bundeskanzlers Erhard in Den Haag

Unterzeichnung des Abkommens zwischen der Bundesrepublik und Bulgarien über den Waren- und Zahlungsverkehr sowie die Errichtung von Handelsvertretungen

Erklärung der sowjetischen Nachrichtenagentur TASS zur Außen- und Deutschlandpolitik der Bundesrepublik

Besuch des schwedischen Ministerpräsidenten Erlander in Bonn

Sowjetisches Aide-mémoire über die Bereitschaft zu Gesprächen mit der Bundesregierung

Modifizierung der Bestimmungen zur Ausgabe von „Temporary Travel Documents“ (TTD) durch den Ständigen NATO-Rat

Erklärung des Bundeskanzlers Erhard vor dem Bundestag: Ablehnung einer Senkung des deutschen Getreidepreises für die Wirtschaftsjahre 1964 und 1965

Eröffnung der Welthandelskonferenz in Genf

Stationierung von UNO-Friedenstruppen auf Zypern (Bereitstellung von finanziellen Mitteln durch die Bundesregierung am 18. März 1964)

Wiederaufnahme der Passierschein-Gespräche mit der DDR

Britischer Vorschlag zur Einbeziehung weiterer Waffensysteme in die geplante MLF

Erklärungen des amerikanischen Präsidenten Johnson und des sowjetischen Ministerpräsidenten Chruschtschow über die Einschränkung der Produktion von spaltbarem Material für militärische Zwecke

Besuch des Bundeskanzlers Erhard in Brüssel

Mitteilung der französischen Regierung: Zurückziehung der Offiziere aus den NATO-Marinestäben

Zusammenschluß von Tanganjika und Sansibar

Ablehnung des Gomulka-Plans vom 29. Februar 1964 durch die Bundesregierung

Auftakt der Verhandlungen im Rahmen des GATT in Genf über einen Zollabbau (Kennedy-Runde)

Besuch des Bundeskanzlers Erhard in Luxemburg 
11. Mai

13. bis 21. Mai

19. Mai

26. Mai

30. Mai

4. Juni

5. Juni

9. bis 13. Juni

12. Juni

13. Juni

26. Juni

1. Juli

3./4. Juli

8./9. Juli

23. Juli
Deutsch-amerikanisches Protokoll über den Devisenausgleich für die Jahre 1965 und 1966 („Hassel-McNamaraAbkommen")

Gespräche der Außenminister der drei Westmächte und der Bundesrepublik in Den Haag über die DeutschlandInitiative

Besuch des Regierenden Bürgermeisters von Berlin, Brandt, in den USA

Gespräche zwischen Bundeskanzler Erhard und führenden Politikern von CDU und CSU am Tegernsee über die Außenpolitik der Bundesrepublik

Einweihung des Moselkanals durch Großherzogin Charlotte von Luxemburg, Staatspräsident de Gaulle und Bundespräsident Lübke

Erstes Gespräch mit Vertretern der Volksrepublik China in Bern über die Aufnahme von Handelsbeziehungen

Unterzeichnung eines Handelsabkommens zwischen der EWG und Israel in Brüssel

Verabschiedung des Ratifizierungsgesetzes zum Teststopp-Abkommen vom 5. August 1963 durch den Bundestag

Besuch des Bundeskanzlers Erhard in Kanada und den USA

Unterzeichnung des Vertrags zwischen der UdSSR und der DDR über Freundschaft, gegenseitigen Beistand und Zusammenarbeit

Gespräch zwischen Botschafter Groepper und dem sowjetischen Ministerpräsidenten Chruschtschow: Einladung zu einem Besuch in die Bundesrepublik

Erklärung der drei Westmächte zum Freundschaftsvertrag zwischen der UdSSR und der DDR

Bundesversammlung in Berlin (West): Wiederwahl von Heinrich Lübke zum Bundespräsidenten

Besuch des französischen Staatspräsidenten de Gaulle in Bonn

Besuch des Bundeskanzlers Erhard in Dänemark

Pressekonferenz des französischen Staatspräsidenten de Gaulle über die Beziehungen zur Bundesrepublik und über Fragen der europäischen Zusammenarbeit 
27. Juli

28. Juli

2. bis 5 . August

14. August

3. September
Unterzeichnung der deutsch-britischen Vereinbarung über den Devisenausgleich für die Jahre 1964/65 und $1965 / 66$

Gespräch des Bundeskanzlers Erhard mit dem Chefredakteur der sowjetischen Zeitung „Izvestija“ und Schwiegersohn des Ministerpräsidenten Chruschtschow, Adschubej

Zwischenfall im Golf von Tongking: Eskalation des Vietnam-Konflikts

Vereinbarung zwischen der Bundesrepublik und der DDR über Wiederaufbau und Unterhaltung der Autobahnbrücke bei Hirschberg (,Saale-Brücke-Abkommen“)

Bekanntgabe der Einladung an Ministerpräsident Chruschtschow zu einem Besuch in die Bundesrepublik

5. bis 11. September Gipfelkonferenz der Arabischen Liga in Kairo

6. September

8. September

24. September

30. September bis 2. Oktober

1. bis 6. Oktober

5. bis 10 . Oktober

14./15. Oktober

16. Oktober
Giftgasanschlag auf Legationssekretär Schwirkmann in Sagorsk

Beschluß des Ministerrats der DDR: Erlaubnis von Besuchsreisen in die Bundesrepublik für Bürger im Rentenalter

Unterzeichnung des Protokolls über die Ausgabe von Passierscheinen an Bewohner von Berlin (West) für Verwandtenbesuche in Ost-Berlin (,2. Passierschein-Abkommen")

Besuch des niederländischen Ministerpräsidenten Marijnen in Bonn

Sondermission des NATO-Botschafters Grewe in Washington zur Klärung der amerikanischen Haltung hinsichtlich der MLF

Konferenz der blockfreien Staaten in Kairo

Absetzung des Ersten Sekretärs des ZK der KPdSU und Vorsitzenden des Ministerrats der UdSSR, Chruschtschow

Ernennung von Leonid Breschnew zum Ersten Sekretär des ZK der KPdSU und von Alexej Kossygin zum Ministerpräsidenten der UdSSR

Rücktritt des britischen Premierministers Douglas-Home

Ernennung von Harold Wilson zum Premierminister nach dem Wahlsieg der Labour Party vom 15. Oktober 
Erster erfolgreicher Kernwaffenversuch der Volksrepublik China

26. Oktober

3. November

4. November

7. November

9. November

9./10. November

22. November

23. November

28. November

1. Dezember

Presseberichte über eine Zusammenarbeit von deutschen und israelischen Nuklearwissenschaftlern sowie über Waffenlieferungen der Bundesrepublik an Israel

Wiederwahl von Lyndon B. Johnson zum amerikanischen Präsidenten

Übermittlung der Vorschläge der Bundesregierung zur Europa-Politik an die Regierungen der EWG-Staaten (,Europa-Initiative“)

Unterzeichnung eines Abkommens zwischen der DDR und Zypern über den Handels- und Zahlungsverkehr

Schreiben des Bundesministers Schröder an Bundeskanzler Erhard: Forderung nach Einstellung der Waffenlieferungen an Israel

Gespräche des ehemaligen Bundeskanzlers Adenauer mit dem französischen Staatspräsidenten de Gaulle in Paris

Gespräch des Bundestagspräsidenten Gerstenmaier mit dem ägyptischen Präsidenten Nasser in Kairo: Einladung zu einem Besuch in die Bundesrepublik

Erklärung des Premierministers Wilson vor dem britischen Unterhaus: Ablehnung des bisherigen Konzepts einer multilateralen Atomstreitmacht

Zurückweisung der Ratifikationsurkunde der Bundesrepublik zum Teststopp-Abkommen vom 5. August 1963 durch die UdSSR

Hinterlegung der Ratifikationsurkunden der Bundesrepublik zum Teststopp-Abkommen vom 5. August 1963 in Washington und London

Einführung eines Zwangsumtauschs für Reisende aus nichtsozialistischen Ländern in die DDR

7. bis 9. Dezember Besuch des Premierministers Wilson in Washington: Gespräche über den britischen Vorschlag zur Schaffung einer Atlantic Nuclear Force (ANF)

7. bis 14. Dezember Staatsbesuch des südkoreanischen Präsidenten Park Chung Hee in der Bundesrepublik

11. Dezember

Besuch des Bundesministers Schröder in London: Gespräche über die MLF/ANF und über Fragen der europäischen Zusammenarbeit 
14. Dezember

15. Dezember

30. Dezember
Erklärung des polnischen Außenministers Rapacki vor der UNO-Generalversammlung: Vorschlag zur Einberufung einer europäischen Sicherheitskonferenz

Beschluß des EWG-Ministerrats über die Regelung des Getreidepreises zum 1. Juli 1967 (nach Zustimmung der Bundesregierung am 1. Dezember 1964)

Entschließung der UNO-Generalversammlung zur Gründung einer Konferenz und eines Ständigen Rats für Handel und Entwicklung (UNCTAD) 


\section{Personenregister}


Bei der Benutzung des Personenregisters sind folgende Hinweise zu beachten:

- Die Personen werden in alphabetischer Folge erfaßt.

- In der Regel wird die maßgebliche Funktion im Jahr 1964 genannt. Falls im Kontext erforderlich, wird zusätzlich auf frühere Funktionen hingewiesen.

- Bei einigen Personen sind im Rahmen der Edition ausschlieBlich bestimmte Funktionen vor dem Jahr 1964 von Interesse. In diesen Fällen erfolgen nähere zeitliche Angaben.

- Steht ein Dokument in seiner Gesamtheit in Beziehung zu einer Person, ist die Dokumentennummer angegeben. Dies ermöglicht auch einen schnellen Zugriff auf das Dokumentenverzeichnis im Band I.

- Beim Nachweis einzelner Seiten beziehen sich hochgestellte Ziffern auf Fußnoten.

- Band I reicht von Dokument 1 bis 179 bzw. von Seite 3 bis 712 und Band II von Dokument 180 bis 402 bzw. von Seite 713 bis 1580 . 
Abboud, Ibrahim Ministerpräsident der Republik Sudan S. 104, 1375

Abdeljalil, Mehdi Botschafter des Königreichs Marokko in Bonn Dok. 378

Abu Shadi, Farid Unterstaatssekretär im ägyptischen Außenministerium S. 998

Abrassimow, Pjotr Andrejewitsch Botschafter der Union der Sozialistischen Sowjetrepubliken in Ost-Berlin S. $1060,1418,1485^{7}$

Abusch, Alexander Stellvertretender Ministerpräsident der DDR S. $3^{1}$

Abu Zeid, Hikmat ägyptische Sozialministerin S. $998^{4}$

Achenbach, Ernst Mitglied des Deutschen Bundestages (FDP) S. 904 ${ }^{1}$

Acheson, Dean G. $\quad$ 1949-1953 Außenminister der Vereinigten Staaten von Amerika S. 36, 468, 793f., 1337, 1365, 1405

Acker Oberstleutnant im Bundesministerium der Verteidigung S. 101, 878 1164

Adande, Alexander dahomeischer Justizminister S. $1150^{3}$

Adenauer, Konrad Vorsitzender der CDU; 1949-1963 Bundeskanzler der Bundesrepublik Deutschland Dok. $184,316,318,321,341$ und S. $10^{2}, 46,90^{6}$, $110,111^{11}, 137^{27}, 167^{5}, 225^{15}, 270^{5}, 301^{10}$, $307,334,337,339,351^{3}, 352^{7}, 366^{1+4}, 384$, $386^{16}, 397,423,431,454,544^{10}, 582,608$, $661,700^{7}, 720^{21}, 735 \mathrm{f} ., 755-757,771$, 808 f., 813,815 f., $821,823^{8}, 828^{19}, 832$, $880,903,942^{1}, 1004,1026,1030,1165$, $1185,1234,1266,1300,1304,1326 \mathrm{f}$., $1340^{7}, 1348^{17}, 1362,1403,1413,1474$, $1488,1520 \mathrm{f}$.

Adschubej, Alexej Iwanowitsch Chefredakteur der Zeitung "Izvestija“ (Moskau) Dok. 212 und S. 412, 463, 530, $879-881,883,894,950$ f., $973,974^{13}$, $1008 \mathrm{f} ., 1017,1172,1317,1382$

Ahomadegbé, Justin Ministerpräsident und Vizepräsident der Republik Dahome S. $1152^{9}$

Albertz, Heinrich Bürgermeister von Berlin und Senator für Sicherheit und
Ordnung, Mitglied des Abgeordnetenhauses (SPD) S. 304, $398 \mathrm{f}$., $605 \mathrm{f}$.

Alexander, Neville südafrikanischer Stipendiat der Alexander-von-Humboldt-Stiftung (am 15. April 1964 in Kapstadt wegen Hochverrats und Sabotage verurteilt) S. 1153

Allardt, Helmut Botschafter der Bundesrepublik Deutschland in Madrid S. $375^{2}, 418,420^{15}$

Allende Gossens, Salvador Vorsitzender der „Frente de Acción Popular" in Santiago de Chile S. 616

Alphand, Hervé Botschafter der Französischen Republik in Washington S. $44^{8}, 356 \mathrm{f} ., 678-680,684,1219^{10}$

Alphand, Nicole Ehefrau von Hervé Alphand S. 113

Amer, Abdel Hakim ägyptischer Erster Vizepräsident und Oberbefehlshaber der Streitkräfte S. 1298

Amrehn, Franz Mitglied des Abgeordnetenhauses von Berlin und Vorsitzender der CDU-Fraktion; ehemaliger Bürgermeister von Berlin S. $1275^{3}$

Andriessen, Jacobus Eye niederländischer Wirtschaftsminister S. 512

Apel, Erich Erster Vorsitzender der Staatlichen Plankommission der DDR S. $292^{6}, 299^{7}$

Apithy, Sourou-Migan seit 19. Januar 1964 Präsident der Republik Dahome Dok. 282 und S. $1202^{15}$

Araouzos, Andreas zyprischer Minister für Handel und Industrie S. 1366, $1416 \mathrm{f}$.

de Araújo, Manuel Gomes portugiesischer Verteidigungsminister S. $979^{5}$

Argod, Hubert Botschafter der Französischen Republik in Pnom Penh S.624

Argoud, Antoine Mitglied der „Organisation de l'Armée Secrète"; ehemaliger französischer Oberst (am 25. Februar 1963 aus einem Münchener Hotel nach Frankreich entführt) S. 30-32, 216219, 238-241, 394, 610, 889

Arndt, Adolf Senator für Wissenschaft und Kunst des Landes Berlin bis 
31. März 1964, Mitglied des Deutschen Bundestages (SPD) S. 197

Arnold, Hans Legationsrat I. Klasse und Vertreter des Leiters im Referat „NATO, WEU (militärische Angelegenheiten) und Verteidigung " des Auswärtigen Amts S. $72^{42}, 120^{1}, 122^{10}, 263^{39}$, $278^{1}, 449^{1}, 1110^{12}, 1193^{1}, 1219^{10}, 1362^{1}$

Attlee, Clement R., seit 1955 1. Earl Attlee 1945-1951 Premierminister des Vereinigten Königreichs von Großbritannien und Nordirland S. $476^{6}$

d'Aumale, Christian Graf Gesandter an der französischen Botschaft in Bonn S. 359, 380, $615^{2}, 844^{8}, 942$ f., 1022 , $1355,1446^{3}$

Ausland, John C. Mitarbeiter im amerikanischen Außenministerium (Supervising Officer, International Relations) S. 528

Baath, Rolf Leiter der Abteilung „Ernährungswirtschaft" im Bundesministerium für Ernährung, Landwirtschaft und Forsten S. $244^{3}$

Babaček, Vladimir stellvertretender Leiter der tschechoslowakischen Delegation beim Handelsausschuß der ECE in Genf S. $1354^{43}$

Babu, Abdul Rahman vom 12. Januar bis 26. April 1964 Außenminister der Volksrepublik Sansibar S. $84^{55}, 188$

Bachmann, Günther Mitarbeiter im Bundeskanzleramt S. 504 $3{ }^{3}, 505,540^{2}$

Bäckstrand, Göran Attaché an der schwedischen Botschaft in Bonn S. 324

Bafile, Corrado Apostolischer Nuntius in Bonn Dok. 229 und S. $1358^{5}$

Bahr, Egon Leiter des Presse- und Informationsamtes des Landes Berlin S. $75^{14}, 303^{16}, 985$

Balaceanu, Petre Gesandter der Volksrepublik Rumänien in Washington S. 1381

Balken, Richard Leiter des Parlaments- und Kabinettsreferats im Auswärtigen Amt S. $268^{12}, 275^{8}, 797^{9}, 845^{1}$
Balkow, Julius Minister für Außenhandel und Innerdeutschen Handel der DDR S. 1366

Ball, George W. Staatssekretär im amerikanischen Außenministerium (Under Secretary of State) Dok. 338, 339 und S. $301^{10}, 347 \mathrm{f} ., 615,621,623$, $1084^{16}, 1109,1218,1222$ f., 1225 , 1256 , 1279 f., $1285,1322,1380,1386,1399$, 1404 f., $1436,1444,1449$ f., $1477,1536^{5}$

Balser, Johannes

Legationsrat I. Klasse im Referat „Wiedervereinigung" des Auswärtigen Amts; seit 3. Februar 1964 Konsul und seit 6. Juli 1964 Botschafter der Bundesrepublik Deutschland in Blantyre-Limbe S. $966^{2}, 967$

Banda, Hastings Kamuzu seit 6. Juli 1964 Ministerpräsident von Malawi S. $966^{2}, 967$

Bandaranaike, Felix R. D. ceylonesischer Minister für Landwirtschaft S. $800^{13}$

Bandaranaike, Sirimavo R. D. Ministerpräsidentin und Außenministerin Ceylons, Verteidigungsministerin S. 801-803, 996

Barnes, Ernest W. Referatsleiter im britischen Außenministerium (Head of Western Organisations and Planning Department) S. 528, 837, 1498

Baronin Gesandter an der sowjetischen Botschaft in Ost-Berlin S. 1483

Barth, Heinz Korrespondent der Zeitung "Die Welt" (Hamburg) in Paris S. $792^{11}$

Baruch, Bernard 1946 Delegierter der Vereinigten Staaten von Amerika bei der Atomenergie-Kommission der UNO S. $552^{6}$

Barzel, Rainer Mitglied des Deutschen Bundestages (CDU) und stellvertretender Vorsitzender der CDU/CSU-Fraktion; ehemaliger Bundesminister für gesamtdeutsche Fragen S.511, 1157 1406

Baschew, Iwan Außenminister der Volksrepublik Bulgarien S. $1018^{11}$, $1466^{12}$ 
de Bassompierre, J. Abteilungsleiter im belgischen Außenministerium S. $968^{5}$

Baudet, Philippe Botschafter der Französischen Republik in Moskau S.668, $678 \mathrm{f} ., 1172$

Baumel, Jacques Generalsekretär der „Union pour la Nouvelle République/ Union Démocratique du Travail" (UNR/ UDT) in Paris S. 1027, 1029

Bayer, René Mitarbeiter der Wochenzeitung „Die Zeit“ (Hamburg) S. 986 ${ }^{12}$

Beam, Jacob D. Abteilungsleiter in der amerikanischen Abrüstungsbehörde in Washington (Assistant Director, International Relations Bureau, Arms Control and Disarmament Agency) S. $1210^{27}$

de Beaumarchais, Jacques Delarüe Caron Kabinettschef des französischen Außenministers (Directeur du Cabinet du Ministre) S. 25 f., $615^{2}$

Behrends, Wolfgang Legationsrat I. Klasse im Referat „NATO, WEU (militärische Angelegenheiten) und Verteidigung" des Auswärtigen Amts S. 1380

Behrendt, Heinz Leiter der Hauptabteilung "Innerdeutscher Handel“ im Ministerium für Außenhandel und Innerdeutschen Handel der DDR S. $308^{20}$, 424 f., $851,988,1137^{2}, 1175^{10}$

Belfrage, Leif Axel Staatssekretär im schwedischen Außenministerium S. 324

Ben Abdullah, Seyyid Jamshid Sultan des Sultanats Sansibar bis 12. Januar 1964 S. $84^{55}$

Ben Bella, Mohammed Ahmed Präsident und Ministerpräsident der Demokratischen Volksstaatlichen Republik Algerien S. 619, 732f., 740, 909 f., $945^{1}$, $946^{5}, 947,1374$

Ben Gurion, David 1949-1953 und 1955-1963 Ministerpräsident des Staates Israel und Verteidigungsminister; Vorsitzender der Mapai-Partei in Tel Aviv bis 15. November 1964 S. 270 f., $366^{1}, 397,734$
Ben Natan, Asher Generaldirektor im israelischen Verteidigungsministerium S. $270^{5}$

Berendonck, Gerd Legationsrat im Referat „Abrüstung und Sicherheit" des Auswärtigen Amts; seit 17. März 1964 Leiter der Vertretung der Bundesrepublik Deutschland in Pnom Penh S. 624

Berg, Fritz Präsident des Bundesverbands der Deutschen Industrie (BDI) in Köln S. $1224^{43}$, 1267

Berger, Hans Botschafter der Bundesrepublik Deutschland in Den Haag S. $181^{5}, 280,290,710^{6}, 1438^{17}, 1445^{13}$

Bergquist, Lars Jonas Pressesekretär im Amt des schwedischen Ministerpräsidenten S. 324

Bergström, Per Richard Botschafter zur besonderen Verwendung im schwedischen Außenministerium; ehemaliger Botschafter in Washington, Paris und Moskau S. 324

Berlet, Karl-Hans Leiter der Wirtschaftsabteilung an der Botschaft der Bundesrepublik Deutschland in London bis zum Ausscheiden aus dem Auswärtigen Dienst am 30. September 1964 S. $873^{10}, 978$

Bernardić, Dragan Gesandter an der jugoslawischen Ständigen Vertretung bei der UNO in New York S. $1002^{8}$

Bevin, Ernest 1945-1951 Außenminister des Vereinigten Königreichs von Großbritannien und Nordirland S. 751

Bidault, Georges Vorsitzender des "Conseil National de la Résistance" (CNR); ehemaliger Außenminister und ehemaliger Ministerpräsident der Französischen Republik S. 241

Bindewald, Rüdiger Legationsrat I. Klasse und Vertreter des Leiters im Referat „Portugal, Spanien, Vatikan, Griechenland, Türkei, Zypern; Nordische Staaten, Österreich, Schweiz, MalteserRitter-Orden" des Auswärtigen Amts bis 24. Juli 1964; seit 28. August 1964 Konsul der Bundesrepublik Deutschland in Guayaquil S. 324 
Binoche, Jean Botschafter der Französischen Republik in Belgrad S. 1001

Birgi, Muharrem Nuri Leiter der Ständigen Vertretung der Republik Türkei bei der NATO in Paris S. $728^{29}$, $976 \mathrm{f}$.

Birladeanu, Andru rumänischer Stellvertretender Ministerpräsident S. $1466^{11}$

Bismarck, Philipp von Mitglied des Vorstands der Kali-Chemie AG in Hannover, Vorsitzender des Arbeitskreises Oder-Neiße S. $1288^{1}$

Bizard, François Abteilungsleiter im französischen Finanz- und Wirtschaftsministerium (Directeur des Relations économiques extérieures) S. $804 \mathrm{f}$.

Blakeney, Frederick J. Botschafter Australiens in Bonn Dok. 245

Blank, Theodor Bundesminister für Arbeit und Sozialordnung S. 149

Blankenhorn, Herbert Botschafter der Bundesrepublik Deutschland in Rom Dok. 257 und S. $80^{35}, 148,181^{5}$, $575,936^{39}, 1089,1213,1214^{8}, 1341^{8}, 1424$, $1452^{9}, 1453^{12}, 1457,1463^{1}$

Blaustein, Jacob Mitglied des Vorstands der "Conference on Jewish Material Claims against Germany" in New York S. 198

Blecha, Kurt Leiter des Presseamtes beim Ministerpräsidenten der DDR S. $850^{11}$

Blessing, Karl Präsident der Deutschen Bundesbank in Frankfurt/Main S. $391,1404^{3}$

de Block, Leo Staatssekretär im niederländischen Außenministerium S. $283,289,418^{3}, 874,914,1113$

Blomeyer-Bartenstein, Horst Botschaftsrat I. Klasse an der Botschaft der Bundesrepublik Deutschland in Washington S. $156^{21}$

Blumenfeld, Erik B. Mitglied des Deutschen Bundestages (CDU) Dok. 148 und S. 1566

Blumenthal, W. Michael Sonderbeauf- tragter des amerikanischen Präsidenten für Handelsfragen S.378f.

del Bo, Rinaldo Präsident der Hohen Behörde der EGKS in Luxemburg S. 911, 1121

Bock, Fritz österreichischer Minister für Handel und Wiederaufbau S. $697^{5}$, 1120

Bock, Georg Vertreter des Leiters im Referat „Deutsche Ostfragen“ des Auswärtigen Amts S. 942 $1026^{7}$

Bock, Hans Leiter der ,Abteilung für die Wahrnehmung der Interessen der Bundesrepublik Deutschland" bei der französischen Botschaft in Belgrad (Schutzmachtvertretung) S. $367^{2}, 926^{2}$

Böhm, Franz Mitglied des Deutschen Bundestages (CDU) und stellvertretender Vorsitzender des Ausschusses für Wiedergutmachung S.1130

Böhme, Georg Mitglied des Deutschen Bundestages (CDU) S. 997 28

Böker, Alexander Leiter der Unterabteilung $B$ in der "Politischen Abteilung I“ des Auswärtigen Amts Dok. 179, $280,282,299,378,388$ und S. 99, $163^{12}$, $189^{10}, 269^{1}, 311,312^{7}, 345,392^{4}, 393^{10}$, $397^{12}, 421^{12}, 497^{5}, 503^{1}, 504^{6}, 682$, $794^{20+21}, 856,971^{1}, 995^{12}, 998^{4}, 1000^{13}$, $1014^{8}, 1243^{10}, 1515^{3}$

Bömcke, Eberhard Ministerialrat und Vertreter des Leiters an der Ständigen Vertretung der Bundesrepublik Deutschland bei EWG und EURATOM in Brüssel S. $275^{7}, 868^{3}, 869 \mathrm{f}$., $1361^{13}$

Böx, Heinrich Leiter der Handelsvertretung der Bundesrepublik Deutschland in Helsinki bis 3. August 1964; seit 27. August 1964 Botschafter in Oslo S. $1520^{8}$

Bolarque, Marquis de Botschafter Spaniens in Bonn S. $418 \mathrm{f}$.

Boltze, Erich vom 19. Februar bis 17. März 1964 mit der Errichtung der Vertretung der Bundesrepublik Deutschland in Pnom Penh beauftragt; 19381945 Botschaftsrat bzw. Gesandter an der deutschen Botschaft in Tokio, seit 1956 im Ruhestand S. 624 
Bolz, Lothar Minister für Auswärtige Angelegenheiten der DDR S. 686

Boon, Hendrik N. Leiter der Ständigen Vertretung des Königreichs der Niederlande bei der NATO in Paris S.692, $728^{29}, 1291^{3}$

Borm, William Vorsitzender des Landesverbandes Berlin der FDP und Mitglied des Abgeordnetenhauses S. 55

Bornemann, Helmut Staatssekretär im Bundesministerium für das Postund Fernmeldewesen S. $3 \mathrm{f}$.

Botsio, Kojo Außenminister der Republik Ghana S. 497-499, $971^{1}$

Boumaza, Bachir algerischer Wirtschaftsminister S. $1122^{35}$

Boumedienne, Houari algerischer Verteidigungsminister und stellvertretender Ministerpräsident S. 1175

Bourchard, Marcel Rektor der Universität Dijon S. $1010^{36}$

Bouteflika, Abdel Aziz Außenminister der Demokratischen Volksstaatlichen Republik Algerien S. 733, 947

Bouverat, Colette Dolmetscherin im Sprachendienst des Auswärtigen Amts S. $132^{1}, 148^{1}, 216^{1}, 615^{2}, 724^{1}, 735^{65+1}$, $1004^{1}$

Bowie, Robert R. Direktor des "Center for International Affairs" an der Havard University in Cambridge/Massachussetts; ehemaliger Leiter des Planungsstabs im amerikanischen Außenministerium S. 1398

Boyd-Carpenter, John Staatssekretär im britischen Schatzamt und Generalzahlmeister (Chief Secretary of the Treasury and Paymaster General) S. 796

Brandt, Willy Regierender Bürgermeister von Berlin und Mitglied des Abgeordnetenhauses; seit 16. Februar 1964 Vorsitzender der SPD Dok. 64, 132 und S. $21,75^{14}, 76,131^{18}, 197,292^{5}, 304$, $307,314,328,409,431,569,605,1057$, $1138^{7}, 1276$

Brasseur, Maurice belgischer Minister für Außenhandel S.512
Braun, Sigismund Freiherr von Beobachter der Bundesrepublik Deutschland bei der UNO in New York S. $98^{36}, 348^{7}$, $457,460,462,515^{5}, 643,732^{51+53}, 1045^{6}$, $1278^{4}, 1386^{31}, 1563$

Brentano, Heinrich von Mitglied des Deutschen Bundestages (CDU) und Vorsitzender der CDU/CSU-Fraktion bis zu seinem Tod am 14. November 1964; ehemaliger Bundesminister des Auswärtigen S. 46, 225 ${ }^{15}, 307,1165$

Breschnew, Leonid Iljitsch Vorsitzender des Präsidiums des Obersten Sowjet der Union der Sozialistischen Sowjetrepubliken bis 15 . Juli 1964 , vom 15 . Juli bis 14. Oktober 1964 Sekretär; danach Erster Sekretär des Zentralkomitees der KPdSU S. 1159, 1210, 1212, 1318, 1352, $1433 \mathrm{f}$., 1518

Brèthes, Jean M. Referatsleiter im französischen Außenministerium (Chef de Service, „Cambodge, Laos, Vietnam") S. $45^{12}$

Briest, Eckart Botschafter der Bundesrepublik Deutschland in Asunción Dok. 371 und S. 353

Brook-Shepherd Korrespondent der Wochenzeitung „Sunday Telegraph" (London) in Bonn S. 982

Brosio, Manlio Botschafter der Italienischen Republik in Paris; seit 14. Mai 1964 Generalsekretär der NATO in Paris Dok. 235, 348 und S. 533, 1147 , $1149,1369 \mathrm{f}$.

Brown, George Abgeordneter des britischen Unterhauses und stellvertretender Vorsitzender der Labour Party S. 570, 1444

Brückner, Hardo Botschaftsrat I. Klasse und Vertreter des Botschafters an der Botschaft der Bundesrepublik Deutschland in Pretoria; seit 12. August 1964 Leiter der Handelsvertretung in Budapest S. $926^{2}$

Buch, Friedrich Botschafter der Bundesrepublik Deutschland in Kopenhagen Dok. 108 und S. $1027^{9}$

Buchan, Alastair Leiter des „Institute for Strategic Studies" in London S. 1053 
Bucher, Ewald Bundesminister der Justiz S. 1131 f., $1133^{16}$

Bünger, Karl Botschafter der Bundesrepublik Deutschland in Seoul bis 27. Oktober 1964; danach Generalkonsul in Hongkong sowie Konsul in Macau S. $1458^{6+7}, 1459^{8}$

Bulganin, Nikolaj Alexandrowitsch 1955-1958 Ministerpräsident der Union der Sozialistischen Sowjetrepubliken S. 1497

Bundy, McGeorge Sonderberater des amerikanischen Präsidenten für Fragen der nationalen Sicherheit Dok. 363 und S. 36, 76, 78, 102, 305, $680^{3}, 915$, $1380^{2}, 1454^{18}, 1552$

Burchard, Otto Botschaftsrat I. Klasse und seit August 1964 Vertreter des Botschafters an der Botschaft der Bundesrepublik Deutschland in Pretoria, von 16. Januar bis 24. Februar 1964 Konsul in Kapstadt S. $278^{2}, 279^{7}$

Burin des Roziers, Etienne Generalsekretär beim französischen Staatspräsidenten (Secrétaire Générale de la Présidence de la République) S. $738^{2}, 777^{2}$, $948^{2}$

Buring, Karl Heinz Dolmetscher im Sprachendienst des Auswärtigen Amts S. $1041^{1}, 1517^{1}$

Burns, Eedson L. M. Leiter der Delegation Kanadas bei der Konferenz der 18-Mächte-Abrüstungskommission in Genf S. $694 \mathrm{f}$.

Butler, Richard A. Außenminister des Vereinigten Königreichs von Großbritannien und Nordirland bis 16 . Oktober 1964 Dok. 13, 15, 99, 124, 199 und S. 20, $32,34,40,63,69,71,135^{17}, 141^{11}, 142$, $282,329^{37}, 401,444,447,464 \mathrm{f} ., 485 \mathrm{f}$., 491 f., $548,650^{34}, 671,874^{4}, 935,996,1052$, $1053^{15}, 1107 \mathrm{f}$.

Cabot, John M. Botschafter der Vereinigten Staaten von Amerika in Warschau S. 546

Caccia, Sir Harold A. Staatssekretär im britischen Außenministerium (Permanent Under-Secretary of State)
Dok. 292 und S. $49^{2}, 401,841,1218^{5}$, $1304,1308^{16}, 1309^{2}, 1316^{2}, 1399,1498$

Calhoun, John A. Leiter der Mission der Vereinigten Staaten von Amerika in Berlin S. $1483^{3}$

Callaghan, L. James seit 16. Oktober 1964 britischer Schatzkanzler S. $1405^{7}$, 1497, 1509

Calmes, Christian Generalsekretär bei den Ministerräten der Europäischen Gemeinschaften; ehemaliger Gesandter im luxemburgischen Außenministerium S. $869,870^{10}$

de Carbonnel, Erik Generalsekretär im französischen Außenministerium (Secrétaire général du Ministère des Affaires étrangères) S. 222, 233, 244 ${ }^{3}, 1187$

Carli, Guido Gouverneur der Banca Italia in Rom S. 558 $8^{17}, 559 \mathrm{f}$.

Carrero Blanco, Luis Leiter der Präsidialkanzlei des spanischen Staatschefs (Ministro Subsecretario de la Citada Presidencia del Gobierno) S. 620

Carrington, Peter Alexander, 6.Baron of Carrington Erster Lord der Admiralität und Mitglied des britischen Oberhauses, Minister ohne Portfolio im britischen Außenministerium bis 16 . Oktober 1964 S. 491

Carstens, Karl Staatssekretär des Auswärtigen Amts Dok. 1, 10, 11, 30, 31, $32,34,36,37,39,43,57,72,82,83,103$, $112,115,120,121,126,127,129,138,139$, $145,146,148,150,166,171,173,176,178$, $186,190,193,199,203,210,211,213,222$, $224,225,228,229,232,247,249,251,252$, $255,260,262,265,267,268,269,270,271$, $274,279,283,285,288,296,297,300,301$, $304,305,308,328,337,339,343,346,351$, $354,356,357,362,364,366,371,374,384$, 390 und S. $10^{1}, 11^{7}, 14^{21}, 19^{3}, 22,25^{1}, 26^{6}$, $35,37^{9}, 38^{14}, 56^{24}, 59^{35}, 73^{4}, 96^{31}, 97^{32}$, $101^{1}, 105,110^{3}, 111^{9}, 118^{1}, 121 \mathrm{f} ., 125^{5}$, $172^{10}, 184^{10}, 189,190,211^{38}, 217^{8}, 218$, $221^{22}, 222,233,240^{13}, 241^{15}, 244^{3}, 269^{1}$, $273^{7}, 277^{9}, 279,280^{8}, 283^{20}, 287^{38}, 306^{10}$, $309^{22}, 316^{6}, 317^{11}, 320^{30+31}, 373,374^{1+2}$, $375^{1+3}, 376^{4+5}, 377^{9+10}, 383^{3}, 393^{6-10}$, $394^{11}, 399^{1}, 400^{5}, 422^{22}, 423^{26}, 432,438^{8}$, $442^{12}, 444^{16}, 454,455^{26}, 456^{29}, 457^{2}, 467 \mathrm{f}$., 
$469^{10+11}, 471^{8+11}, 472^{15+17}, 473^{18+19}$, $474^{25}, 480,491$ f., $495^{9}, 497^{2}, 501,517^{19}$, $525,526^{4}, 543^{5-7}, 554^{16+18}, 562,565^{17+19}$, $588^{9}, 589^{10+12}, 599^{4}, 600,604^{1}, 610^{22}$, $615^{2}, 640^{10}, 643,646^{14}, 667^{2}, 670,677^{3}$, $680^{3}, 691^{1}, 697^{1}, 708^{8+10}, 711^{2}, 729^{30}$, $732^{52}, 738^{2}, 763^{24}, 777^{2}, 819,836^{21}, 845$, $850^{14}, 852^{19}, 861^{10+11}, 866^{6}, 867^{11}, 871^{1}$, $873^{9+10}, 882^{10}, 908^{1}, 924^{23}, 940^{9}, 941^{13}$, $943^{4}, 944^{3}, 952^{2}, 953^{6}, 954^{7}, 955 \mathrm{f} ., 978$, $984,987^{15}, 998,1012^{49}, 1037^{12}, 1038$, $1039^{25}, 1061^{5}, 1062^{8+9}, 1063^{10}, 1065^{15}$, 1066, 1091, 1093, 1095, 1099f., $1117^{11}$, $1126^{5}, 1133^{16}, 1135,1149,1156^{7}, 1164^{3}$, $1165, \quad 1167^{18}, 1173^{1+2}, 1174^{9}, \quad 1175$, $1181^{19}, 1182,1183^{10}, 1184^{13}, 1193,1195^{10}$, $1197,1209^{25}, 1229^{1+4}, 1230^{5+3}, 1232^{9}$, $1236^{6}, 1244^{1}, 1246^{11}, 1250^{1}, 1255^{4}, 1263^{5}$, $1264,1273^{5}, 1279$ f., $1285^{4}, 1286^{3}, 1293^{1}$, $1295^{11}, 1296^{13+14}, 1300^{5}, 1302^{11}, 1304$, $1308,1305^{5+7}, 1313,1315,1319 \mathrm{f} ., 1325^{6}$, $1326^{8}, 1328^{22}, 1333^{1+7}, 1355^{50}, 1366$, $1368^{11}, 1369^{16}, 1374,1378^{18}, 1386,1389$, $1399,1415^{4}, 1417^{12}, 1422^{5}, 1423^{8+10}$, $1424,1457^{2}, 1463^{1}, 1467^{20}, 1484^{4+6}$, $1516^{7}, 1534^{4}, 1535,1538^{2-4}, 1540^{9+11}$, $1544^{1}, 1546^{9}, 1549^{13}, 1553^{19}, 1556^{4+6}$, $1557,1558^{9}, 1559^{3+6}, 1560^{1}, 1564^{8-12}$ $1565^{13+3}, 1567^{13}, 1569^{7}$

Cartellieri, Wolfgang Staatssekretär im Bundesministerium für Wissenschaftliche Forschung S. $397^{10}, 1294^{8}$

Caspari, Fritz Botschaftsrat I. Klasse und Vertreter des Beobachters der Bundesrepublik Deutschland bei der UNO in New York S. $347^{4}, 348^{6}, 641^{6}, 1002^{8}$

Castelo Branco, Humberto de Alencar seit 15. April 1964 Präsident und Ministerpräsident der Vereinigten Staaten von Brasilien S. 617

Castiella y Maiz, Fernando M. Außenminister Spaniens S. 418, 420, 618f.

Castro Ruz, Fidel Ministerpräsident der Republik Kuba S. 552

Cattani, Attilio Generalsekretär im italienischen Außenministerium (Segretario Generale) Dok. 271 und S. 80, 82, $138,709^{4}, 710^{5}, 914,1089,1103,1120^{26}$, $1122,1154,1214^{8}, 1291$ f., 1496

Cavaletti di Oliveto Sabino, Marquis Francesco Leiter der Delegation der
Italienischen Republik bei der Konferenz der 18-Mächte-Abrüstungskommission in Genf S. $694 \mathrm{f}$.

Chaban-Delmas, Jacques Präsident der französischen Nationalversammlung S. $360,1173,1174^{9}, 1175^{10}$

Chalfont siehe Gwynne-Jones

Chamoun, Camille 1952-1958 Präsident des Libanon S. 931

Chang Key Young stellvertretender Ministerpräsident der Republik Korea S. $1457^{2}$

Charlotte Großherzogin von Luxemburg S. $580^{1}$

Chatenet, Pierre Präsident der EURATOM-Kommission in Brüssel; ehemaliger französischer Innenminister S. 911

Chen Yi Außenminister der Volksrepublik China S. $511^{9}, 587,1023^{41}$

Choi Duk-shin Botschafter der Republik Korea in Bonn S. $1457^{2}$

Choi Yong Kun stellvertretender Vorsitzender des Zentralkomitees der Koreanischen Arbeiterpartei und Vorsitzender des Präsidiums der Volksversammlung der Demokratischen Volksrepublik Korea S. 1375

Christensen, Sigurd Abteilungsleiter im dänischen Außenministerium S. 475

Chruschtschow, Nikita Sergejewitsch Erster Sekretär des Zentralkomitees der KPdSU und Ministerpräsident der Union der Sozialistischen Sowjetrepubliken bis 14. Oktober 1964 Dok. 162, 259,291 und S. $20^{10}, 32,38,50^{6}, 51,53$, 55, 57 f., 60 f., $73^{2+4}, 74,86,88^{10}, 90^{2}, 91$, $95,96^{28}, 176^{16}, 198,213-215,257$ f., 303 , $320,332,333^{7}, 335,339-341,356,362$, $383^{6}, 386^{17}$, 411 f., 430 f., $457,460,463^{30}$, $471,476,489,491,498,522,524,528,549$, 568 f., $603,606,607$ f., $625,627,629^{12}, 630$, 634 f., 637 f., 639 f., 644-648, 656, 667-669, $672,679,687,699$ f., 702-704, 707, 726$728,731,742,749,751,767,772,788 \mathrm{f}$., 835 f., $840,842,844,848,879,881,880^{7}$, 894f., 896-898, 900, 902-904, 931, 951, 996, $1004 \mathrm{f}$., $1009 \mathrm{f}$., $1015,1017 \mathrm{f} ., 1023 \mathrm{f}$., 
$1025^{2}, 1027,1029$ f., $1039,1043 \mathrm{f} ., 1052^{13}$, $1055 \mathrm{f} ., 1082,1099,1158,1159^{5}, 1191$, $1194,1210,1212,1230$ f., 1252 f., 1268 1271, $1317 \mathrm{f}$., 1342, 1351-1355, 1380-1382, $1412,1497,1510^{4}, 1532$

Churchill, Sir Winston L. S. 1940 1945 sowie 1951-1955 Premierminister des Vereinigten Königreichs von Großbritannien und Nordirland S. 1226

Coiffard, Jacques Botschafter der Französischen Republik in Sofia S. 1060

Conant, James B. 1953-1955 Botschafter der Vereinigten Staaten von Amerika in Bonn S. 1276, $1277^{11}$

de Courcel, Geoffroy Botschafter der Französischen Republik in London S. $34^{41}, 85,401,491$

Cousins, Frank Generalsekretär der britischen Transportarbeiter-Gewerkschaft S. 1444

Couve de Murville, Maurice Außenminister der Französischen Republik Dok. 45, 46, 48, 117, 124, 153, 154, 181, $182,185,186,296,297,311,377,387,389$ und S. $40,78,244^{3}, 274,358,362^{46}, 444$, $491 \mathrm{f} ., 536,542^{6}, 548,551^{4}, 552,682,698$, $740-742,779,806,824,825^{12}, 837,838^{8}$, $866^{8}, 887^{11}$, 912 f., 972,1007 f., 1027 , $1107 \mathrm{f} ., 1117^{8+9}, 1118,1163,1223^{37}$, $1289 \mathrm{f}$., $1332,1345,1355^{52}, 1370,1425$, 1449 f., 1452 f., 1487, 1490, 1507, $1542^{11}$

Crafoord, Carl-George Botschaftsrat an der schwedischen Botschaft in Bonn S. 324

Creel, Robert C. Referatsleiter im amerikanischen Außenministerium (Director, Office of German Affairs) S.549, 643

Crossmann, Richard Abgeordneter des britischen Unterhauses und Vorstandsmitglied der Labour Party; 1946 Mitglied der britisch-amerikanischen Palästina-Kommission S. 1132

da Cunha, Vasco Leitão Außenminister der Vereinigten Staaten von Brasilien S. 617

Dahlgrün, Rolf Bundesminister der Finanzen S. 61, 125, 166, $190 \mathrm{f} ., 313,495 \mathrm{f}$.,
504 f., $539,738^{2}, 744,777,796$ f., 840,1115 , $1130,1131^{6}, 1166^{16}, 1390^{4}, 1394,1423^{8}$

Dantas, Francisco Clementino San Tiago 1961-1962 Außenminister der Vereinigten Staaten von Brasilien S. 616

David, Václav Außenminister der Tschechoslowakischen Sozialistischen Republik S. $421^{10}, 1018^{11}, 1020,1354 \mathrm{f}$., 1370,1465

Davis, Richard H. stellvertretender Abteilungsleiter im amerikanischen $\mathrm{Au}$ ßenministerium (Senior Deputy Assistant Secretary of State for European Affairs) S. $1485^{7}$

Dean, Sir Patrick Leiter der Ständigen Vertretung des Vereinigten Königreichs von Großbritannien und Nordirland bei der UNO in New York S. 344

Dehler, Thomas Mitglied des Deutschen Bundestages (FDP) und Vizepräsident; ehemaliger Bundesminister der Justiz S. 304, $356^{9}, 398^{17}, 1165^{7}$

Dewidar Mitarbeiter im ägyptischen Wirtschaftsministerium S. 1297

Diederichs, Georg Ministerpräsident des Landes Niedersachsen S. $961^{11}$

Diehl, Günter Leiter der Abteilung „Ausland" im Presse- und Informationsamt der Bundesregierung S. 324

\section{Diem siehe Ngo Dinh Diem}

Diesel, Jürgen Legationsrat I. Klasse und Vertreter des Leiters im Referat „Abrüstung und Sicherheit" des Auswärtigen Amts; seit 1. Juli 1964 Legationsrat I. Klasse am Generalkonsulat bzw. an der Vertretung der Bundesrepublik Deutschland bei den internationalen Organisationen in Genf S. $182^{1}$, $371,1048^{15}$

Dillon, Douglas amerikanischer Finanzminister Dok. 134 und S.505, 1399

Dittmann, Herbert Botschafter der Bundesrepublik Deutschland in Tokio S. $863^{4}, 864^{8}, 1120^{23}$

Dobrynin, Anatolij Fjodorowitsch Botschafter der Union der Sozialisti- 
schen Sowjetrepubliken in Washington S. $1231^{6}$

Doe, George E. K. Botschafter der Republik Ghana in Bonn S. $497^{5}, 500,971$, $972^{4}$

Douglas-Home, Sir Alexander Frederick, bis 26. Oktober 1963 Alexander Frederick Douglas, 14. Earl of Home Premierminister des Vereinigten Königreichs von Großbritannien und Nordirland bis 17. Oktober 1964; ehemaliger Außenminister Dok. 12, 13,14 und $S .32^{31}, 81,85,205,262,325$, $679^{11}, 915,1045^{6}, 1407^{7}$

Dowling, Walter C. 1959-1963 Botschafter der Vereinigten Staaten von Amerika in Bonn S. $110^{3}$

Drndić, Ljubo Leiter der WesteuropaAbteilung im jugoslawischen Außenministerium; 1963 Leiter der Delegation bei den Wirtschaftsverhandlungen mit der Bundesrepublik Deutschland S. $995^{15}$

Dröge, Heinz Legationsrat im Referat „Vereinte Nationen, weltweite internationale Organisationen; multilaterale Zusammenarbeit auf dem Gebiet der Atomenergie (mit Ausnahme der europäischen Organisationen), internationale Beziehungen auf dem Gebiet der Weltraumforschung, politische Fragen auf technisch-wissenschaftlichem Gebiet" des Auswärtigen Amts S. 562 ${ }^{1}$

Dröscher, Wilhelm Mitglied des Deutschen Bundestages (SPD) S. 997

Ducci, Roberto Sonderbeauftragter der italienischen Regierung für Fragen der MLF S. 121

Duckwitz, Georg Ferdinand Botschafter der Bundesrepublik Deutschland in Neu-Delhi S. $311,312^{9}, 865^{3}, 982^{2}$

Düselius, Hanns Otto Attaché an der schwedischen Botschaft in Bonn S. 324

Dufhues, Josef Hermann Geschäftsführender Vorsitzender der CDU und Mitglied des Landtages von NordrheinWestfalen S. $808^{1}$
Dulles, John Foster 1953-1959 Außenminister der Vereinigten Staaten von Amerika S. 468, 1259, 1337

Duong Van Minh Vorsitzender des Revolutionären Militärrats und Staatschef der Republik Vietnam bis 30 . Januar 1964 S. $622^{27}$

Duynstee, A. E. M. Delegierter des Königreichs der Niederlande bei OEEC und WEU in London S. 1413

Eckardt, Felix von Staatssekretär und Bevollmächtigter der Bundesrepublik Deutschland in Berlin S. 1137

Eden, Sir R. Anthony, seit 1961 1. Earl of Avon 1940-1945 sowie 1951-1955 Außenminister; danach bis 1957 Premierminister des Vereinigten Königreichs von Großbritannien und Nordirland S. $523^{15}, 596^{12+13}$

d'Eeckhoutte, Maurice Iweins Generalsekretär der WEU in London S. 1135

Eger, Wolfgang Legationsrat I. Klasse und Vertreter des Botschafters an der Botschaft der Bundesrepublik Deutschland in Lagos; bis 27. Dezember 1963 Legationsrat I. Klasse im Referat ,Vertragsrechtliche Fragen und Verbindung zu den gesetzgebenden Körperschaften “ des Auswärtigen Amts S. $427^{7}$

Eichmann, Adolf 1939-1945 Leiter des „Referats für Judenangelegenheiten“ im Reichssicherheitshauptamt S. 354

Eickhoff, Ekkehard Leiter der Kulturabteilung an der Botschaft der Bundesrepublik Deutschland in Bern S. 871

Eisenhower, Dwight D. 1950-1952 Oberbefehlshaber der NATO-Streitkräfte in Europa (SACEUR); 1953-1961 Präsident der Vereinigten Staaten von Amerika S. $291^{53}, 428,455,654,1084^{1}$, $1085^{7}, 1086,1087^{14}, 1088^{15}, 1226$

Eklund, Sigvard Generaldirektor der Internationalen Atomenergie-Organisation (IAEO) in Wien S. 1294

Elisabeth II. Königin des Vereinigten Königreichs von Großbritannien und Nordirland S. $672,1284^{3}, 1307^{11}, 1445$ 
Emde, Hans Georg Mitglied des Deutschen Bundestages (FDP) S. $1165^{7}$

Emminger, Otmar Mitglied des Direktoriums der Deutschen Bundesbank in Frankfurt/Main S. 560 22

Engemann, Winfried Legationsrat und Vertreter des Botschafters an der Botschaft der Bundesrepublik Deutschland in Asunción S. $1442^{10}$

Engling, Haide Dolmetscherin im Sprachendienst des Auswärtigen Amts S. $1440^{1}$

Erhard, Ludwig Bundeskanzler der Bundesrepublik Deutschland; ehemaliger Bundesminister für Wirtschaft Dok. 5, 8, 12, 13, 14, 25, 27, 28, 29, 42, 44, $47,49,50,51,59,63,64,67,68,87,93,98$, $110,112,123,134,136,137,157,159,160$, $161,180,183,187,188,189,195,198,200$, $209,212,225,244,259,263,266,276,286$, $307,312,313,326,338,340,355,376,380$, 386 und S. $8,10^{1}, 25 \mathrm{f}$., $38,40,74^{10}, 75 \mathrm{f}$., $79,82,86,88^{10}, 90^{6}, 91^{10}, 95^{25}, 120,123$, $125^{5}, 159,165,166,170^{1}, 187^{11}, 217,219^{14}$ $274^{9}, 298^{13}, 313 \mathrm{f}$., $323,342^{5}, 350^{6}, 352$, $356,359,361$ f., $366,380,382,383,386^{17}$, $393^{8}, 395 \mathrm{f}$., $409,420,422,431,448 \mathrm{f}$., 454 f., $465,491,495$ f., $497,505,510$ f., 527 , $540,541,544,574,579,580$ f., 589,590 , $592,597^{15}, 599^{1+4}, 603,604,610,624 \mathrm{f}$., 625 f., 628-630, 639 f., 661, 663, 665-667, $668,671,680^{3}, 687,697,699,703,707$, $724,726,750,796,808,810,818 \mathrm{f}$., 821 , $823,837,869$ f., $872,874,885,887^{11}, 894$, 915 f., $923,964^{9}, 965^{12}, 970,972^{1}, 1000$, $1017,1030,1033$ f., $1043,1051,1055,1064$, $1078,1100,1103,1112,1122,1124$ f., 1141, $1146 \mathrm{f}$., $1149,1155,1161 \mathrm{f}$., $1165,1174 \mathrm{f}$. $1183,1199 \mathrm{f}$., $1228,1230 \mathrm{f}$., 1242,1244 , $1249,1255 \mathrm{f}$., $1258,1262,1264,1265,1272$, $1273^{4}, 1274,1281,1286^{3}, 1288,1290,1300$, $1312,1319,1330,1344^{8}, 1359,1361,1362^{1}$, $1372,1378,1383,1388$ f., 1394 f., 1397 , $1404,1413,1437^{11}, 1502,1509^{31}, 1516$, $1556,1563,1566,1579$

Erkin, Feridum Cemal Außenminister der Republik Türkei Dok. 21, 317 und S. $101,346^{25}, 1299,1301,1365,1434$

Erlander, Tage Ministerpräsident des Königreichs Schweden Dok. 67 und S. 833
Erler, Fritz Mitglied des Deutschen Bundestages und stellvertretender Vorsitzender der SPD-Fraktion S. $31^{21}, 197$, $307,1188^{5}, 1332$

Erroll, Frederick britischer Minister für Energie bis 16. Oktober $1964 \quad$ S. 49

Eshkol, Levi Ministerpräsident des Staates Israel und Verteidigungsminister Dok. 312 und S. 126, 351, 382, $395 \mathrm{f}$., $398,415,423,733 \mathrm{f}$., $906,963 \mathrm{f}$., $1133 \mathrm{f}$., $1239,1241,1240^{9}$

Etzdorf, Hasso von Botschafter der Bundesrepublik Deutschland in London Dok. 89, 236, 292 und S. $49^{2}, 61^{41}$, $62^{46}, 78^{26}, 85^{65}, 115^{4}, 435^{22}, 469,650^{34}$, $673^{17}, 838,873^{10}, 982^{6}, 1218^{5}, 1304,1309^{2}$, $1316^{2}, 1388,1389^{6}, 1391^{3}, 1392,1443^{4}$, $1495^{9}, 1498,1563^{7}$

Ewagnignon, Nicolas Amoussou Botschafter der Republik Dahome in Bonn S. $1150^{3}, 1153^{14}$

Eytan, Walter Botschafter des Staates Israel in Paris S. 908

Fanfani, Amintore 1958/1959 und 1960-1963 Ministerpräsident der Italienischen Republik S. 33, 1100, $1348^{17}$, 1430

Faure, Edgar 1955/56 Ministerpräsident der Französischen Republik S. 136

Fawzi, Mahmoud Außenminister der Vereinigten Arabischen Republik Dok. 280 und S. 163 f., 998

Fayat, Henri stellvertretender belgischer Außenminister S. 487, 48811

Federer, Georg Generalkonsul der Bundesrepublik Deutschland in New York bis 11. März 1964; seit 4. Juli 1964 Botschafter in Kairo Dok. 242, 295, 345,352 und S. $1126^{4}, 1133^{17}, 1142 \mathrm{f}$. $1144^{6+8}, 1150^{2}, 1284,1285^{4}, 1298^{5}, 1415^{8}$, $1556^{6}$

Feisal ibn Abdul-Aziz seit 2. November 1964 König des Königreichs SaudiArabien S. 1481

Felfe, Heinz ehemaliger Leiter des Referats "Sowjetunion" beim Bundesnachrichtendienst (am 6. November 1961 ver- 
haftet und am 23. Juli 1963 wegen Landesverrats verurteilt) S. $706^{13}$

Ferber, Ernst Leiter der „Unterabteilung II" im Führungsstab der Bundeswehr; seit 4. Juni 1964 Direktor des reorganisierten Planungsstabs der Standing Group der NATO in Washington S. $245^{5}, 937^{44}$

Ferring, Franz Botschafter der Bundesrepublik Deutschland in Manila bis 13. März 1964; seit 16. März 1964 Botschafter in Seoul S. $1457^{2}$

Finke-Osiander, Renate Legationsrätin im Referat „Polen, Tschechoslowakei, Jugoslawien, Albanien, Bulgarien, Rumänien, Ungarn; China (Volksrepublik und Formosa), Mongolische Volksrepublik, Nordkorea, Nordvietnam, Hongkong und Macau“ des Auswärtigen Amts S. 437

Finletter, Thomas K. Leiter der Ständigen Vertretung der Vereinigten Staaten von Amerika bei der NATO in $\mathrm{Pa}$ ris Dok. 98, 281 und S. 345, 448, 454456, 693, $976^{8}, 1081 \mathrm{f}, 1155 \mathrm{f}$.

Finn, Richard B. stellvertretender Referatsleiter im amerikanischen Außenministerium (Deputy Director, Office of German Affairs) S. 1380

Fischer, Gerhard Konsul der Bundesrepublik Deutschland in Madras; seit 24. August 1964 Legationsrat I. Klasse und Vertreter des Leiters im Referat „Süd- und Ostasien" des Auswärtigen Amts S. $1320,1345^{2}$

Fischer, Paul Staatssekretär im dänischen Außenministerium S. $475 \mathrm{f}$.

Fischer-Lossainen, Reinhold von Legationsrat I. Klasse und Vertreter des Leiters im Referat „Süd- und Ostasien“ des Auswärtigen Amts bis 23. August 1964; seit 1. September 1964 Generalkonsul der Bundesrepublik Deutschland in Lüttich S. $797^{1}$

Flandorffer, Rosemarie Dolmetscherin im Bundesministerium für Wirtschaft S. 227

Fontaine, André Leiter der außenpolitischen Redaktion der Zeitung "Le Monde" (Paris) S. 1034
Fornari, Giovanni Abteilungsleiter im italienischen Außenministerium (Direttore Generale degli Affari Politici) S. 1370

Foster, William C. Leiter der amerikanischen Abrüstungsbehörde in Washington (Director, U.S. Arms Control and Disarmament Agency) S. 182, 186, $600,694 \mathrm{f}$., $1049,1052^{12}, 1293^{5}$

Fouchet, Christian französischer Erziehungsminister; ehemaliger Vorsitzender des Sachverständigenausschusses zur Ausarbeitung der Statuten für eine europäische politische Union S. $709^{4}, 738^{2}, 782$ f., $806^{3}$

Foxley-Norris, Christopher Neil britischer General (Air Vice Marshall, Assistant Chief of Defence Staff) S. 692

François-Poncet, André 1931-1938 Botschafter der Französischen Republik in Berlin; 1949-1953 Hoher Kommissar in Deutschland; danach bis 1955 Botschafter in Bonn S. 1337

Franco y Bahamonde, Francisco Spanischer Staatschef und Generalissimus der Nationalen Streitkräfte Dok. 185 und S. 618-620, 752, 815 14,901

Frank, Paul Vortragender Legationsrat I. Klasse im Planungsstab des Auswärtigen Amts Dok. 290

Freeman, Orville L. amerikanischer Landwirtschaftsminister S. $378 \mathrm{f}$.

Frei Montalva, Eduardo Vorsitzender der "Partido Democrata Cristiano" in Santiago de Chile; seit 3 . November 1964 Präsident der Republik Chile S. 616

Frey, O. Korrespondent der „Neue Zürcher Zeitung" in Berlin S. 1484

Friedensburg, Ferdinand Mitglied des Deutschen Bundestages (CDU) S. $1229^{17}$

Fritsch, Günther seit 8. Februar 1964 Geschäftsträger an der Botschaft der DDR in Sansibar S. 503

Froger, Rudolph Botschaftsrat an der niederländischen Botschaft in Bonn S. $80^{36}$ 
Fulbright, James W. Senator des Staates Arkansas und Vorsitzender des Auswärtigen Ausschusses des amerikanischen Senats S. 414 f., $546^{18}, 547,550$

Gaerte, Felix Konsul I. Klasse und Vertreter des Leiters am Konsulat der Bundesrepublik Deutschland in Bombay bis 11. Januar 1964; seit 5. Februar 1964 Legationsrat I. Klasse im Referat „Abrüstung und Sicherheit" des Auswärtigen Amts S. $1035^{1}$

Gaillard, Felix 1957/58 Ministerpräsident der Französischen Republik S. 575

Gaitskell, Hugh 1955-1963 Abgeordneter des britischen Unterhauses und Vorsitzender der Labour Party S. $1392^{4}$

Gallois, Pierre General a.D. der französischen Luftwaffe S. 1054, 1337

Garoufalias, Pedros griechischer Verteidigungsminister S. 1329

Gastambide, Raymond stellvertretender Abteilungsleiter im französischen Außenministerium (Ministre plénipotentiaire, Désarmement) Dok. 133

de Gaulle, Charles Staatspräsident der Französischen Republik Dok. 20, 27, $44,49,50,51,66,141,180,183,184,186$, $187,188,189,195,198,210,217,218,234$, $264,318,321,341,342,350$ und S. 23 , 25 f., $28-32,34$ f., $45^{12}, 46$ f., 68,70 f., 79 $81,95^{24}, 98^{37}, 141 \mathrm{f} ., 154,192-195,198$, $217,223^{9}, 225^{13}, 273^{5}, 280$ f., 283,285 f., $290,291^{53}, 301^{11}, 325,341,361,374,394 \mathrm{f}$. 413 f., 418 f., $426,458,464,478,502,516^{9}$, $550,553,569,575,607 f$., $610,614,617$, 621,624 f., $646,653,680$ f., $682,736,755$, $757,760 \mathrm{f} ., 763^{24}, 797,809-811,818 \mathrm{f}$. $820^{15}, 825,828^{19}, 832 \mathrm{f} ., 843-845,899^{10}$, $932,935,934^{29}, 936^{39}, 942,943$ f., $948-950$, $955 \mathrm{f}$., 1004-1008, $1010 \mathrm{f}$., $1025^{2}, 1026$, 1028, 1031, 1033, 1066 f., $1079^{6}, 1084^{1}$, $1103,1118,1121$ f., $1149,1161,1173,1179$, $1185,1187,1199$ f., 1207,1219 f., 1223 $1226,1234,1235^{15}, 1249 \mathrm{f}$., $1263^{6}, 1266$, $1300,1315,1323$, 1326f., $1331 \mathrm{f} ., 1343 \mathrm{f}$., $1348^{17}, 1350,1363,1372,1390,1397 \mathrm{f}$, $1402 \mathrm{f} ., 1406,1409-1412,1413,1430$, $1438 \mathrm{f} ., 1445,1449,1452,1464^{7}, 1474$,
$1477^{49}, 1487-1492,1495$ f., 1508,1541 , 1545

Gebert, Boleslaw Botschafter der Volksrepublik Polen in Ankara S. $1107^{5}, 1560 \mathrm{f}$.

Gehlen, Walther von Leiter der Unterabteilung B in der Abteilung für Personal und Verwaltung des Auswärtigen Amts S. 5397

\section{Geithner, Heidi siehe Thoenes}

Gemünd, Karl Leiter des Referats „Allgemeine handelspolitische Fragen" im Auswärtigen Amt Dok. 109

Genevey, Pierre Generalinspekteur des Heeres und Berater des französischen Außenministeriums in Fragen der Strategie und der Rüstungskontrolle S. 551,553

Gerring, Gunnar Botschaftsrat an der schwedischen Botschaft in Bonn S. 324

Gerstenmaier, Eugen Präsident des Deutschen Bundestages und stellvertretender Vorsitzender der CDU Dok. 325, 352, 385 und S. 314, 3514, $398^{17}, 580,1118^{14}, 1250,1255,1266,1333$, $1357,1481,1534,1535^{8}$

Gewandt, Heinrich Mitglied des Deutschen Bundestages (CDU) S. $1298^{5}$

Gheorghiu-Dej, Gheorghe Vorsitzender des Staatsrats der Volksrepublik Rumänien und Erster Sekretär der Rumänischen Arbeiterpartei S. 5286 732

Gilpatric, Roswell L. Staatssekretär im amerikanischen Verteidigungsministerium (Deputy Secretary of Defense) bis 20. Januar 1964 S. $61^{40}, 1554,1575$

Giscard d'Estaing, Valéry französischer Finanz- und Wirtschaftsminister S. 33, 147, $192^{11}, 220,227$ f., $230,244^{3}$, 248 f., 262,272 f., $274^{9}, 320,555,561,744-$ 746, 777, 804

Gocht, Rolf Leiter der Abteilung „Wirtschaftspolitik" im Bundesministerium für Wirtschaft S. 504 ${ }^{3}, 505,560^{22}$

Goercke, Paul deutscher Ingenieur in der VAR S. 272 
Goldmann, Nahum Präsident des „World Jewish Congress" und der „Conference on Jewish Material Claims against Germany" in New York Dok. 276 und S. 198

Goldwater, Barry M. Senator des Staates Arizona S. 613, 623, 652, 654, 656, $658,812,1570^{2}$

Gomulka, Wladyslaw Erster Sekretär des Zentralkomitees der Polnischen Vereinigten Arbeiterpartei S. $285^{29}$, 955

de La Gorce, François Erster Botschaftsrat an der französischen Botschaft in Bonn S. 493, 1345 2

Gordon, Lincoln Botschafter der Vereinigten Staaten von Amerika in Rio de Janeiro S. 449

Gordon Walker, Patrick Abgeordneter des britischen Unterhauses (Labour Party); seit 18. Oktober 1964 Außenminister des Vereinigten Königreichs von Großbritannien und Nordirland Dok. $334,335,336,381,382,387,389$ und S. 34, 1173-1175, 1205, 1213, $1218 \mathrm{f}$., $1221,1256,1286,1324$ f., 1330-1332, 1345, $1363,1383,1385$ f., $1389,1393,1399,1401$, $1407,1408 \mathrm{f}$., $1443 \mathrm{f}$., 1514, 1563

Gottwald, Klement von 1946 bis Juni 1948 Ministerpräsident; danach bis 1953 Präsident der Tschechoslowakischen Sozialistischen Republik S.928

Goulart, João Belchior Marques Präsident der Vereinigten Staaten von Brasilien bis 15. April 1964 S. $617^{10}$

Granow, Hans Ulrich Botschafter der Bundesrepublik Deutschland in Stockholm bis zu seinem Tod am 9. August 1964 S. 324

Greenhill, Denis Arthur seit 15. September 1964 Referatsleiter im britischen Außenministerium (Superintending Under Secretary of State, Northern Department) S. $1563^{7}$

Grewe, Wilhelm G. Leiter der Ständigen Vertretung der Bundesrepublik Deutschland bei der NATO in Paris; ehemaliger Botschafter in Washington Dok. 172, 235, 254, 261, 281, 284, 330 . und S. $123^{13}, 128^{2}, 158^{4}, 200^{6}, 296^{5}, 428^{3}$,
$429,448^{5}, 452^{14}, 453^{18}, 454,456,468,537$, $576^{2}, 728^{29}, 838^{10}, 1081^{9}, 1081^{1}, 1082 \mathrm{f}$., $1084^{16}, 1104^{1}, 1109,1110^{10}, 1160,1168$, $1185,1213^{2}$

Groeben, Hans von der Mitglied der EWG-Kommission in Brüssel, Leiter der Abteilung für Wettbewerb S. $483 \mathrm{f}$.

Groepper, Horst Botschafter der Bundesrepublik Deutschland in Moskau Dok. 19, 155, 158, 162, 163, 291, 310, 369 und S. $174^{11}, 214^{45}, 326^{16}, 335^{19}, 361^{39}$, $383^{6}, 386^{18}, 466,469,603,651^{5}, 672,673^{17}$, $678,699,700^{6}, 879$ f., $895,896^{2}, 951,1017$, $1039,1159^{5}, 1269,1419^{8}, 1510^{4}$

Gromyko, Andrej Andrejewitsch Außenminister der Union der Sozialistischen Sowjetrepubliken S. $58^{29}, 78,214^{45}$, $317^{13}, 329^{37}, 521,531^{19}, 671,727^{22}, 840$, $1045^{6}, 1052^{13}, 1250$ f., 1253 f., 1294,1381 , 1434,1493 f., $1498,1508,1518^{4}, 1525$, $1526^{19}, 1529$ f., $1533,1554^{21}$

Grotewohl, Otto Ministerpräsident der DDR S. $160^{2}$

Grund, Walter Staatssekretär im Bundesministerium der Finanzen S. 1137

Grundmann, Konrad Arbeits- und Sozialminister des Landes NordrheinWestfalen S. 1421, 1423

Gruson, Sydney Korrespondent der Zeitung "The New York Times" in London S. $35^{3}$

Güde, Max Mitglied des Deutschen Bundestages (CDU); ehemaliger Generalbundesanwalt S. $1157^{1}$

Guidotti, Gastone Botschafter der Italienischen Republik in Bonn; seit 23. Oktober 1964 Botschafter in London Dok. 223 und S. 122 f., 2374 1394

Gumbel, Karl Leiter der Personalabteilung im Bundesministerium der Verteidigung S. 878, 101249, 1040, 1176 $1300^{2}, 1321,1537$

Guttenberg, Karl Theodor Freiherr von und zu Mitglied des Deutschen Bundestages (CSU) S. $808^{1}$

Gwynne-Jones, Alun seit Dezember 1964 Lord Chalfont seit 27. Oktober 1964 Staatsminister für Fragen der Ab- 
rüstung im britischen Außenministerium S. 1213, 1498, 1506, 1508

Gyptner, Richard Sonderbeauftragter der DDR; ehemaliger Botschafter in Warschau S. $854^{24}$

Haas, Walter Botschaftsrat I. Klasse und Vertreter des Botschafters an der Botschaft der Bundesrepublik Deutschland in Ankara; seit 12. September 1964 Botschafter in Conakry Dok. 293 und S. $346^{25}$

Haas, Wilhelm 1956-1958 Botschafter der Bundesrepublik Deutschland in Moskau S. 662

Habib-Deloncle, Michel Staatssekretär im französischen Außenministerium (Secrétaire d'État aux Affaires étrangères) S. $430,554^{17}, 1028^{19}, 1345,1397$

Haeften, Gerrit von Leiter der Rechtsabteilung im Auswärtigen Amt bis zum Eintritt in den Ruhestand am 31. Mai 1964 S. $265,362,417^{37}, 702^{10}$

Haekkerup, Per Außenminister des Königreichs Dänemark S. $475 \mathrm{f}$., 533

Haile Selassie Kaiser des Kaiserreichs Äthiopien S. 1060

Hallstein, Walter Präsident der EWGKommission in Brüssel; ehemaliger Staatssekretär des Auswärtigen Amts S. $125,288^{45}, 480,484,558,611^{26}, 874$, $911,1114^{15}, 1116,1289 \mathrm{f}$.

Hamadi, Mohammed Shamte Ministerpräsident im Sultanat Sansibar bis 12. Januar 1964 S. $84^{55}$

Hamm, Harry Mitarbeiter der „Frankfurter Allgemeine Zeitung“ S. 542

Hanga, Abdullah Kassim vom 12. Januar bis 26. April 1964 Ministerpräsident der Volksrepublik Sansibar S. $84^{55}, 188$

Hansen, Niels Konsul I. Klasse und Vertreter des Botschafters an der Botschaft der Bundesrepublik Deutschland in Bern Dok. 206 und S. 543, 585

Hardenberg, Hans Graf von Generalkonsul und Leiter der Ständigen Vertretung der Bundesrepublik Deutschland bei den Internationalen Organisationen in Genf bis 5. April 1964; danach Leiter der Unterabteilung $A$ in der Abteilung für Handels- und Entwicklungspolitik des Auswärtigen Amts Dok. 125 und S. $869,878^{5}, 1119^{22}, 1129^{10}, 1164^{3+5}$, $1176^{7}, 1274^{7}, 1446,1558^{6}, 1567^{13}$

Harkort, Peter Günther Leiter der Ständigen Vertretung der Bundesrepublik Deutschland bei EWG und EURATOM in Brüssel Dok. 205, 216 und $S .482^{13}, 1177^{4}, 1178^{9}, 1181^{16}, 1361^{13}$, $1396^{18}, 1456^{25}$

\section{Harlech siehe Ormsby-Gore}

Harriman, W. Averell Unterstaatssekretär im amerikanischen Außenministerium (Under Secretary of State for Political Affairs) S. $36,44^{8}, 643,794^{21}$, 968

Hartkopf, Günter Mitarbeiter des Bevollmächtigten des Landes Berlin in Bonn S. 1137

Hartlieb, Wilhelm Botschaftsrat I. Klasse und Vertreter des Botschafters an der Botschaft der Bundesrepublik Deutschland in Ottawa bis 4. Juli 1964; seit 6. Juli 1964 Botschaftsrat I. Klasse an der Ständigen Vertretung bei der NATO in Paris Dok. 393 und S. 633 ${ }^{1}$

Hase, Karl-Günther von Staatssekretär und Chef des Presse- und Informationsamtes der Bundesregierung Dok. 306 und S. $49^{2}, 244^{3}, 253,270$, $397^{12}, 480,579,738^{2}, 785,796,887^{11}, 896^{2}$, $915^{7}, 942,964^{9}, 1090^{6}, 1142^{5}, 1203^{17}, 1227$, $1236,1241^{11}, 1242,1245$ f., $1406,1516^{8}$

Hasluck, Paul seit 24. April 1964 AuBenminister Australiens S. $1012 \mathrm{f}$.

Hassan II. König des Königreichs Marokko S. 420

Hassan, Abdel Fatah Leiter der Delegation der Vereinigten Arabischen Republik bei der Konferenz der 18Mächte-Abrüstungskommission in Genf S. 5777 , 694, 696, 1052

Hassel, Kai-Uwe von Bundesminister der Verteidigung Dok. 327 und S.61 f., $70^{34}, 102,106,116^{13}, 157^{6}, 158 \mathrm{f} ., 179 \mathrm{f}$., $191,194^{21}, 244^{3}, 245,393^{8}, 417,496,502^{8}$, $504-506,518,526,540^{2}, 556,593 \mathrm{f} ., 604$, $656,659,742$ f., $777^{2}, 796 f ., 808^{1}, 933$, 
$957^{4}, 1012,1089$ f., 1104 f., 1163,1165 , 1174 f., $1176^{7}, 1249,1256^{6}, 1260$ f., 1263 , 1264,1302 f., $1304^{18}, 1325,1326^{12}, 1333$, $1362^{1}, 1371,1373,1391,1398,1454^{17}$, $1489,1491^{43}, 1537^{2}, 1545^{4}, 1566$

Hassouna, Mohammed Abdel Khalek Generalsekretär der Arabischen Liga in Kairo S. $998^{4}$

Hauber, Otto Konsul am Generalkonsulat bzw. an der Ständigen Vertretung der Bundesrepublik Deutschland bei den Internationalen Organisationen in Genf bis 29. Februar 1964; seit 2. März 1964 Legationsrat I. Klasse im Referat „Abrüstung und Sicherheit" des Auswärtigen Amts S. $1035^{1}, 1562^{1}$

Havemann, Robert Professor an der Humboldt-Universität in Ost-Berlin (am 12./13. März 1964 aus der SED ausgeschlossen und von den Lehrverpflichtungen entbunden) S. 528

Hayman, Peter T. seit Oktober 1964 Leiter der Mission des Vereinigten Königreichs von Großbritannien und Nordirland in Berlin S. 1483, $1484^{5}$

Healey, Dennis seit 16. Oktober 1964 britischer Verteidigungsminister S. 1401, 1444, 1549

Heath, Edward britischer Minister für Industrie, regionale Entwicklung und Handel bis 16. Oktober 1964 Dok. 137 und S. $7^{3}, 63-67,81,512$

Heck, Bruno Bundesminister für Familien- und Jugendfragen S. $194^{21}, 244^{3}$, $250,738^{2}, 780-782$,

Hecker, Gottfried Leiter des Referats "Zivilrecht und ZivilprozeBrecht" im Auswärtigen Amt S.631

Heibach, Bernhard Konsul der Bundesrepublik Deutschland in Lourenço Marques S. 9794

Heine, Heinrich S. 786

Henderson, John N. Privatsekretär des britischen Außenministers S. 1498

Henry, Paul Zweiter Botschaftsrat an der französischen Botschaft in Bonn S. $25^{1}, 27,1345^{2}$

Herrenschmidt, Jean-Pierre Handels- rat an der französischen Botschaft in Bonn S. 1578

Herrera Lane, Felipe Präsident der "Inter-American Development Bank" in Washington S. 426

Herter, Christian A. Sonderberater für Handelsfragen des amerikanischen Präsidenten; ehemaliger Außenminister der Vereinigten Staaten von Amerika S. $28^{7}, 37^{8}, 49,53^{14}, 512,659,1380^{2}$

Herwarth von Bittenfeld, Hans Heinrich Staatssekretär und Chef des Bundespräsidialamtes S. 189

Herzog, Maurice französischer Staatssekretär für Jugend und Sport S. $244^{3}$, 250 f., $738^{2}, 781$

Heß, Rudolf 1933-1941, „Stellvertreter des Führers" und Reichsminister ohne Portfolio S. $277^{9}$

Hillenbrand, Martin J. Gesandter an der amerikanischen Botschaft in Bonn S. $5 \mathrm{f}, 168,180^{3}, 350^{7}, 428,970,1035 \mathrm{f}$., $1038,1100 \mathrm{f}$.

Hillger, Hermann Legationsrat im Referat "Völkerrecht und Staatsverträge" des Auswärtigen Amts S. $1091^{6}$

Hirsch, Martin Mitglied des Deutschen Bundestages (SPD) und Vorsitzender des Ausschusses für Wiedergutmachung S. 1130

Hitler, Adolf 1933/34 Reichskanzler und 1934-1945 „Führer und Reichskanzler" des Deutschen Reiches S. 595, 626 f., $647,660,663,666,776,901,1383$, 1464

Höcherl, Hermann Bundesminister des Innern S. 159, 854, 957

Hohler, Henry A. F. Gesandter an der britischen Botschaft in Paris S. 1535, $1536^{3}$

Hohmann, Karl Leiter des Kanzlerbüros im Bundeskanzleramt S. 324, 643

Hoffmann, Carl Julius Legationsrat I. Klasse und Vertreter des Botschafters an der Botschaft der Bundesrepublik Deutschland in Algier S. $945^{1}$ 
Hoffmann, Franz Josef Leiter des Referats „USA, Kanada“ im Auswärtigen Amt S. $1176^{8}$

Hoffmann, Klaus Botschaftsrat I. Klasse und Vertreter des Botschafters an der Botschaft der Bundesrepublik Deutschland in Wien S. $697^{5}$

Hofmann, Wilfried Legationsrat im Referat "Süd- und Ostasien“ des Auswärtigen Amts S. $797^{1}$

Hogen, Shinsaku Leiter der Abteilung „Europa“ im japanischen Außenministerium S. $864^{9}$

Holleben, Ehrenfried von Chef des Protokolls im Auswärtigen Amt S.324

Holmer, Paul C. H. Mitarbeiter im britischen Außenministerium (Assistant, Western Department) S. 1498

Home siehe Douglas-Home

Homem de Mello, Manuel seit 29. April 1964 Botschafter der Republik Portugal in Bonn Dok. 237

Hood, Samuel, 6. Viscount Hood Unterstaatssekretär im britischen Außenministerium (Deputy Under-Secretary of State) Dok. 89, 126 und S.525, $1321^{2}, 1389^{6}, 1392^{5}, 1394^{8}, 1399$ f., 1444 , $1498,1528^{4}$

Hopf, Volkmar Staatssekretär im Bundesministerium der Verteidigung S. 504, 506, 538

Hoppe, Hans-Günter Senator für Finanzen des Landes Berlin und Mitglied des Abgeordnetenhauses (FDP) S. 1057

Hüttebräuker, Rudolf Staatssekretär im Bundesministerium für Ernährung, Landwirtschaft und Forsten S. 868, $870^{10}, 1161$

Humphrey, Hubert H. Senator des Staates Minnesota und Kandidat für das Amt des amerikanischen Vizepräsidenten S. 1575

Hussein II. König des Haschemitischen Königreichs Jordanien S. 420, 1388,1482

Huyn, Hans Graf Legationsrat im Referat „Europäische politische Integra- tion; Europarat und nichtstaatliche europäische Organisationen; WEU (nichtmilitärische Angelegenheiten)" des Auswärtigen Amts S. $1091^{6}$

Ikeda, Hayato Ministerpräsident des Kaiserreichs Japan S. 83

Iljitschow, Iwan Iwanowitsch Leiter der „3. Europäischen Abteilung“ im sowjetischen Außenministerium S. $361^{39}$

Illia, Arturo U. Präsident der Republik Argentinien S. 616

Imhoof, Werner Mitarbeiter der „Neue Zürcher Zeitung“ S. 1084 f., 1087

Inönü, Ismet Ministerpräsident der Republik Türkei Dok. 333 und S. 793 f.

Ittersum, Gerhard Eliza Baron van Botschafter des Königreichs der Niederlande in Bonn S. 280, 290, 710, $1141 \mathrm{f}$.

Iwinskaja, Olga Lebensgefährtin von Boris Pasternak (nach dessen Tod am 30. Mai 1960 inhaftiert, am 2. November 1964 freigelassen) S. $1352^{36}$

Jacub, Mustafa A. 1963 Außenminister der Arabischen Republik Jemen S. $161^{7}$

Jaeger, Richard Mitglied des Deutschen Bundestages (CSU) und Vizepräsident; Vorsitzender des Ausschusses für Verteidigung $\mathrm{S} .1165^{7}$

Jaene, Hans Dieter Redakteur des Nachrichtenmagazins "Der Spiegel“" (Hamburg) S. $845^{1}$

Jahn, Gerhard Mitglied des Deutschen Bundestages (SPD) S. 353

Jaksch, Wenzel Mitglied des Deutschen Bundestages (SPD) und Präsident des Bundes der Vertriebenen S. $1125^{6}$

Jansen, Josef Leiter der „Politischen Abteilung I" im Auswärtigen Amt Dok. 17, 21, 40, 70, 86, 90, 95, 135, 164, $191,218,223,234,309,332,342,344,349$, $355,368,385,394,395$ und S. $30^{17}, 34^{41}$, $49^{1+2}, 63^{1}, 118^{1}, 119^{8}, 145^{23}, 181^{4}, 219^{14}$, $222,233,237^{4}, 244^{3}, 290^{51}, 324,330^{46+48}$ $348^{6}, 356,358,363-365,362^{46}, 396^{6}, 397^{10}$, $398^{17}, 475^{4}, 615^{2}, 618,668^{7}, 710,732^{53}$, 
$913,956,957^{5}, 958^{7}, 980^{10}, 981,1012^{49}$ $1017^{1}, 1027^{9}, 1118^{12}, 1143^{3}, 1150^{1}, 1195$, $1196^{8}, 1197^{9+10}, 1227^{1}, 1244^{5}, 1245^{9}$, $1247^{18}, 1281^{3}, 1316^{2}, 1320,1358^{5}, 1365^{16}$ $1367^{8+9}, 1373^{9}, 1386^{32}, 1387^{36}, 1456^{26+28}$, $1480^{2+4}, 1482^{15}$

Janz, Friedrich-Rudolf 1959-1961 Leiter der Rechtsabteilung im Auswärtigen Amt S. $354^{9}$

Jaspar, Baron Marcel Henry Botschafter des Königreichs Belgien in $\mathrm{Pa}$ ris $S .1223^{37}$

Jay, Douglas seit 18. Oktober 1964 britischer Handelsminister S. 1313

Jayanama, Direck Botschafter des Königreichs Thailand in Bonn S. 682

Jermoschin, Pawel Konstantinowitsch Botschafter der Union der Sozialistischen Sowjetrepubliken in Nikosia S. 1416

Jestaedt, Rudolf Legionatsrat I. Klasse und Vertreter des Leiters im Referat "Gesandtschafts- und Konsularrecht, Wiedergutmachung, Verkehrsrecht, Beamtenrecht" des Auswärtigen Amts S. 437, $1463^{2}$

Jödahl, Ole Botschafter des Königreichs Schweden in Bonn S. 324

Johannes XXIII. (Angelo Giuseppe Roncalli) Papst bis zu seinem Tod am 3. Juni 1963 S. 463

John, Herbert Redakteur des Nachrichtenmagazins "Der Spiegel“ (Hamburg) S. $1442^{9}$

Johnson, Charles K. Mitarbeiter im amerikanischen Außenministerium (Officer in Charge, German Economic Affairs) S. 643

Johnson, Lyndon B. Präsident der Vereinigten Staaten von Amerika Dok. 136, 161, 401 und S. 19, $22 \mathrm{f}$., $25 \mathrm{f}$., 28 f., 33 f., $36-38,47,51,57,75$ f., 78,134 , 141,182 , 192 f., 204 f., $242,257,259$ f., 262 f., $282,300,302$ f., 321, 334, 341, 350, $411,413,417,428$ f., 454 f., $460,506,507^{2}$, $508,514,518,516^{14}, 517^{17}, 531,543^{7}$, 547 f., $550,552^{7}, 557,583,602^{8}, 643^{3}, 644$, $647,680 \mathrm{f} ., 682,694,719,733^{59}, 750,770$, $791,793-795,811-814,915,968^{3}, 1007$,
$1013^{5}, 1016,1051,1078,1081,1084^{16}$, $1146^{1}, 1147,1155,1218,1220 \mathrm{f}, 1231$, $1293 \mathrm{f}, 1296,1301 \mathrm{f} ., 1324,1327,1338$, $1381^{6}, 1384,1411,1449,1454,1485$, 1487 f., $1491,1494,1499^{9}, 1502,1526^{19}$, 1529, 1541 f., $1553,1554^{20}$

Joxe, Louis französischer Staatsminister; ehemaliger Botschafter der Französischen Republik in Bonn S.731, $742,948,972^{2}, 1020,1248$

Juma, Madhet Botschafter des Haschemitischen Königreichs Jordanien in Bonn S. $670,1515^{3}$

Jung, Ernst Legationsrat I. Klasse im Referat "Wiedervereinigung" des Auswärtigen Amts S. $1137^{1+2}, 1138$

Jungfleisch, Edwin Legationsrat und Vertreter des Botschafters an der Botschaft der Bundesrepublik Deutschland in Rangun S. $1202^{13}$

Kalkhorst Ministerialdirigent im Bundesministerium für Wirtschaft $\mathrm{S} .1137$

Kambona, Oscar S. Außenminister der Republik Tanganjika und Verteidigungsminister bis 26. April 1964; danach Außenminister der Vereinigten Republik von Tanganjika und Sansibar (seit 29. Oktober 1964: Vereinigte Republik Tansania) S. 393, 957 f., 1176

Kameke, Karl-August von Botschafter der Bundesrepublik Deutschland in Cotonou S. $1150^{3}, 1153,1202^{15}$

Kanga, Victor kamerunischer Wirtschafts- und Finanzminister S. $779^{11}$

Karume, Abeid Amani vom 12. Januar bis 26. April 1964 Präsident der Volksrepublik Sansibar; danach Erster Vizepräsident der Vereinigten Republik von Tanganjika und Sansibar (seit 29. Oktober 1964: Vereinigte Republik Tansania) $\mathrm{S} .84^{55}, 188,503^{3}, 504,958^{9}$

Kasper, Siegfried Vertreter des Leiters in der Hauptverwaltung Straßenwesen der DDR S.988

Kastl, Hans Jörg Legationsrat I. Klasse und Vertreter des Leiters im Pressereferat des Auswärtigen Amts S. $49^{2}, 615^{2}, 887^{11}, 1380,1498$ 
Katzenstein, Ernst Direktor für Deutschland der „Conference on Jewish Material Claims against Germany" in New York S. 1130

Kaul, Friedrich-Karl Rechtsanwalt in Ost-Berlin und Vizepräsident der ,Vereinigung demokratischer Juristen in der DDR“ S. 4, $1157^{1}$

\section{Keil, Rolf Dietrich Dolmetscher} S. $896^{1}$

Keller, Rupprecht von Leiter des Referats „Vertragsrechtliche Fragen und Verbindung $\mathrm{zu}$ den gesetzgebenden Körperschaften" im Auswärtigen Amt; seit 1. Mai 1964 Generalkonsul und Leiter der Ständigen Vertretung der Bundesrepublik Deutschland bei den internationalen Organisationen in Genf Dok. 253

Kennedy, John F. 1961-1963 Präsident der Vereinigten Staaten von Amerika S. $28^{7}, 48^{14}, 65^{9}, 90^{2}, 111$ f., $113^{16}, 120^{4}$, $134,154,211,242,259$ f., $301^{10}, 305,416$, $454,460,556,583,613,621,654,718$, $767^{7}, 770,795,1015,1045^{6}, 1087$ f., 1337 , 1408,1449

Kennedy, Robert F. amerikanischer Justizminister S. 83, 1269

\section{Kennet siehe Young}

Kenyatta, Jomo Ministerpräsident von Kenia; seit 12. Dezember 1964 Präsident der Republik Kenia S. 84 f., 503

Keramane, Hafid Botschafter der Demokratischen Volksstaatlichen Republik Algerien in Bonn S. $366^{3}, 732^{52}$

Khoman, Nai Thanat Außenminister des Königreichs Thailand S. 683

Khonti, Suphamongkhon Generalsekretär der SEATO in Bangkok Dok. 169

Kidd, Coburn B. Botschaftsrat an der amerikanischen Botschaft in Bonn S. $589,794^{20}, 1534$

Kiesewetter, Wolfgang Stellvertretender Minister für Auswärtige Angelegenheiten der DDR S. 161, 163-65, 503, $854^{24}$

Kiesinger, Kurt-Georg Ministerpräsi- dent des Landes Baden-Württemberg S. 314, $782 \mathrm{f}$.

Kirchner, Hans-J. Geschäftsführer des „Ostausschusses der deutschen Wirtschaft" in Köln S. 542, 585-587

Kirilenko Zweiter Sekretär an der sowjetischen Botschaft in Ost-Berlin S. $443^{15}$

Kirk, Grayson Louis Präsident der Columbia University in New York S. 305, 416

Klaiber, Manfred Botschafter der Bundesrepublik Deutschland in Paris Dok. 7, 66, 117, 141, 168, 194, 311, 316, $350,359,389$ und S. $20^{8}, 33^{34}, 34^{45}, 43^{7}$, $45^{12}, 97^{33}, 101^{44}, 136^{23}, 184^{12}, 192^{11}, 220^{17}$, $222,233,244^{3}, 252^{27}, 615^{2}, 618^{13}, 713^{3}$, $734^{61}, 738^{2}, 777^{2}, 793^{16}, 804^{4}, 948,1006^{17}$, $1076,1077^{12}, 1087^{12}, 1160,1187,1199 \mathrm{f}$., $1223^{37}, 1224^{43+44}, 1263^{6}, 1355^{50}, 1449^{1}$, $1464^{7}, 1466^{12+14}, 1477^{49}, 1536^{3+5}, 1578^{3}$

Klarenaar, Rudolf Leiter des Referats "Wirtschaftsbeziehungen zum Osten" im Auswärtigen Amt S. 2692 $927^{6}$

Klein, Walter 1953-1963 Leiter des Protokoll- und Auslandsamtes des Landes Berlin S. $443^{15}$

Klein Leiter der Delegation der Bundesrepublik Deutschland bei der Welthandelskonferenz in Genf S. 590 ${ }^{3}, 591^{6}$

Kleinwächter, Hans deutscher Ingenieur in der VAR S. 272

Klicka, Otto tschechoslowakischer Stellvertretender Außenminister S. 1061

Kliesing, Georg Mitglied des Deutschen Bundestages (CDU) S.510, $1165^{7}$

Knappstein, Karl Heinrich Botschafter der Bundesrepublik Deutschland in Washington Dok. 9, 20, 71, 79, 152, $167,170,217,264,401$ und S. $41^{10}, 98^{37}$, $260^{24}, 261^{30}, 262^{34}, 266^{3+4}, 315^{2}, 344^{14}$, $356 \mathrm{f} ., 426^{6}, 465 \mathrm{f}$., $468,470^{6}, 515^{8}, 548$, $589^{11}, 639^{3}, 645^{13}, 674^{2}, 729^{30}, 968,1073^{5}$, $1219^{10}, 1223^{35}, 1254^{16}, 1278^{4}, 1285,1286^{6}$, $1325^{5}, 1380,1404^{5}, 1484^{5}, 1493^{4}$

Knieper, Werner Leiter der Abteilung „Verteidigungswirtschaft" im Bundes- 
ministerium der Verteidigung Dok. 18 und S. $191^{4}, 878^{5}, 1164$

Knoke, Karl Hermann Gesandter und Vertreter des Botschafters an der Botschaft der Bundesrepublik Deutschland in Paris Dok. 227 und S. $301^{11}, 621^{23}$, $887^{11}, 926^{4}, 943^{5}, 948,949^{7}, 972^{1+2}$, $974^{11+13}, 1187$

Koenig, Joseph Botschafter der Bundesrepublik Deutschland in Nikosia Dok. 365 und S. $181^{6}, 347^{2}, 1366-1368$

Kohler, Foy D. Botschafter der Vereinigten Staaten von Amerika in Moskau S. 668, 678f., 1172, 1231

Kopf, Hermann Mitglied des Deutschen Bundestages (CDU) und Vorsitzender des Ausschusses für auswärtige Angelegenheiten S. 353, 510, $904^{1}$

Korber, Horst Leiter der ,Allgemeinen und Politischen Abteilung" der Senatskanzlei beim Regierenden Bürgermeister von Berlin Dok. 26 und S. $3^{1}, 6$, 91 f., $292^{4}, 309,409$ f., 851 f., $987,989,991$, $1021,1022^{33}, 1038,1068,1070 \mathrm{f}$.

Korff, Hans C. Leiter der Abteilung „Bundeshaushalt" im Bundesministerium der Finanzen S. 504 ${ }^{3}, 505$

Kossygin, Alexej Nikolajewitsch Erster Stellvertretender Vorsitzender des Ministerrats der Union der Sozialistischen Sowjetrepubliken bis 14 . Oktober 1964; danach Ministerpräsident Dok. 310 und S. 1159 f., 1212, 1250 f., $1253,1318,1517^{3}, 1518,1526^{21}, 1531 \mathrm{f}$.

Kostopoulos, Stavros Außenminister des Königreichs Griechenland S. $494^{7}$

Krag, Jens Otto Ministerpräsident des Königreichs Dänemark S. $289^{48}, 475 \mathrm{f}$, $645,821^{18}, 833$

Krapf, Franz Leiter der „Politischen Abteilung II" im Auswärtigen Amt Dok. $17,26,38,58,60,61,77,96,100,101,114$, $131,140,143,149,177,201,204,250,256$, 258,400 und S. $3,5,10^{1,} 2,21^{12}, 58^{33}, 59^{34}$, $86^{3}, 121^{8}, 122,142^{14}, 146^{28}, 171,172^{8}$, $180^{3}, 186^{1}, 203^{17}, 245^{5}, 273^{5}, 276^{7}, 277^{10}$, $288^{41}, 307^{15}, 308^{20}, 329^{40}, 344^{14}, 355^{4}$, 358-360, 362 f., $375^{1}, 380^{7}, 428^{1}, 432,448^{5}$, $466^{39}, 508^{5}, 510^{5}, 528,540^{2}, 569^{24}, 607^{5}$,
$615^{2}, 639,643,684^{1}, 691^{2}, 838^{10}, 956$, $1079^{6}, 1080^{4-6}, 1089,1108,1195^{10}, 1201^{3}$

Krautwig, Carl Staatssekretär im Bundesministerium für gesamtdeutsche Fragen S. 3, 305, 987 $7^{15}, 1137,1139,1141$, $1198^{5}$

Kreisky, Bruno Außenminister der Republik Österreich S. 697

Krekeler, Heinz L. Mitglied der EURATOM-Kommission in Brüssel; ehemaliger Botschafter der Bundesrepublik Deutschland in Washington S. 1179

Kresse, Walter Oberbürgermeister von Leipzig S. $998^{4}$

Kriebel, Rainer Militärattaché an der Botschaft der Bundesrepublik Deutschland in Kairo S. 604, 670, $1164^{5}, 1165^{6}$

Kristiansen, Georg Leiter der Ständigen Vertretung des Königreichs Norwegen bei der NATO in Paris S. $405^{5}$

Kroll, Hans 1958-1962 Botschafter der Bundesrepublik Deutschland in Moskau S. $360^{34}$

Krone, Heinrich Bundesminister für besondere Aufgaben und Vorsitzender des Bundesverteidigungsrats; ehemaliger Vorsitzender der CDU/CSUFraktion im Deutschen Bundestag Dok. 319, 320 und S. $32^{25}, 159,574,738^{2}$, $777^{2}, 1104,1249 \mathrm{f}$.

Kruse, Hans-Heinrich Legationsrat I. Klasse im Referat „EWG, EGKS, EURATOM“ des Auswärtigen Amts; vom 7. Oktober bis 16. November 1964 mit dem Aufbau der Handelsvertretung der Bundesrepublik Deutschland in Sofia beauftragt $\mathrm{S} .1060^{18}$

Krylow, Nikolaj Iwanowitsch sowjetischer Stellvertretender Verteidigungsminister und Oberbefehlshaber der Raketenstreitkräfte S. $174^{11}$

Kühlmann-Stumm, Knut Freiherr von Mitglied des Deutschen Bundestages und stellvertretender Vorsitzender der FDP-Fraktion S. $55^{19}, 307$

Kühnle Mitglied des Vorstands der Ruhr-Stickstoff-AG in Essen S. $424^{2}$ 
Kütchük, Fazil zyprischer Vizepräsident S. $115^{3}$

Kumykin, Pawel Nikolajewitsch sowjetischer Stellvertretender Minister für Außenhandel S. $438^{7}, 1211^{10}$

Kusterer, Hermann Dolmetscher und Vertreter des Leiters im Sprachendienst des Auswärtigen Amts S.19, $27^{1}, 73^{1}, 160^{1}, 203^{1}, 237^{1}, 570^{1}, 607^{1}, 640^{1}$, $682^{1}, 713^{1}, 749^{1}, 768^{1}, 822^{1}, 830^{1}, 1015^{1}$, $1025^{1}, 1255^{1}, 1267^{1}, 1399^{1}, 1404^{1}, 1408^{1}$, $1435^{1}, 1443^{1}, 1463^{1}, 1498,1510^{1}$

Kutscher, Ernst Botschaftsrat I. Klasse an der Botschaft der Bundesrepublik Deutschland in Paris bis 22. Januar 1964; danach Leiter des Referats "Sowjetunion" im Auswärtigen Amt S. $457^{8}, 1506^{21}, 1545^{4}$

Kyprianou, Spyros Außenminister der Republik Zypern S. $1254^{16}$

Lahn, Lothar Leiter des Referats „Abrüstung und Sicherheit" im Auswärtigen Amt Dok. 133 und S. $182^{1+4}, 199^{1}$, $295^{1}, 507^{1}, 865^{1}, 938^{1}, 1204^{1}, 1210^{26+27}$, $1562^{1}$

Lahr, Rolf Staatssekretär im Auswärtigen Amt Dok. 2, 24, 28, 41, 55, 56, 69, $73,76,81,85,88,94,97,102,116,128$, $192,207,208,215,219,230,231,233,243$, $272,273,287,314,322,329,358,373,402$ und S. $10^{3}, 24^{5}, 101^{1}, 102^{3}, 106^{22}, 118^{1}$, $228^{12}, 251^{25}, 280,286^{33}, 315^{1}, 324,330$, 343 f., $346^{26}, 477^{1}, 612,632^{4}, 633^{5}, 712^{7+9}$, $722^{26}, 748^{45}, 766,870^{10}, 894^{5}, 913,914$, $946^{5}, 947^{8+12}, 954^{9}, 970,974^{15}, 978^{4}$ $989^{22}, 991^{9}, 995,1012^{49}, 1021,1035,1040$, $1058^{8}, 1096-1098,1138 \mathrm{f} ., 1150^{3}, 1176^{7}$, $1181^{19}, 1182^{1}, 1187 \mathrm{f} ., 1195,1227^{6}, 1300^{2}$ 1304, 1311f., $1359^{1}, 1360,1368^{11}, 1404^{3}$, $1415^{6}, 1421,1537^{3}, 1559^{6}, 1566^{6}$

Lahusen, Carl Legationsrat I. Klasse und Vertreter des Leiters im Referat „Frankreich, Belgien, Niederlande, Luxemburg, Italien" des Auswärtigen Amts S. $1027^{10}, 1028^{19}$

Laloy, Jean stellvertretender Abteilungsleiter im französischen Außenministerium (Directeur adjoint des Affaires politiques) Dok. 17 und S. 575
Lang, Norbert Legationsrat I. Klasse und Vertreter des Leiters im Referat „Europäische politische Integration; Europarat und nichtstaatliche europäische Organisationen; WEU (nichtmilitärische Angelegenheiten)" des Auswärtigen Amts S. $80^{36}, 615^{2}, 1091^{6}, 1345^{2}$, $1355^{53}$

Lange, Halvard M. Außenminister des Königreichs Norwegen S.533f., 929, $1520^{8}$

Langer, Wolfram Staatssekretär im Bundesministerium für Wirtschaft S. $308^{20}, 424,425^{7}, 447^{11}, 869,987^{15}$, $988^{20}, 1273$

Lautenschlager, Hans Mitglied des Deutschen Bundestages (SPD) S. 99728

Lawrow, Iwan Michajlowitsch Gesandter an der sowjetischen Botschaft in Bonn Dok. 36 und S. $86^{4}, 170$ f., 1009, $1195^{10}$

Lebel, Claude Abteilungsleiter im französischen Außenministerium (Directeur des services d'information et de presse) $\mathrm{S} .615^{2}$

Ledwidge, William B. Referatsleiter im britischen Außenministerium (Head of Central Department) S. 1304, 13092, 1498

Lee Hu Rak Generalsekretär im Präsidialamt der Republik Korea S. $1457^{2}$

Lee Tong Won Außenminister der Republik Korea S. $1457^{2}$

Lege Oberstleutnant im Bundesministerium der Verteidigung S. $101 \mathrm{f} ., 104$

Leicht, Albert Mitglied des Deutschen Bundestages (CDU) und Vorsitzender des Ausschusses für Rechnungsprüfung S. $1165^{7}$

Lemma, Aseffa Botschafter des Kaiserreichs Äthiopien in Bonn S. $105^{18}$

Lemnitzer, Lyman L. Oberbefehlshaber der amerikanischen und der NATOStreitkräfte in Europa (SACEUR) S. $71^{39}, 72,601,602^{10}, 937^{42}, 1263,1305$, 1476

Leopold, Kurt Leiter der „Treuhandstelle für den Interzonenhandel" in Ber- 
lin (West) bis 31. Oktober 1964 S. $308^{20}, 424$ f., 851,987 f., $1137-1139$

Leuschner, Bruno Stellvertretender Ministerpräsident der DDR S. 267, 311, $355,799^{8}$

de Leusse, Pierre Botschafter der Französischen Republik in Rabat S. $1201 \mathrm{f}$.

de Leusse de Syon, Bruno Gesandter an der französischen Botschaft in Washington S. $1219^{10}$

Levi-Sandri, Vionello Vizepräsident der EWG-Kommission in Brüssel und Präsident des Europäischen Sozialfonds S. 235, 484

Lilienfeld, Georg von Gesandter und Vertreter des Botschafters an der Botschaft der Bundesrepublik Deutschland in Washington Dok. 111, 132, 259 und S. $19^{5}, 37,44^{8}, 184^{9}, 206^{18}, 416^{32}, 432^{14}$, $509^{13}, 528,1046^{6}, 1279^{7}, 1285,1380,1444$ $1454^{18}, 1494^{5}, 1526^{19}$

Li Meng Hou Handelsrat an der Botschaft der Volksrepublik China in London S. 978

Lippmann, Walter amerikanischer Journalist S. $98^{37}, 113,1572$

Lopez Rodo, Laureano Direktor des Planungsamtes der spanischen Regierung S. 620

Lozes, Gabriel Außenminister der Republik Dahome S. $1153^{14}$

Lucet, Charles Abteilungsleiter im französischen Außenministerium (Directeur des Affaires politiques) Dok. $75,126,247,248,249,344$ und S. $43^{7}$, $96^{31}, 97,99 \mathrm{f} ., 222,233,244^{3}, 525,615^{2}$, $710^{7}, 738^{2}, 777^{2}, 919^{14}, 955^{3}, 956,972^{2}$, 1076f., $1187,1193,1528^{4}, 1536^{3}, 1542^{11}$

Luciolli, Mario seit 5. November 1964 Botschafter der Italienischen Republik in Bonn S. 1393

Lübke, Heinrich Bundespräsident der Bundesrepublik Deutschland S. 83 , $164,189,198^{35}, 253^{33}, 259$ f., $413^{17}, 426$, $447^{1}, 449,485^{2}, 580^{1}, 606^{6}, 615$ f., 672 , $683^{7}, 742^{28}, 780,859,958,995,1036,1039$, $1153^{11+14}, 1176,1244^{2}, 1284$ f., $1362^{1}$, $1378,1459 \mathrm{f} ., 1482^{16}$
Luedde-Neurath, Kurt R. Leiter des Referats „Polen, Tschechoslowakei, Jugoslawien, Albanien, Bulgarien, Rumänien, Ungarn, China (Volksrepublik und Formosa), Mongolische Volksrepublik, Nordkorea, Nordvietnam, Hongkong und Macau" im Auswärtigen Amt Dok. 104, 275, 298, 303 und S. 367' $407^{10}, 437,470^{2}, 494^{7}, 517^{16}, 530^{14}$, $576^{1+4}, 707^{1}, 708^{8}, 952^{2}, 1058^{12}, 1061^{1+5}$, $1066^{16}, 1111^{18}, 1018^{11}, 1124^{2}, 1213^{2}, 1351$, $1353-1355,1421^{2}$

Luns, Joseph Außenminister des Königreichs der Niederlande Dok. 59, 266 und S. 533f., 624, 710, 750, 753, 826, $838,1103,1112 f$., 1134 f., 1186,1221

Macapagal, Diosdado Präsident der Republik der Philippinen S. 83

MacArthur, Douglas 1942-1945 Oberbefehlshaber der amerikanischen Streitkräfte im Südwest-Pazifik; danach bis 1950 Oberbefehlhaber der Besatzungstruppen in Japan; 1950 Oberbefehlshaber der UNO-Streitkräfte in Korea S. 211

Macmillan, Harold 1957-1963 Premierminister des Vereinigten Königreichs von Großbritannien und Nordirland S. $291^{53}, 767^{7}, 1089,1497$

Macovei, Pompiliu Alexandru rumänischer Stellvertretender Außenminister S. 1421

Mäkelä, Kaarlo Veikko Leiter der Handelsvertretung der Republik Finnland in Köln S. $1120^{23}$

Magill, Robert N. Erster Sekretär für Politische Angelegenheiten an der amerikanischen Botschaft in Bonn S. $186^{1}$, $329^{40}, 600$

Mahroug, Ismail Direktor der Algerischen Entwicklungsbank in Algier und Staatssekretär im algerischen Finanzministerium S. $909^{6}, 945 \mathrm{f}$.

Majonica, Ernst Mitglied des Deutschen Bundestages (CDU) und Vorsitzender des außenpolitischen Arbeitskreises der CDU/CSU-Fraktion S. $352^{7}, 599^{1}, 613^{33}, 673,1091^{4}$ 
Makarios III. Myriarthes (Michael Christodulos Muskos) Erzbischof und Präsident der Republik Zypern Dok. 365 und S. $115^{3}, 169^{5}, 181^{4+6}, 234$, $259,320,975,976^{7}, 977,1253^{10}, 1254$, 1301, 1329, 1364 f., 1366-1368

Malaju, Burhanuddin Gesandter an der indonesischen Botschaft in Bonn S. $995^{12}$

Malinowskij, Rodion Jakowlewitsch sowjetischer Verteidigungsminister S. 522

Manescu, Corneliu Außenminister der Volksrepublik Rumänien S.729

Manning, Robert J. Abteilungsleiter im amerikanischen Außenministerium (Assistant Secretary of State for Public Affairs) S. 643, 1205, 1208

Manschulo, Alexej N. Abteilungsleiter im sowjetischen Ministerium für $\mathrm{Au}$ Benhandel S. 107

Mansfield, Michael J. Senator des Staates Montana S. 623

Mansholt, Sicco L. Vizepräsident der EWG-Kommission in Brüssel und Leiter der Abteilung für Landwirtschaft; ehemaliger niederländischer Minister für Landwirtschaft, Fischerei und Ernährung $S .66^{16}, 286,289,378 \mathrm{f}$., $482 \mathrm{f}$., $870^{10}, 1114$

Mansour, Gamal E. seit 29. Juni 1964 Botschafter der Vereinigten Arabischen Republik in Bonn S.999, 1143, $1281,1284^{3}, 1515^{3}, 1555 \mathrm{f}$.

Mao Tse-tung Vorsitzender des Politbüros und des Zentralkomitees der Kommunistischen Partei Chinas S. $211,528^{5}, 682$

de Margerie, Emmanuel Jacquin Leiter des Osteuropa-Referats im französischen Außenministerium (Conseiller, Délégué dans les fonctions de Sous-Directeur) S. $956^{8}$

de Margerie, Roland Jacquin Botschafter der Französischen Republik in Bonn Dok. 8, 11, 244, 255, 355, 402, und S. 5 f., $217^{8}, 222,225,233,234^{10}, 238^{8}$, $244^{3}, 276,491 \mathrm{f} ., 615^{2}, 738^{2}, 777^{2}, 1027^{9}$,
$1040^{3}, 1076 \mathrm{f} ., 1100 \mathrm{f} ., 1103 \mathrm{f} ., 1121,1372$, $1413 f ., 1418 f$., $1449 f$.

Marijnen, Victor G. M. Ministerpräsident des Königreichs der Niederlande Dok. 59 und S. 301, 1093 f., 1096, 1098, 1103, $1112 \mathrm{f}$.

Marjolin, Robert Vizepräsident der EWG-Kommission in Brüssel und Leiter der Abteilung für Wirtschaft und Finanzen; ehemaliger französischer Wirtschaftsminister S. 483

Marré, Hans Herrmann Legationsrat I. Klasse und Vertreter des Leiters im Referat „USA, Kanada“ des Auswärtigen Amts; ehemaliger Vizekonsul an der Gesandtschaft der Bundesrepublik Deutschland in Stockholm S. 324

Marschall von Bieberstein, Walther Freiherr von Legationsrat im Referat „Völkerrecht und Staatsverträge" des Auswärtigen Amts S. $4^{6}, 371$

Marshall, George C. 1947-1949 Außenminister der Vereinigten Staaten von Amerika S. 49920

Martin, Berthold Mitglied des Deutschen Bundestages (CDU) und Vorsitzender des Ausschusses für Kulturpolitik und Publizistik S. 1298

Martin, Paul J. J. M. Außenminister Kanadas S. 533 f., $633^{2}, 1413$

Martino, Gaetano Präsident des Europäischen Parlaments in Luxemburg; ehemaliger Außenminister der Italienischen Republik S.534, 929

Masaryk, Jan G. 1940-1945 Außenminister der Tschechoslowakischen Provisorischen Regierung bzw. der tschechoslowakischen Exilregierung in London; 1945-1948 Außenminister der Tschechoslowakischen Sozialistischen Republik S. $596^{12}$

Mason, Sir Paul stellvertretender Leiter der britischen Delegation bei der Konferenz der 18-Mächte-Abrüstungskommission in Genf S. $694 \mathrm{f}$.

Matarella, Bernardo italienischer Minister für Außenhandel S. $145^{22}, 512$ 
Matern, Hermann Mitglied des Politbüros und des Zentralkomitees der SED S. $544^{12}$

Matsch, Franz Leiter der Ständigen Vertretung der Republik Österreich bei der UNO in New York und Vorsitzender des Ausschusses für die friedliche Nutzung des Weltraums S. $1278^{4}$

Maudling, Reginald britischer Schatzkanzler bis 16. Oktober 1964; ehemaliger Sonderbeauftragter für die Verhandlungen zur Errichtung einer Europäischen Freihandelszone S. 63 f., 67

Maurer, Ion Gheorghe Ministerpräsident der Volksrepublik Rumänien S. $363^{50}, 729,740^{19}, 926,955 \mathrm{f}$., 1020

Maurice-Bokanowski, Michel französischer Industrieminister S. 322, 745

Mayer, Michael Flüchtling aus der DDR (am 13. September 1964 an der Berliner Mauer schwer verletzt) S. $1059^{16}$

Mayhew, Christopher Abgeordneter des britischen Unterhauses (Labour Party) S. $1007^{19}$

McBride, Robert H. Gesandter an der amerikanischen Botschaft in Paris S. $1449^{1}$

McCloskey, Robert J. Referatsleiter im amerikanischen Außenministerium (Director, Office of News) S. $1205^{9}$

McCloy, John J. Vorsitzender des "Council on Foreign Relations" in New York; ehemaliger Hoher Kommissar der Vereinigten Staaten von Amerika in Deutschland Dok. 341 und S. 416

McGhee, George C. Botschafter der Vereinigten Staaten von Amerika in Bonn Dok. 5, 42, 51, 63, 72, 93, 103, $136,189,195,196,232,246,255,307,370$, 392 und S. $186,273^{5}, 276,380,514,540$, $541,555,557,589,643,1006,1264,1286^{3}$, $1329,1330,1380,1418$ f., 1485,1487 , $1566^{10}$

McIntyre, Laurence Botschafter Australiens in Tokio S. $863^{4}$

McNamara, Robert S. amerikanischer Verteidigungsminister S. $70^{34}, 417,496$, $504,518,526$ f., $540^{2}, 551,556,566,621^{25}$,
$656,659,796,1147,1165,1260,1285^{1}$, $1371,1373,1503,1545,1572,1575^{16}$

Meeker, Leonard C. Rechtsberater im amerikanischen Außenministerium S. $1386^{35}$

Meir, Golda Außenministerin des Staates Israel S. 352, 398, 9087

Melchers, Wilhelm Botschafter der Bundesrepublik Deutschland in Athen bis zum Eintritt in den Ruhestand am 30. November 1964 S. $235^{12}$

Melen, Ferid türkischer Finanzminister S. 1302

Melville, Eugene Gesandter an der britischen Botschaft in Bonn S. $7^{1}, 570$, $1313^{18}$

Mende, Erich Bundesminister für gesamtdeutsche Fragen und Vorsitzender der FDP S. $55^{19}, 305,307,314,424^{4}, 539$, 766 , 985 f., $989^{22}, 1141^{19}, 1165,1197$, $1198^{3+6}, 1464^{7}, 1517$

Mengele, Josef ehemaliger Lagerarzt im Konzentrationslager Auschwitz Dok. 74, 371

Menon, P. Achutha Botschafter der Republik Indien in Bonn bis 17. Dezember 1964 Dok. 65

Merchant, Livingston T. Sonderbeauftragter des amerikanischen Präsidenten für Sicherheitsfragen; ehemaliger Unterstaatssekretär im amerikanischen Außenministerium S. 454, $1110^{13}$

Mercker, Reinhold Leiter der ,Abteilung I" im Bundeskanzleramt S. 305, $324,1274^{7}, 1333^{5}$

Merkatz, Hans-Joachim von Mitglied des Deutschen Bundestages (CDU); ehemaliger Bundesminister für Angelegenheiten des Bundesrates und der Länder S. $751,803^{19}, 1347$

Messmer, Pierre französischer Verteidigungsminister Dok. 319 und S. 44 $4^{11}$, $244^{3}, 245$ f., $682,743^{32}, 744,777^{2}, 956$, $1105^{4}, 1173,1175^{10}, 1261,1435^{2}, 1491^{43}$, 1545,1575

van der Meulen, Joseph Leiter der Ständigen Vertretung des Königreichs Belgien bei EWG und EURATOM in Brüssel S. 1117 
Meyer-Lindenberg, Hermann Vertreter des Leiters in der Rechtsabteilung des Auswärtigen Amts Dok. 52, 147, 156 und S. $178^{20}, 610^{22}, 1108,1423^{9}$

Meyer-Lohse, Hans-Werner Legationsrat I. Klasse und Vertreter des Leiters im Referat „Mittel- und Südamerika" des Auswärtigen Amts S. $1442^{10}$

Michelet, Edmond 1945/46 französischer Verteidigungsminister, 1958/59 Minister für Veteranen und Kriegsopfer, 1959-1961 Justizminister S. 1249

Middelmann, Helmut Legationsrat I. Klasse und Vertreter des Leiters im Referat „Internationale Wirtschaftsfragen der Verteidigung, des Verkehrs, des Post- und Fernmeldewesens und des Fremdenverkehrs" des Auswärtigen Amts; seit 21. Februar 1964 Leiter des Referats S. $191^{4}, 878^{5}, 1164^{1+5}, 1165^{6}$, $1559^{1}$

Middleton, Drew Korrespondent der Zeitung "The New York Times" in Paris S. $261,1369^{2}$

Mießner, Herwart Mitglied des Deutschen Bundestages (FDP) S. $997^{28}$

Mikojan, Anastas Iwanowitsch sowjetischer Erster Stellvertretender Ministerpräsident bis 15. Juli 1964; danach Vorsitzender des Präsidiums des Obersten Sowjet der Sozialistischen Sowjetrepubliken S. $383^{6}, 1212,1224^{44}, 1252$, $1254,1488,1521 \mathrm{f}$.

\section{Minh siehe Duong Van Minh}

Mirbach, Dietrich Freiherr von Botschafter zur besonderen Verwendung im Auswärtigen Amt Dok. 62, 365 und S. $708,1064^{13}, 1066,1123^{48}, 1464^{4}$

Modrzewski, Franciszek polnischer Stellvertretender Minister für Außenhandel S. $375^{2}, 514$

Möller, Alex Mitglied des Deutschen Bundestages (SPD) S. $151^{10}$

Mollet, Guy Generalsekretär der Sozialistischen Partei Frankreichs; ehemaliger Ministerpräsident der Französischen Republik S. $100,101^{44}, 921^{20}$, $1268 \mathrm{f}$.
Molotow, Wjatscheslaw Michajlowitsch 1939-1949 und 1953-1956 Volkskommissar bzw. Minister für Auswärtige Angelegenheiten der Union der Sozialistischen Sowjetrepubliken S. $177^{19}$

Mommer, Karl Mitglied des Deutschen Bundestages und Parlamentarischer Geschäftsführer der SPD-Fraktion S. $1165^{7}$

Mommsen, Ernst Wolf Generaldirektor der Phoenix-Rheinrohr AG in Düsseldorf $\mathrm{S} .947^{8}$

Monnet, Jean Vorsitzender des ,Aktionskomitees für die Vereinigten Staaten von Europa"; ehemaliger Präsident der Hohen Behörde der EGKS in Luxemburg Dok. 405 und S. 485, 81911, $1160,1291^{4}, 1327,1350$

Moreira, Jorge Lopez Botschafter der Republik Paraguay in Bonn Dok. 371

Moro, Aldo Ministerpräsident der Italienischen Republik Dok. 27, 28 und S. $33^{37}, 121^{5}, 155,207,283,714^{8}$

Morosow, I. A. Erster Sekretär und Leiter der Konsularabteilung an der sowjetischen Botschaft in Bonn bis zur Ausweisung am 15. Januar 1964 S. $361 \mathrm{f}$.

Mountbatten, Louis, seit 1947 1. Earl Mountbatten of Burma Chef des britischen Verteidigungsstabes S. 1287

Mühlen, Ewald Legationsrat I. Klasse und Vertreter des Leiters im Referat „EWG, EGKS, EURATOM“ des Auswärtigen Amts S. $402^{1}, 1180^{15}$

Mühlen, Klaus Freiherr von Mitglied des Deutschen Bundestages (FDP) S. $1165^{7}$

Mühlenfeld, Hans Kultusminister des Landes Niedersachsen S.961

Mühllener, Konrad Brigadegeneral im Bundesministerium der Verteidigung S. 1164,1559

Müller, Konrad Staatssekretär im niedersächsischen Kultusministerium S. $960^{9}$ 
Müller, Kurt Legationsrat I. Klasse und Vertreter des Leiters im Ministerbüro des Auswärtigen Amts S. $49^{2}$

Müller-Chorus, Gerhard Legationsrat im Referat „Afrika südlich der Sahara“ des Auswärtigen Amts S. $188^{1}$

Müller-Roschach, Herbert Leiter des Planungsstabs im Auswärtigen Amt Dok. 16, 17, 226, 331, 391 und S. $118^{1}$, $312^{8}, 356-358,361,363 \mathrm{f}$., $466,469,904 \mathrm{f}$., $948^{1}, 1108,1320$

el-Muhandis, Mohammed ägyptischer Gesundheitsminister S. $998^{4}$

Muller, Hilgard Außenminister der Republik Südafrika S.1153

Mumm von Schwarzenstein, BerndEugen Leiter der Handelsvertretung der Bundesrepublik Deutschland in Warschau S. 375, 599, $926^{2}$

Munzel, Kurt Botschafter der Bundesrepublik Deutschland in Léopoldville bis 3 . September 1964; seit 18. September 1964 Botschafter in Beirut S. 1164

Murumbi, Joseph Staatsminister beim kenianischen Ministerpräsidenten; seit 12. Dezember 1964 Außenminister der Republik Kenia S.503

Mussolini, Benito $1922-1925$ Ministerpräsident; danach bis 1943 Regierungschef und Präsident des „Faschistischen Großrates“ im Königreich Italien S. $150^{7}$

Nagy, Imre 1953-1955 und im Oktober/ November 1956 Ministerpräsident der Ungarischen Volksrepublik (nach dem Volksaufstand nach Rumänien verschleppt und am 16. Juni 1958 in Budapest hingerichtet) S. $883^{12}$

Nahm, Peter Paul Staatssekretär im Bundesministerium für Vertriebene, Flüchtlinge und Kriegsgeschädigte S. 1124

Narita, Katsushiro Botschafter des Kaiserreichs Japan in Bonn Dok. 203

Nasser, Gamal Abdel Präsident der Vereinigten Arabischen Republik Dok. 32, 95, 242, 340, 352, 394 und S. $352^{7}, 382,415 \mathrm{f}$., $457^{8}, 458 \mathrm{f}$., $552,649 \mathrm{f}$.,
$656,996,1182^{2}, 1183 \mathrm{f} ., 1237 \mathrm{f}$., 1245,1247 $1281-1283,1284,1285^{4}, 1328,1356^{2}$, $1481,1515,1516^{5}$

Naszkowski, Marian polnischer Stellvertretender Außenminister S. 362

Naumann, Walter deutscher Student (seit September 1961 in sowjetischer Haft) S. 706, 1212

Naupert, Heinz Leiter der Wirtschaftsabteilung an der Botschaft der Bundesrepublik Deutschland in Moskau bis zur Ausweisung aus der UdSSR am 22. März 1964; seit 22. April 1964 Legationsrat I. Klasse und Vertreter des Leiters im Referat „Allgemeine handelspolitische Fragen" des Auswärtigen Amts Dok. 19 und S. 361

N'Douré, Hamaciré malischer Minister für Handel und Verkehr S. 106

Neef, Fritz Staatssekretär im Bundesministerium für Wirtschaft $\mathrm{S} .23^{2}, 445$, $480,805,869$

Nehru, Ratan K. Leiter der Delegation der Republik Indien bei der Konferenz der 18-Mächte-Abrüstungskommission in Genf S. 982' $1048 \mathrm{f}$.

Nehru, Shri Jawaharlal Ministerpräsident und Außenminister der Republik Indien bis $\mathrm{zu}$ seinem Tod am 27. Mai 1964 S. 311f., 694, 696, 996

Nenni, Pietro Generalsekretär der Sozialistischen Partei Italiens Dok. 29 und S. 195 f., 207, 283, 1454

Nettewar Mitarbeiter im tschechoslowakischen Außenministerium S. 1061

Neumann, Alfred B. Vorsitzender des Staatlichen Komitees für Körperkultur und Sport der DDR S. $998^{3}$

Neumann, Alois tschechoslowakischer Justizminister S. 113211

Neumann, Franz Leiter des Referats „Wirtschaftsbeziehungen zum Westen“ im Auswärtigen Amt S. $61^{40}$

Neusel, Hans Persönlicher Referent des Chefs des Bundeskanzleramtes S. 869,1137 
Newington, Michael J. Erster Sekretär für Wirtschaft an der britischen Botschaft in Bonn S. 1165

Nevermann, Paul Präsident des Senats und Erster Bürgermeister der Freien und Hansestadt Hamburg S. 314

Ngo Dinh Diem Präsident der Republik Vietnam bis zu seinem Sturz am 1. November 1963 (am 2. November 1963 ermordet) S. $622^{27}, 921$

Nguyen Khanh seit 30. Januar 1964 Staatschef und seit 8 . Februar $1964 \mathrm{Mj}$ nisterpräsident der Republik Vietnam S. $541,622^{27}$

Nguyen Ngoc Tho Ministerpräsident der Republik Vietnam bis 2. Februar 1964 S. $622^{27}$

Nguyen Qui Anh seit 16. April 1964 Botschafter der Republik Vietnam in Bonn S. 448, 541, 818

Niederalt, Alois Bundesminister für Angelegenheiten des Bundesrates und der Länder S. $124 \mathrm{f}$.

Nikesić, Marko Staatssekretär im jugoslawischen Außenministerium Dok. 243

Nilsson, Torsten Außenminister des Königreichs Schweden S. 324, $328 \mathrm{f}$.

Nixon, Richard M. 1953-1961 Vizepräsident der Vereinigten Staaten von Amerika S. 428, 455, 613, 654

Nkrumah, Kwame Präsident der Republik Ghana Dok. 116 und S. 971 f., 995, $1202^{12}, 1374$

Nogueira, Alberto Franco Außenminister der Republik Portugal S. 534

Norstad, Lauris 1951- 1953 Oberbefehlshaber der amerikanischen Luftstreitkräfte in Europa; 1956-1962 Oberbefehlshaber der NATO-Streitkräfte in Europa (SACEUR) S. $71^{39}, 72,316^{8}$, 601, $1262 \mathrm{f} ., 1305,1413$

Novotny, Antonin Erster Sekretär des Zentralkomitees der Kommunistischen Partei der Tschechoslowakei und Präsident der Tschechoslowakischen Sozialistischen Republik S. 1354
Novotny, Pavel Leiter der Deutschland-Abteilung im tschechoslowakischen Außenministerium Dok. 256

Nowikow, Kirill Wassiljewitsch stellvertretender Leiter der Abteilung „Internationale Organisationen" im sowjetischen Außenministerium, Delegierter der Union der Sozialistischen Sowjetrepubliken bei der UNO-Generalversammlung in New York S. 384

Nyerere, Julius K. Präsident der Republik Tanganjika bis 27. April 1964; danach Präsident der Vereinigten Republik von Tanganjika und Sansibar (seit 29. Oktober 1964: Vereinigte Republik Tansania) Dok. 118 und S. $392 \mathrm{f}$., $957 \mathrm{f}$.

Ochab, Edward seit 12. August 1964 Vorsitzender des Staatsrats der Polnischen Volksrepublik S. $955^{4}$

Oeser, Ingo Leiter einer Delegation der DDR in Nikosia S. 1416

Oldenburg, Troels Abteilungsleiter im dänischen Außenministerium S. 475

Ollenhauer, Erich 1952-1963 Vorsitzender der SPD-Fraktion im Deutschen Bundestag und Vorsitzender der SPD S. 1165

Olsen, Arthur J. Korrespondent der Zeitung "The New York Times" in Bonn S. $887^{11}$

Oncken, Dirk Leiter des Referats ,Wiedervereinigung "im Auswärtigen Amt Dok. 302 und S. $39^{1}, 128^{1}, 130^{14}, 197^{32}$, $266^{1}, 277^{8}, 371^{4+5}, 372^{7}, 493,528,674^{1}$, $675^{5}, 1037^{11}, 1059^{13}, 1418^{4}, 1418^{6}, 1483^{1}$, $1484^{5}, 1528^{1}, 1568^{1}$

Oppler, Kurt Botschafter der Bundesrepublik Deutschland in Ottawa S. $642^{7}$

Ormsby-Gore, William David, 5. Baron of Harlech Botschafter des Vereinigten Königreichs von Großbritannien und Nordirland in Washington S. 678 f., 685

Ortona, Egidio Abteilungsleiter im italienischen Außenministerium (Direttore Generale, Affari Economici) S. 144,146 
Osterheld, Horst Leiter des Außenpolitischen Büros im Bundeskanzleramt S. $19,27,28^{5}, 31^{22}, 32^{26,27+29}, 34^{39+42}$, $110^{2}, 187^{11}, 191,227^{6+10}, 11,228^{14-18}$ $229^{19}+20,244^{3}, 255,256^{7+9+10}, 257^{12}$, $263^{40}, 274^{9}, 300,301^{8}, 302^{15}, 324,332,336$, $383^{3}, 555,566,570,571^{4}, 643,768^{9}, 785^{20}$, $787,811,879,1004,1005^{10}, 1008^{23+26}$, $1009^{28-31}, 1009^{33}, 1010^{34+35}, 1011,1096^{17}$ $1098^{30}, 1124^{3}, 1130,1132,1218,1219^{6}$ $1219^{8+9}, \quad 1220^{14+15}, \quad 1220^{18+19+21}$, $1221^{22+24+25}, 1235,1244^{1}, 1245^{9}, 1264$, $1284^{1}, \quad 1319^{15}, \quad 1328^{15}, \quad 1486^{4+7-9}$, $1488^{16+18}, \quad 1488^{21+22}, \quad 1489^{23+25-29}$,

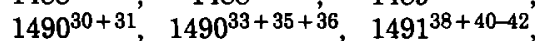
$1492^{44-47}, 1517,1525,1566^{10}$

Osterwind, Heinz Vertreter des Vorsitzenden im Aufsichtsrat der Allgemeinen Elektrizitäts-Gesellschaft (AEG) in Frankfurt/Main S. $962^{3}$

de Ouro Preto, Carlos Sylvestre Botschafter der Vereinigten Staaten von Brasilien in Bonn S. $445^{3}$

Pagenhardt, Robert von Mitarbeiter der amerikanischen Ständigen Vertretung bei der NATO in Paris, „Principal Secretary" der MLF-Arbeitsgruppe S. 451

Palamas, Christian Xanthopoulos Leiter der Ständigen Vertretung des Königreichs Griechenland bei der NATO in Paris S.976

Palewski, Jean-Paul Abgeordneter der französischen Nationalversammlung (UNR/UDT) S. 1027, 1029, 1033, 1123

Panin Protokollchef der sowjetischen Botschaft in Ost-Berlin S. 1483, 1485

Papandreou, Georgios seit 19. Februar 1964 Ministerpräsident des Königreichs Griechenland und Erziehungsminister S. $234^{11}, 1301$

Park Chung Hee Präsident der Republik Korea Dok. 376 und S. 1375

Park Choong Hoon Handelsminister der Republik Korea S. 1462

Pasternak, Boris S. 1352

Paul VI. (Giovanni Battista Montini) Papst S. 463
Pauls, Rolf F. Leiter der Unterabteilung $B$ in der Abteilung für Handelsund Entwicklungspolitik des Auswärtigen Amts Dok. 289 und S. $282^{18}, 330^{44}$, $427^{9}, 504^{3}, 505,779^{11}, 946^{6}, 1122^{35}$

Paulsson, Gustaf Valfrid Staatssekretär beim schwedischen Ministerpräsidenten S. 324

Paulucci, Mario Alessandro Gesandter an der italienischen Botschaft in Bonn S. 345, 1089f., $1110^{12}, 1154$

Paye, Lucien Botschafter der Französischen Republik in Dakar; seit April 1964 Botschafter in Peking S. $365^{58}$, 581

Pearson, Lester B. Ministerpräsident Kanadas Dok. 157 und S. 534, 642, 929

Pelaghias Generaldirektor im zyprischen Außenministerium S. 1416

Pele, Gheorghe rumänischer Stellvertretender Außenminister S. $1421^{4}$

Perera, Benjamin F. Botschafter Ceylons in Bonn S. 803

Perera, N. Martin Vorsitzender der "Lanka Sama Samaja Party" in Colombo; seit 11. Juni 1964 ceylonesischer Finanzminister S. $801^{15}, 802$

Peres, Shimon stellvertretender israelischer Verteidigungsminister; ehemaliger Generalsekretär im israelischen Verteidigungsministerium S. $270^{5}, 271$, 574

Perlzweig, Maurice Vizepräsident des „World Jewish Congress" in New York S. 907

Peyrefitte, Alain französischer Informationsminister S. $244^{3}, 253,738^{2}, 786$, 1008,1187 f., $1290,1477^{49}$

Pfeffer, Franz Persönlicher Referent des Staatssekretärs Carstens Dok. 337 und S. 278, 2797, 394 1,837 , $949^{7}, 1072^{4}, 1089^{1}, 1187,1245^{9}, 1330$

Pflimlin, Pierre Präsident der Beratenden Versammlung des Europarats; ehemaliger französischer Finanzminister S. 284 
Philip, André Leiter der Delegation der Französischen Republik bei der Welthandelskonferenz in Genf S. $722^{26}$

Philipp Herzog von Edinburgh S. 1445

Pilavachi, Costas N. Botschaftssekretär an der zyprischen Botschaft in Bonn; seit Juli 1964 Geschäftsträger S. 1368

Pilz, Wolfgang deutscher Ingenieur in der VAR S. 272

Pisani, Edgar französischer Landwirtschaftsminister S. $747 \mathrm{f}$., $777^{2}, 1119$, 1161

Pius XII. (Eugenio Pacelli) 1939-1958 Papst S. 462

Plaja, Eugenio Abteilungsleiter im italienischen Außenministerium (Direttore Generale, Direzione Generale della Emigrazione) S. $144 \mathrm{f}$.

Plehwe, Friedrich Karl von Leiter des Referats „Großbritannien, Gemeinsame Fragen des Commonwealth, Australien, Neuseeland, Irland" im Auswärtigen Amt; S. $49^{1+2}, 1309^{1+2}, 1316^{24+1+2}$

Plesch, Erhard Vorsitzender des Bundesvorstands der Landsmannschaft der Siebenbürger Sachsen S. $1422^{6}$

Pleskot, Vaclav Botschafter der Tschechoslowakischen Sozialistischen Republik in Paris S. 1354

Podgornyj, Nikolaj Wiktorowitsch Mitglied des Präsidiums und Sekretär des Zentralkomitees der KPdSU S. 320,360 f., 530

Poljanow, Nikolaj E. stellvertretender Chefredakteur der Zeitung "Iswestija“ (Moskau) S. 214

Polk, James Hilliard amerikanischer Stadtkommandant in Berlin bis September 1964 S. 3, 6, 93

Pollak, Alfred seit 1. November 1964 Leiter der Treuhandstelle für den Interzonenhandel in Berlin (West) S. 1138

Pompidou, Georges Ministerpräsident der Französischen Republik Dok. 47, 320 und S. 26, 35, 238, 243 f., $244^{3}, 250$, $254,320^{34}, 478,738^{2}, 777,780,793,811^{17}$,
$972^{2}, 1007$ f., $1187^{4}, 1223^{37}, 1249$ f., 1267 , $1327,1435^{2}, 1541$

Popović, Koča Außenminister der Sozialistischen Föderativen Republik Jugoslawien S. 731, 1001, 1020

Popper, David H. Referatsleiter im amerikanischen Außenministerium (Director, Office of Atlantic Political and Military Affairs) S. $1571^{6}$

Posadowsky-Wehner, Harald Graf von Botschafter der Bundesrepublik Deutschland in Lagos bis 2. Juni 1964; seit 20. August 1964 Leiter des Referats „Afrika südlich der Sahara" im Auswärtigen Amt S. 979, $1153^{14}$

Potter Mitarbeiter der Zeitung "The Baltimore Sun" S. 1571

Praß, Johannes Leiter der Abteilung für Wirtschaft im Bundeskanzleramt S. $306^{11}, 309^{23}, 359^{23}, 1137$

Prill, Felician Leiter der Vertretung der Bundesrepublik Deutschland beim Europarat in Straßburg S. $1351^{30}$

Proske, Rüdiger Hauptabteilungsleiter beim Norddeutschen Rundfunk (Hamburg) S. $398^{17}$

Puaux, François seit Februar $1964 \mathrm{Ab}$ teilungsleiter im französischen Außenministerium (Chargé des affaires d'Europe à l'administration centrale) $\mathrm{S}$. $357 \mathrm{f} ., 360,1018,1020-1022,1397 \mathrm{f}$.

Puhan, Alfred Referatsleiter im amerikanischen Außenministerium (Director, Office of German Affairs) S. 1380

Puhl, Hans amerikanischer Militärpolizist in Berlin S. 1059

Pusey, Nathan M. Präsident der Harvard University in Cambridge/Massachusetts S. 416

Puttkamer, Ellinor von Leiterin des Referats „Vereinte Nationen, weltweite internationale Organisationen; multilaterale Zusammenarbeit auf dem Gebiet der Atomenergie (mit Ausnahme der europäischen Organisationen), internationale Beziehungen auf dem Gebiet der Weltraumforschung, politische Fragen 
auf technisch-wissenschaftlichem $\mathrm{Ge}$ biet“ im Auswärtigen Amt S. $43^{5}, 562^{1}$, $565^{18}$

Rákosi, Mátyás 1944-1956 Generalsekretär der Partei der Ungarischen Werktätigen und 1952/53 Ministerpräsident der Ungarischen Volksrepublik S. $883^{12}$

Ramisch, Rolf Legationsrat I. Klasse und Vertreter des Botschafters an der Botschaft der Bundesrepublik Deutschland in Colombo S. $799^{8}, 994^{7}, 995^{13}$

de Ranitz, Johan Anton Leiter der Politischen Abteilung im niederländischen Außenministerium S. $1445^{13}$

Rantzau, Detlev Graf zu Legationsrat an der Botschaft der Bundesrepublik Deutschland in Washington S. $646^{14}$

Rapacki, Adam Außenminister der Volksrepublik Polen Dok. 398 und S. $296^{7}, 1018^{11}$

Redies, Helmut Legationsrat und Vertreter des Botschafters an der Botschaft der Bundesrepublik Deutschland in Khartum; seit 5. Mai 1964 Legationsrat im Referat „Naher Osten und Nordafrika" des Auswärtigen Amts S. $1299^{8}$

Rehs, Reinhold Mitglied des Deutschen Bundestages (SPD) und Vorsitzender des Ausschusses für Heimatvertriebene S. 1289

Rehwinkel, Edmund Präsident des Deutschen Bauernverbandes in Bonn S. $289,1256^{7}, 1312,1328^{16}, 1390,1395$

Reichhold, Walter Botschafter der Bundesrepublik Deutschland in Accra bis 3. Juli 1964; seit 7. November 1964 Botschaftsrat I. Klasse und Vertreter des Botschafters an der Botschaft in Ottawa S. $497^{2}$

Reinhardt, Hermann Leiter der Abteilung „Außenwirtschaft und Entwicklungshilfe" im Bundesministerium für Wirtschaft S. 324, 804, $945^{1}$

Reinkemeyer, Hans-Albert Vertreter des Leiters in der „Politischen Abteilung II" des Auswärtigen Amts bis zu seinem Tod am 8. April 1964 Dok. 17, $35,75,84$ und S. $115^{1}$, S. $131^{16+17}, 132^{20}$,
$200^{8}, 201^{10}, 202^{13}, 369^{14}, 405^{5}, 407^{9}, 443^{15}$, $1278^{5}$

Reston, James R. Leiter des Büros der Zeitung "The New York Times" in Washington S. 1084-1088, 1571, 1573, $1572^{8}$

Reufels, Josef Legationsrat I. Klasse an der Botschaft der Bundesrepublik Deutschland in Buenos Aires bis 20. Oktober 1964; seit 25. Oktober 1964 Legationsrat I. Klasse im Referat „Wirtschaftsbeziehungen zu Mittel- und Südamerika" des Auswärtigen Amts S. $1303^{13}$

Rey, Jean Mitglied der EWG-Kommission in Brüssel und Leiter der Abteilung für Außenbeziehungen; ehemaliger belgischer Wirtschaftsminister S. $483,512,874^{4}$

Rezek, Rudolf stellvertretender Abteilungsleiter im tschechoslowakischen Außenministerium S. $437 \mathrm{f}$.

Rheker, Gisela Legationsrätin I. Klasse und Vertreterin des Leiters im Referat „Polen, Tschechoslowakei, Jugoslawien, Albanien, Bulgarien, Rumänien, Ungarn, China (Volksrepublik und Formosa), Mongolische Volksrepublik, Nordkorea, Nordvietnam, Hongkong und Macau" des Auswärtigen Amts S. 437

Richter, Herbert Botschafter der Bundesrepublik Deutschland in Algier bis zum Eintritt in den Ruhestand am 31. Juli 1964 S. $732^{52}, 946^{5}, 947$

Richter, Karl Dolmetscher im Sprachendienst des Auswärtigen Amts S. $173^{1}, 879^{1}, 1158^{1}$

Richter, Swjatoslaw sowjetischer Pianist S. 1419

Richthofen, Oswald Freiherr von Botschafter der Bundesrepublik Deutschland in Khartum S. $104^{17}$

Riphagen, Willem Rechtsberater im niederländischen Außenministerium S. 264

Risse, Roland Leiter der Abteilung „Gewerblicher Mittelstand, Absatzwirt- 
schaft, Leistungssteigerung" im Bundesministerium für Wirtschaft S. 1137

Ristedt, Johann Legationsrat im Referat „NATO, WEU (militärische Angelegenheiten) und Verteidigung " des Auswärtigen Amts S. $493^{1}$

Ritter, Joachim Friedrich Botschafter der Bundesrepublik Deutschland in Canberra; 1961-1963 Vertreter des Leiters in der Handelspolitischen Abteilung des Auswärtigen Amts und Beauftragter für Handelsvertragsverhandlungen S. $309^{21}$

Roberts, Sir Frank K. Botschafter des Vereinigten Königreichs von Großbritannien und Nordirland in Bonn; ehemaliger Botschafter in Moskau Dok. 165, 372 und S. $49^{2}, 168 \mathrm{f}$., $180^{3}, 276,344^{14}$, $380,435,796,838,842,1060,1304,1316$, $1318,1320,1406$ f., 1418-1420, 1498, 1509

Roberts, James A. seit Mai 1964 stellvertretender NATO-Generalsekretär S. $533^{3}$

Robertse ehemaliger Militärattaché an der südafrikanischen Botschaft in $\mathrm{Pa}$ ris S. $278 \mathrm{f}$.

Robertson, Sir Brian H. 1947-1949 Militärgouverneur und 1949/50 Hoher Kommissar des Vereinigten Königreichs von Großbritannien und Nordirland in Deutschland S. 751

Rochereau, Henri Mitglied der EWGKommission in Brüssel und Leiter der Abteilung für überseeische Gebiete; ehemaliger französischer Minister für Landwirtschaft S. 480

Rockefeller, Nelson A. Gouverneur des Staates New York S. 658

Röding, Horst Leiter des Referats „Europäische politische Integration, Europarat und nichtstaatliche europäische Organisationen; WEU (nichtmilitärische Angelegenheiten)" im Auswärtigen Amt bis 15. Januar 1964; danach Leiter des Referats „Haushalt und Fi. nanzen" S. 251

Röhrig, Georg Botschaftsrat I. Klasse und Vertreter des Botschafters an der Botschaft der Bundesrepublik Deutschland in Brüssel S. 208
Rötger, Thilo Legationsrat im Referat „Portugal, Spanien, Vatikan, Griechenland, Türkei, Zypern; Nordische Staaten, Österreich, Schweiz, Malteser-Ritter-Orden" des Auswärtigen Amts S. $1366^{1}$

Romney, George W. Gouverneur des Staates Michigan S. 654

Rostow, Walt W. Leiter des Planungsstabs im amerikanischen Außenministerium (Counselor and Chairman of the Policy Planning Council) S.915, 1398

Rudnjow, Konstantin Nikolajewitsch sowjetischer Stellvertretender Ministerpräsident und Vorsitzender des Komitees für die Koordination der wissenschaftlichen Forschung S. $33^{34}, 320$

Ruete, Hans Generalkonsul der Bundesrepublik Deutschland in Kalkutta bis 27. Mai 1964; seit 1. Juli 1964 Vertreter des Leiters in der „Politischen Abteilung II" des Auswärtigen Amts Dok. 221, 238, 239, 240, 310, 379, 398 und S. $952^{2}, 953^{6}, 994^{9}, 1018,1072^{2}$, $1129^{11}, 1203^{18+19}, 1210^{26}, 1263^{6}, 1307^{11}$, $1320,1380,1384^{26}, 1418,1446^{3}, 1513^{2}$, $1528^{4+5}, 1542^{11}, 1549^{15}$

Ruffin, Henri Mitarbeiter im französischen Außenministerium (Conseiller des Affaires étrangères, Pactes - Affaires spatiales) S. 1398

Rusk, Dean D. Außenminister der Vereinigten Staaten von Amerika Dok. 124, 152, 160, 327, 353, 360, 387 und S. $36-38,40,44,54^{18}, 58^{29}, 75$ f., 78 , $111,114,134,187,317^{13}, 411$ f., 432 f., 435 , $444,447 \mathrm{f} ., 464,470,485 \mathrm{f}$., $491 \mathrm{f}$., 533 , $535^{12}, 536,547-550,557,621^{25}, 653,659$, $722^{25}, 839-841,940^{9}, 968^{3}, 1016^{6}, 1038$, $1045^{6}, 1081^{1}, 1084,1087,1107 \mathrm{f}$., $1110^{10}$, 1147 f., 1185 f., $1205,1209,1218,1219^{10}$, $1222,1405,1410^{15}, 1437,1487$ f., $1499^{9}$, $1526^{19}, 1545,1572,1576$

Sabri, Ali Ministerpräsident der Vereinigten Arabischen Republik Dok. 32 und S. 1298

Sabri, Ibrahim Botschafter der Vereinigten Arabischen Republik in Bonn S. $1281^{2}$ 
Sabri, Sulfiqar stellvertretender ägyptischer Außenminister S. 164, 459

Sachs, Hans-Georg Leiter der Abteilung für Handels- und Entwicklungspolitik im Auswärtigen Amt Dok. 18, 113, 396,399 und S. $7^{1}, 49^{2}, 62^{43}, 115^{1}, 116^{12}$, $313,324,330^{45}, 333^{8}, 445^{3}, 615,878^{5}$, $1119^{21}, 1121,1166^{16}, 1196^{6}, 1227,1318$, $1367^{8+9}, 1396^{18}, 1448^{9}, 1509^{31}$

el-Sadat, Anwar Präsident der ägyptischen Nationalversammlung S.9984, $1374^{2}$

Sahm, Ulrich Botschaftsrat I. Klasse und Vertreter des Leiters an der Ständigen Vertretung der Bundesrepublik Deutschland bei der NATO in Paris S. $61^{38}, 182^{3}, 203^{17}, 507^{2}, 818^{3}, 976^{7}$, $977^{10}, 1053^{15}, 1219^{10}, 1291^{3}$

de Saint-Légier de la Sausaye, René außenpolitischer Berater des französischen Staatspräsidenten (Conseiller technique au secrétariat géneral, Présidence de la République) S. $680 \mathrm{f}$.

Salazar, Antonio de Oliveira Ministerpräsident der Republik Portugal und Verteidigungsminister S. $752,815^{14}$

al-Sallal, Abdullah Präsident der Arabischen Republik Jemen S. $162^{9}$

Samoré, Antonio Titular-Erzbischof von Tirnovo; Abteilungsleiter im päpstlichen Staatssekretariat S. $1357^{1}$

Sancar, Ilhami türkischer Verteidigungsminister S. 1300, 1328

Sanchez Bella, Alfredo Botschafter Spaniens in Rom S. 147

Sanguinetti, Alexandre Abgeordneter der französischen Nationalversammlung (UNR/UDT) S. 1033

Sante, Hans Heinrich Gesandter und Vertreter des Botschafters an der Botschaft der Bundesrepublik Deutschland in Moskau S. 1052 ${ }^{13}$

Sapena Pastor, Raúl Außenminister der Republik Paraguay S. 3537, 354, $1440^{4}$

Sapir, Pinhas israelischer Minister für Finanzen, Handel und Industrie S. 126
Saragat, Guiseppe Außenminister der Italienischen Republik bis 28. Dezember 1964; danach Staatspräsident Dok. 28, 375 und S. 33, 135, 139, 155, $195,197^{32}, 274,282^{17}, 283,421^{12}, 1100$, $1213,1222,1424,1463^{1}$

Sarag El Din Abteilungsleiter im ägyptischen Außenministerium S. $1143^{2}$

Sattler, Dieter Leiter der Kulturabteilung im Auswärtigen Amt S. 251 ${ }^{20}$

Savir, Leo Botschaftsrat an der IsraelMission in Köln S.906f., $1215 \mathrm{f}$.

Schäfer, Friedrich Mitglied des Deutschen Bundestages und Parlamentarischer Geschäftsführer der SPD-Fraktion S. $1165^{7}$

Schäfer, Hans Staatssekretär im Bundesministerium des Innern S. 987

Schärf, Adolf Präsident der Republik Österreich S. 697

Schaffarczyk, Herbert Botschafter der Bundesrepublik Deutschland in Lissabon S. $979^{5}$

Scharf, Kurt Propst für den Bereich Brandenburg in der Kirchenprovinz Berlin-Brandenburg, Vorsitzender des Rats der Evangelischen Kirche in Deutschland S. $1244^{2}$

Schaus, Eugène Außenminister des Großherzogtums Luxemburg bis 20. Juli 1964 S. $286^{33}, 418^{3}, 484$

Scheel, Walter Bundesminister für wirtschaftliche Zusammenarbeit S. 116, 159, 194 $21,244,245,251$ f., 313, $366,592,738^{2}, 778$

Scheibe, Elisabeth Legationsrätin I. Klasse und Vertreterin des Leiters im Referat "Allgemeine handelspolitische Fragen" des Auswärtigen Amts bis 21. April 1964; danach Leiterin der Wirtschaftsabteilung an der Botschaft der Bundesrepublik Deutschland in Bern S. $445^{2}$

Schenck, Dedo von Leiter des Referats "Völkerrecht und Staatsverträge" im Auswärtigen Amt Dok. 78 und S. $380^{4}$, $417^{38}, 437,438^{7}, 961,1138^{7}, 1211^{10}, 1277^{1}$, $1280^{11}, 1320$ 
Scherpenberg, Albert Hilger van Botschafter der Bundesrepublik Deutschland beim Heiligen Stuhl in Rom; ehemaliger Staatssekretär des Auswärtigen Amts S. 438, 457, 462, $463^{30+31}, 1357$, $1358^{5}$

Scheske, Ulrich Leiter des Referats „NATO, WEU (militärische Angelegenheiten) und Verteidigung" im Auswärtigen Amt S. $116^{13}, 120^{1}, 245^{4}, 278^{1}, 449^{1}$, $493^{1}, 600^{1}, 977^{10}, 1304,1320 \mathrm{f} ., 1371^{11}$, $1380,1498,1571^{6}$

Schiffers, Hans-Georg Leiter der Abteilung "Zentralplanung, Finanzen, Haushalt und Organisation" im Bundesministerium der Verteidigung S. $504^{3}$

Schiller, Karl Senator für Wirtschaft des Landes Berlin und Mitglied des Abgeordnetenhauses (SPD) S. 197, 1140

Schirach, Baldur von 1931-1940 „Reichsjugendführer" der NSDAP; danach bis 1945 Gauleiter und „Reichsstatthalter" in Wien S. $277^{9}$

Schirmer, Hans Leiter des Referats "Naher Osten und Nordafrika" im Auswärtigen Amt Dok. 54, 214 und S. 1264, $395^{2}, 420^{1}, 669^{1}, 670,711^{1}, 963^{7}, 1216^{7}$, $1239^{1+2+4}, \quad 1240^{8+10}, 1241^{12}, \quad 1244^{1}$, $1246^{12}, 1248^{19}, 1284^{1}, 1298^{6}, 1333^{1}$, $1334^{11}, 1335^{16}, 1515,1516^{5}, 1535^{8}, 1555$

Schlitter, Oskar Beauftragter für Vertragsverhandlungen aus dem Bereich der Abteilung für Handels- und Entwicklungspolitik S. $364,369,995^{15}$, $1354^{43}$

Schmid, Walter Botschafter der Bundesrepublik Deutschland in Dakar und Nouakchott bis 27. September 1964; danach Generalkonsul in Dacca S. $365^{58}$, $398^{17}$

Schmidt, Martin Mitglied des Deutschen Bundestages (SPD) S. $378^{5}$

Schmidt, Michael Legationsrat und Vertreter des Botschafters an der Botschaft der Bundesrepublik Deutschland in Nairobi S. 189, $503^{5}$

Schmidt, Otto Mitglied des Deutschen Bundestages (CDU) und Vorsitzender des Finanzierungsausschusses S. $997^{28}$
Schmidt-Pauli, Edgar von Leiter des Büros Staatssekretär im Auswärtigen Amt bis 3. September 1964; seit 29. September 1964 Generalkonsul der Bundesrepublik Deutschland in Boston S. $252^{30}, 273^{7}, 467$

Schmitt, Matthias Vorstandsmitglied der Allgemeinen Elektrizitäts-Gesellschaft (AEG) in Frankfurt/Main S. $963^{4+5}, 1273$

Schmitt, Thomas Mitarbeiter im AuBenpolitischen Büro des Bundeskanzleramts S. 411

Schmücker, Kurt Bundesminister für Wirtschaft Dok. 33 und S. $145^{22}, 149$, $194^{21}, 233,235$ f., $244^{3}, 248$ f., $275^{6}, 378$, $446,480,484,505,512,514,558^{17}, 570$ $572,592,744,766,777,804,1116^{3}, 1390^{4}$, $1396^{18}$

Schnippenkötter, Swidbert Vortragender Legationsrat I. Klasse im Planungsstab des Auswärtigen Amts; seit 16. November 1964 Vertreter des Leiters im Planungsstab S. 906, 1106-1108

Schnitzler, Karl-Eduard von Redakteur des staatlichen Rundfunks der DDR und Chefkommentator des Deutschlandfunks in Ost-Berlin S. $287^{38}$

Schoeller, Franz Joachim Legationsrat im Referat „Höherer Dienst, Wahlkonsuln" des Auswärtigen Amts; ehemaliger Legationsrat an der Botschaft der Bundesrepublik Deutschland in Daressalam Dok. 40

Schoenbrun, David Mitarbeiter der Zeitung "Die Welt" (Hamburg) S. 1085, $1087 \mathrm{f}$.

Scholz, Ernst Beauftragter der DDR in Kairo Dok. 32 und S. 503, 854 ${ }^{24}, 999$

Scholz, Paul stellvertretender Ministerpräsident der DDR S. $998^{3}, 1150^{3}$, 1151, 1202

Schram-Nielsen, Erik Leiter der Ständigen Vertretung des Königreichs Dänemark bei der NATO in Paris S. 345

Schröder, Gerhard Bundesminister des Auswärtigen Dok. 4, 6, 13, 15, 21, $28,33,45,46,48,65,74,80,99,103,107$, 
$118,124,130,144,151,153,154,165,169$, $174,175,181,182,185,196,197,220,241$, $245,246,248,315,334,335,336,347,348$, $353,360,361,363,370,372,375,377,381$, $382,383,387,392,397$ und S. $8^{7}, 33^{37}, 35$, $40,42,45,47,72,92^{16}, 102^{3}, 107^{1}, 157$, $158,169^{7}, 173,176,187,192,194^{21}, 254$, $275^{8}, 280,286$ f., $289,291,281^{8}, 283^{20}$, $285^{29}, 305,308,310,315^{1}, 319^{24}, 324,326$, $328 \mathrm{f}$., $337^{22+23}, 338^{27}, 339^{30+32}, 343 \mathrm{f}$., $350,351^{3}, 383,391^{13}, 392^{3}, 393^{8}, 399,401$, $429,439,444,460,462,464-467,461^{22}$, $485,492,494^{7}, 497,510$ f., $533,535,548$, $574,631,633^{5+2}, 639,643,667,670,677^{1}$, $691,695,739,749^{1}, 750,766^{2}, 777,780$, $796^{1}, 806,806^{1}, 807^{7}, 808,830,837,838^{8}$, $839^{14}, 840,842,845^{4}, 855^{26}, 856,868,879^{1}$, $896,903,904,906^{5}, 917^{3}, 919^{11-13}, 919^{15}$, $920^{19}, 923^{28}, 924^{29+31}, 925^{38+39^{\prime}}, 940^{9}$, $941^{14}, 943^{4}, 957 \mathrm{f} ., 960,964^{10}, 967^{6}, 970$, $975,989,1009,1034^{17}, 1036,1038,1041$, $1072,1091^{6}, 1107 \mathrm{f} ., 1117^{9}, 1119^{18}, 1134 \mathrm{f}$., $1153^{11}, 1165,1173,1183$ f., $1188^{7}, 1190^{17}$, $1192,1197,1199$ f., 1222, 1228, 1248, 1255, $1262^{25}, 1274,1282,1285,1290^{7}$, $1342^{11+12}, 1344^{6+8}, 1345,1356,1388$, $1391,1394,1396,1414,1446^{1}, 1448^{10}$, $1485,1487-1489,1513,1579$

Schroeder, Herbert Botschafter der Bundesrepublik Deutschland in Daressalam S. $188^{3}, 189^{10}, 957 \mathrm{f}$.

Schubert, Conrad von Botschafter der Bundesrepublik Deutschland in Addis Abeba S. $1060^{23}$

Schütz, Klaus Senator für Bundesangelegenheiten sowie für das Post- und Fernmeldewesen des Landes Berlin, Bevollmächtigter des Landes Berlin in Bonn S. $3^{2}, 4,305,308,310,410,987^{15}$, 1137 f., 1140 f., $1193,1275^{4}$

Schütz, Wilhelm Wolfgang geschäftsführender Vorsitzender des „Kuratoriums Unteilbares Deutschland“" S.986

Schulte-Strathaus, Ludwig Legationsrat I. Klasse an der Botschaft der Bundesrepublik Deutschland in London S. 63,1498

Schuman, Robert 1947/48 Ministerpräsident und 1948-1953 Außenminister der Französischen Republik S.761, $1029^{25}$
Schumann, Maurice Abgeordneter der französischen Nationalversammlung (UNR/UDT) und Vorsitzender des Auswärtigen Ausschusses S. $1343 \mathrm{f}$.

Schwartze, Kurt-Arthur Legationsrat an der Botschaft der Bundesrepublik Deutschland in Kairo S. $421^{16}$

Schwarz, Werner Bundesminister für Ernährung, Landwirtschaft und Forsten S. $166,611^{25}, 747,777^{2}, 1390^{4}$, $1396^{18}$

Schwarzmann, Hans Botschafter der Bundesrepublik Deutschland in Beirut bis 25. April 1964; seit 2. November 1964 Leiter der Dienststelle Berlin des Auswärtigen Amts S. $1419^{6}$

Schwirkmann, Horst Sicherheitsbeauftragter an der Botschaft der Bundesrepublik Deutschland in Moskau bis 8 . September 1964 Dok. 252 und S. 1075

Schwörbel, Herbert Leiter des Referats "Haushalt und Finanzen“ im Auswärtigen Amt bis 31. Januar 1964; seit 4. April 1964 Botschafter der Bundesrepublik Deutschland in Colombo S.797800,802

Scranton, William W. Gouverneur des Staates Pennsylvania S. 654, 658

Seebohm, Hans-Christoph Bundesminister für Verkehr und Vorsitzender des Bundesvorstandes der Sudetendeutschen Landsmannschaft S. 579, 594 ${ }^{2}$, $637,646,919,956,1125^{5}$

Sefrin, Max Stellvertretender Ministerpräsident und Gesundheitsminister der DDR S. $998^{3}$

Segers, Paul-Willem belgischer Verteidigungsminister S. 1286

Segni, Antonio Staatspräsident der Italienischen Republik bis 28. Dezember 1964 S. 136, 138, 141, 206 f., 281, 915

Seibt, Dankmar Persönlicher Referent des Bundeskanzlers S. 492 , 324, 643

\section{Sekou Touré siehe Touré}

Semjonow, Wladimir Semjonowitsch sowjetischer Stellvertretender Außenminister S. $1419^{8}, 1530$ 
Serbanescu rumänischer Rechtsanwalt (mit Familienzusammenführung befaßt) S. 1422

Seuffert, Walter Mitglied des Deutschen Bundestages (SPD) S. $997^{28}$

Seydel, Hans Legationsrat I. Klasse und Vertreter des Leiters im Referat „Naher Osten und Nordafrika“ des Auswärtigen Amts S. $1557^{1}$

Seydoux de Clausonne, François Leiter der Ständigen Vertretung der Französischen Republik bei der NATO in Paris S. $244^{3}, 1185$

el-Shafii, Hussein Vizepräsident der Vereinigten Arabischen Republik S. $998^{4}$

Shermake, Abdel Rashid Ali Ministerpräsident der Somalischen Republik S. 84

Shinnar, Felix E. Leiter der Israel-Mission in Köln Dok. 88, 230, 312 und S. $162,164,351,366^{4}, 382^{3}, 908^{7}, 999$, $1215,1239,1242,1378$

Shriver, Sergent Leiter des US-Friedenskorps in Washington S. 448, 518,

Shuckburgh, Sir Evelyn Leiter der Ständigen Vertretung des Vereinigten Königreichs von Großbritannien und Nordirland bei der NATO in Paris S. 452f., 691-693, 837, 839, 1147-1149, 1156

Siebourg, Gisela Dolmetscherin im Sprachendienst des Auswärtigen Amts S. $1345^{2}, 1541^{1}$

Siegfried, Herbert Botschafter der Bundesrepublik Deutschland in Brüssel S. $710^{5}, 826^{15}, 968^{5+6}, 1495^{13+14}$

Sihanouk, Prinz Samdech Norodom Staatschef im Königreich Kambodscha S. 44, 211

Sijaona, L. Nang'wanda vom 27. April bis 4. November 1964 Staatsminister für Verteidigung der Vereinigten Republik von Tanganjika und Sansibar; danach tansanischer Minister für Besiedlungswesen und Wasserwirtschaft S. 957

Simaček, Jan Mitarbeiter im tschechoslowakischen Außenministerium S. 1061
Simon, Klaus Leiter des Ministerbüros und Persönlicher Referent des Bundesministers des Auswärtigen S. $615^{2}$, $671^{1}, 856^{2}, 989,1124^{1}, 1173^{1}, 1244^{1}, 1380$, $1421^{2}, 1463^{1}, 1493^{1}, 1498,1528^{1}, 1541^{1}$

Siraud, Pierre Chef des Protokolls im französischen Außenministerium S. 1249

Sisco, Joseph stellvertretender Abteilungsleiter im amerikanischen Außenministerium (Deputy Assistant Secretary, International Organization Affairs) S. 348

Smirnow, Andrej Andrejewitsch Botschafter der Union der Sozialistischen Sowjetrepubliken in Bonn Dok. 68, 176, 209, 252, 286, 304, 386 und S. 21, $53^{15}, 179,362,383,386,431,603,625-628$, $661,663,666,841,894^{5}, 951,1009$

Soepeni Delegierte der Republik Indonesien auf der Botschafterkonferenz der blockfreien Staaten in Colombo S. $995^{13}$

Sonnenhol, Gustav Adolf Leiter der Abteilung „Finanz- und Wirtschaftsfragen der Entwicklungshilfe" im Bundesministerium für wirtschaftliche Zusammenarbeit S. $244^{3}$

Sonntag, Peter deutscher Student (seit September 1961 in sowjetischer Haft) S. 706, 1212

Sorin, Walerian Alexandrowitsch sowjetischer Stellvertretender Außenminister; seit 9. Juni 1964 Leiter der Delegation der Union der Sozialistischen Sowjetrepubliken bei der Konferenz der 18-Mächte-Abrüstungskommission in Genf S. 686, 694, $1208^{20}$

Soumaliot, Gaston kongolesischer Rebellenführer, seit Juni 1964 Chef eines gegen die Regierung der Republik Kongo gerichteten Regimes S. $968^{4}$

Souvannah Phouma Ministerpräsident des Königreichs Laos S. 211

Spaak, Paul-Henri Außenminister des Königreichs Belgien; ehemaliger Generalsekretär der NATO Dok. 197, 198, 216 und S. 274, 284, 418 f., 487 f., 533-535, $709^{3}, 710^{5}, 837$ f., $888,968^{6}, 1006$ f., 1027 , 
$1029,1056,1223,1286,1347 \mathrm{f} ., 1350,1425$, $1428,1452,1495$ f., 1508

Spahn, G. G. Leiter der Delegation der Bundesrepublik Deutschland bei der Tagung der Internationalen Kaffeeorganisation in London S. $445^{2}, 446$

Speer, Albert 1942-1945 Reichsminister für Bewaffnung und Munition bzw. für Rüstung und Kriegsproduktion S. $277^{9}$

Spierenburg, Dirk Leiter der Ständigen Vertretung des Königreichs der Niederlande bei EWG und EURATOM in Brüssel S. $631 \mathrm{f}$.

Spiers, Ronald Mitarbeiter im amerikanischen Außenministerium (Deputy Director, Office of Atlantic Political and Military Affairs) S. $1488,1499^{9}, 1501^{12}$, 1513

Springer, Axel Verleger in Hamburg und Berlin (West) S. $1157^{5}$

Springsteen, George Persönlicher Referent des Staatssekretärs im amerikanischen Außenministerium (Special Assistant to the Under Secretary of State) S. 1330

Stackelberg, Herbert Freiherr von Gesandter an der Botschaft der Bundesrepublik Deutschland in Washington S. $74^{8}, 304^{23}, 1526^{21}$

Staden, Berndt von Botschaftsrat I. Klasse an der Botschaft der Bundesrepublik Deutschland in Washington S. 643

de Staercke, André Leiter der Ständigen Vertretung des Königreichs Belgien bei der NATO in Paris S. 692

Stalin, Jossif Wissarionowitsch 1922 1953 Generalsekretär der KPdSU und 1941-1953 Vorsitzender des Rats der Volkskommissare bzw. des Ministerrats der Union der Sozialistischen Sowjetrepubliken S. 1268

Starkey, Joseph F. Zweiter Sekretär an der amerikanischen Botschaft in Bonn S. $104^{15}$

Stechow, Johann von Leiter des Referats "Internationale Wirtschaftsfragen der Verteidigung, des Verkehrs, des
Post- und Fernmeldewesens und des Fremdenverkehrs" im Auswärtigen Amt bis 20. Februar 1964; seit 24. März 1964 Botschafter der Bundesrepublik Deutschland in Manila S. 101, 105

Stedtfeld, F. Leiter der Delegation der Bundesrepublik Deutschland bei den Verhandlungen der Kennedy-Runde in Genf Dok. 122 und S. 875

Steg, Rudolf Leiter des Referats „Frankreich, Belgien, Niederlande, Luxemburg, Italien" im Auswärtigen Amt S. $140^{1}, 1254^{15}, 1338^{1}$

Stein, Hans Freiherr von Legationsrat im Referat „Internationale Wirtschaftsfragen der Verteidigung, des Verkehrs, des Post- und Fernmeldewesens und des Fremdenverkehrs" des Auswärtigen Amts; seit 25. September 1964 Angehöriger der Botschaft der Bundesrepublik Deutschland in Addis Abeba S.101, $104^{15}$

Steinmann, Hans-Georg Legationsrat I. Klasse und Vertreter des Leiters im Referat „Zivilrecht und Zivilprozeßrecht" des Auswärtigen Amts S. 631

Steltzer, Hans-Georg Leiter des Referats „Afrika südlich der Sahara“ im Auswärtigen Amt bis 4. August 1964; seit 15. August 1964 Botschafter der Bundesrepublik Deutschland in Accra S. $188^{1}, 252^{26}, 393^{8}, 966^{2}, 967,981^{12}$

Stempel, Otto Baron von Leiter des Referats „EWG, EGKS, EURATOM“ im Auswärtigen Amt S. $402^{1}, 697^{6}, 1177^{1}$

Stevenson, Adlai E. Leiter der Ständigen Vertretung der Vereinigten Staaten von Amerika bei der UNO in New York S. $1208^{20}$

Stewart, Michael seit 18. Oktober 1964 britischer Minister für Erziehung und Wissenschaft S. $1497^{23+25}, 1554^{21}$

Stewart, Michael Norman F. seit Oktober 1964 Gesandter an der britischen Botschaft in Washington S. $1444^{10}$

Stikker, Dirk U. Generalsekretär der NATO in Paris bis 14. Mai 1964; ehemaliger Leiter der Ständigen Vertretung 
des Königreichs der Niederlande bei der NATO Dok. 292 und S. $494^{6}, 533 \mathrm{f}$.

Stolzmann, Paulus von Botschafter der Bundesrepublik Deutschland in Luxemburg S. $286^{33}$

Stoph, Willi Erster Stellvertretender Ministerpräsident der DDR S. 21

Storm, Friedrich-Karl Mitglied des Deutschen Bundestages (CDU) und stellvertretender Vorsitzender des Ausschusses für Heimatvertriebene S. $997^{28}$

Strauß, Franz Josef Mitglied des Deutschen Bundestages und Vorsitzender der CSU; ehemaliger Bundesminister der Verteidigung S. $61^{40}, 179,270^{5}$, $271,307,351^{4}, 359,398^{17}, 510$ f., $575,680^{3}$, 808 f., $814^{11}, 821^{18}, 1165,1173$ f., $1175^{10}$, $1333^{5}, 1486,1489$

Strobel, Käte Mitglied des Deutschen Bundestages (SPD) und Vizepräsidentin des Europäischen Parlaments in Straßburg S. $1344^{6}$

Stroessner, Alfredo Präsident der Republik Paraguay S. 353

Stübel, Caroline Hilfsreferentin im Referat „Internationale Wirtschaftsfragen der Verteidigung, des Verkehrs, des Post- und Fernmeldewesens und des Fremdenverkehrs" des Auswärtigen Amts S. $1566^{9}$

Subandrio Außenminister der Republik Indonesien und Minister für AuBenhandel S. 542

Suhr, Otto 1949-1952 Mitglied des Deutschen Bundestages (SPD), 19551957 Regierender Bürgermeister von Berlin S. $1275^{5}$

Sukarno, Ahmed Präsident der Republik Indonesien S. 83, 995

Sulzberger, Cyrus Mitarbeiter der Zeitung "The New York Times“ S. 1085, 1572

Suslow, Michail Andrejewitsch Sekretär des Zentralkomitees der KPdSU S. $488^{11}$

Sutterlin, James S. Erster Sekretär für Politische Angelegenheiten an der amerikanischen Botschaft in Bonn S. $1534 \mathrm{f}$.

Swartz, Carl Petter stellvertretender Leiter der Handelsabteilung im schwedischen Außenministerium S. 324

Sympher, Peter Legationsrat I. Klasse und Vertreter des Leiters im Referat „Völkerrecht und Staatsverträge" des Auswärtigen Amts S. 264 ${ }^{1}$

Syngman Rhee 1948-1960 Präsident der Republik Korea S. 1375

Talleyrand, Charles-Maurice de $\quad 1788-$ 1838 Bischof von Autun, 1797-1807 AuBenminister Frankreichs S. 208

Taviani, Emilio italienischer Innenminister; ehemaliger Verteidigungs- und Finanzminister S. $1173^{6}$

Taylor, Maxwell D. amerikanischer General und Vorsitzender der Vereinigten Stabschefs der amerikanischen Streitkräfte S. $1506^{21}, 1573$

Thierfelder, Rudolf Gesandter und Vertreter des Botschafters an der Botschaft der Bundesrepublik Deutschland in London bis 31. Juli 1964; seit 3. August 1964 Leiter der Rechtsabteilung im Auswärtigen Amt Dok. 323, 324, 367 und S. $49^{2}, 952^{2}, 960^{8}, 961,1002^{10}, 1227^{1}$, $1228^{9+12+14}, 1309^{4}, 1320,1386$

Thoenes, Heidi Dolmetscherin im Sprachendienst des Auswärtigen Amts S. $555^{1}, 566,1485^{1}$

Thompson, Llewellyn E. Botschafter zur besonderen Verwendung im amerikanischen Außenministerium; ehemaliger Botschafter in Moskau Dok. 126, 259 und S. 36 f., 266 f., 447 , 485 f., 525, $547,590,1380 \mathrm{f},{ }^{2}, 1528^{4}$

Thomsen, Henning Vortragender Legationsrat und Vertreter des Leiters im Referat „Internationale Wirtschaftsfragen der Verteidigung, des Verkehrs, des Post- und Fernmeldewesens und des Fremdenverkehrs" des Auswärtigen Amts S. $1366^{4}$

Thorez, Maurice Vorsitzender der Kommunistischen Partei Frankreichs (KPF) bis zu seinem Tod am 11. Juli 1964 S. 1058 
Thorneycroft, Peter britischer Verteidigungsminister bis 16 . Oktober 1964 S. 593

Tien Li-chun Handelsrat an der Botschaft der Volksrepublik China in Bern S. 871

Tito, Josip Broz Staatspräsident der Sozialistischen Föderativen Republik Jugoslawien S. 363, 368f., 459, 471, 607, 639, $731 \mathrm{f}$., 742, 900, 1334

Todorow, Stanko bulgarischer Stellvertretender Ministerpräsident S. $1554^{21}$

Török, Alexander von Leiter des Referats „Wirtschaftsbeziehungen zu Afrika südlich der Sahara" im Auswärtigen Amt S. $778^{7}, 779^{11}$

Toffin, Jean-Louis stellvertretender Abteilungsleiter im französischen $\mathrm{Au}$ Benministerium (Sous-Directeur, Europe Centrale) S. $360,615^{2}$

Togliatti, Palmiro Generalsekretär der Kommunistischen Partei Italiens (KPI) bis zu seinem Tode am 25. August 1964 S. 1058,1353

Tomas, Américo Deus Rodrigues Staatspräsident der Republik Portugal S. 979

Tomkins, Edward E. Referatsleiter im britischen Außenministerium (Head of Western Department); seit April 1963 Gesandter an der Botschaft in Bonn Dok. 255 und S. 5 f., $59^{34}, 1100$ f., $1392^{5}$

Toscano, Mario Abteilungsleiter im italienischen Außenministerium (Servizio Studi - Capo Servizio) S. $1452^{9}$

Toulouse, Pierre Edouard französischer Stadtkommandant in Berlin bis September 1964 S. 3, 6, 93

Touré, E. Ismael guineischer Minister für wirtschaftliche Entwicklung S. 1176

Touré, Sekou Präsident der Republik Guinea S. $1175 \mathrm{f}$.

Trampczynski, Witold polnischer Minister für Außenhandel S. 599

Trettner, Heinz Generalinspekteur der
Bundeswehr S. $169^{7}, 244^{3}, 296^{6}, 1249$, $1260,1285^{1}$

Trevelyan, Sir Humphrey Botschafter des Vereinigten Königreichs von Großbritannien und Nordirland in Moskau S. $668 \mathrm{f}$., $672,678 \mathrm{f}$., $1052^{13}, 1172$

Triboulet, Raymond französischer Minister für wirtschaftliche Zusammenarbeit S. 245,251 f., $738^{2}, 779$

Truckenbrodt, Walter Vortragender Legationsrat I. Klasse und Vertreter des Leiters im Planungsstab des Auswärtigen Amts; seit 16. November 1964 Vertreter des Leiters in der Rechtsabteilung S. $1320 \mathrm{f}$.

Truman, Harry S. 1945-1953 Präsident der Vereinigten Staaten von Amerika S. $476^{6}$

Trumpf, Jürgen Legationsrat an der Botschaft der Bundesrepublik Deutschland in London S. $49^{2}$

Tschiang Kai-schek Präsident der Republik China, Vorsitzender der Kuomintang und Oberkommandierender der Streitkräfte S. 43, 194, 890

Tschombé, Moise seit 10. Juli $1964 \mathrm{Mi}$ nisterpräsident und Außenminister der Demokratischen Republik Kongo S. 968

Tschou En-lai Ministerpräsident der Volksrepublik China S. 84, $96^{29}, 619^{18}$, $733^{57}, 1374^{4}$

Tsui Chi-yuan Botschaftsrat an der Botschaft der Volksrepublik China in Bern Dok. 206 und S. 543, 585-588

Tuomioja, Sakari S. vom 25. März 1964 bis zu seinem Tod am 9. September 1964 UNO-Vermittler in der Zypern-Krise; ehemaliger Ministerpräsident der Republik Finnland S. 3487 $, 515,793,1253^{10}$

Turki, Ahmed Riad ägyptischer Forschungsminister S. $998^{4}$

Turnwald, Wilhelm Leiter des Referats „Deutsche Ostfragen“ im Auswärtigen Amt S. 1124

Tyler, William R. Abteilungsleiter im amerikanischen Außenministerium (Assistant Secretary of State for European 
Affaires) S. $447,486,639,643,679 \mathrm{f}$. $685,1279^{7}, 1380,1398$

\section{Ulbricht, Walter Erster Sekretär des} Zentralkomitees der SED und Vorsitzender des Staatsrats der DDR S. 22, $50^{10}, 90,91^{10}, 131^{18}, 132,161 \mathrm{f} ., 164,172$, 214 f., $257,303,335,504,522,529,545$, $548,606,639,644 \mathrm{f}$., $663 \mathrm{f}$., $672,685 \mathrm{f}$., 727 f., 767,847 f., $850^{11}, 1001-1003,1074$, $1385,1433,1527,1539 \mathrm{f}$.

Ungerer, Werner abgeordnet an die Ständige Vertretung der Bundesrepublik Deutschland bei EWG und EURATOM in Brüssel bis 15. März 1964; danach Legationsrat I. Klasse im Referat „EWG, EGKS, EURATOM“ des Auswärtigen Amts S. $1177^{1}$

Ungern-Sternberg, Reinhold Freiherr von Botschafter der Bundesrepublik Deutschland in Teheran bis 28. August 1964; seit 1. September 1964 Gesandter und Vertreter des Botschafters an der Botschaft in London S. $1122^{39}, 1394^{8}$, $1399,1436^{3}, 1444,1498$

Urban, Jaroslav Leiter der Vertretung tschechoslowakischer Außenhandelsgesellschaften in Frankfurt/Main S. $437 \mathrm{f}$., $1066^{16}, 1354^{43}$

U Thant, Sithu Generalsekretär der UNO in New York Dok. 70, 159 und S. $83^{54}, 320,348^{7}, 461,515^{5}, 583^{9}, 584$, 648,732 f., $740,977,1204,1386$

Venturini, Antonio Leiter der Ständigen Vertretung der Italienischen Republik bei EWG und EURATOM in Brüssel S. $869 \mathrm{f}$.

Vialon, Friedrich-Karl Staatssekretär im Bundesministerium für wirtschaftliche Zusammenarbeit S. 313, 945 ${ }^{1}$

Viktor Emanuel III. 1900-1946 König des Königreichs Italien S. $150^{7}$

Villiers, George Präsident des französischen Arbeitgeberverbandes S. 1267

Vogel, Hans-Jochen Oberbürgermeister von München S. 398

Vogel, Rolf Herausgeber der „Deutschland-Berichte" S. 907, 908 ${ }^{7}$
Vogeler, Wilfried Legationsrat im Referat „NATO, WEU (militärische Angelegenheiten) und Verteidigung" des Auswärtigen Amts S. 1321

Voigt, Heinz Leiter der Unterabteilung $A$ in der "Politischen Abteilung I" des Auswärtigen Amts Dok. 237, 277, 294 und S. $80^{36}, 115^{1+5}, 125^{2}, 242^{20}, 290^{52}$, $330^{46}, 418^{2}, 488^{11}, 910,958^{7}, 1084^{1}$, $1313^{18}, 1351^{28}, 1446^{3}, 1463^{1}, 1498,1504^{18}$, $1509^{31}$

Wagner, Leo Mitglied des Deutschen Bundestages (CSU) S. 511 ${ }^{12}$

Walther, Gebhardt von. Botschafter der Bundesrepublik Deutschland in Ankara Dok. 317, 333 und S. 347 ${ }^{3}$, $1107^{5}, 1560 \mathrm{f}$.

Wang Ping-nan Stellvertretender AuBenminister der Volksrepublik China S. 547

Weber, Heinz Dolmetscher und Vertreter des Leiters im Sprachendienst des Auswärtigen Amts S. $45^{1}, 49^{2}, 191^{1}$, $255^{1}, 300^{1}, 311^{1}, 411^{1}, 430^{1}, 651^{1}, 787^{1}$, $811^{1}, 817^{1}, 1012^{1}, 1218^{1}, 1304,1309^{2}$, $1316^{2}, 1324^{1}, 1336^{1}, 1457^{2}$

Weber, Walter Botschafter der Bundesrepublik Deutschland in Kairo bis zum Eintritt in den Ruhestand am 31. Mai 1964 S. $160^{4}, 162$ f., $352^{7}, 420^{3}$, $421^{10}, 422^{23}, 457,460,459^{15}$

Wehner, Herbert Mitglied des Bundestages (SPD) und Vorsitzender des Ausschusses für gesamtdeutsche und Berliner Fragen S. 31

Weitprecht stellvertretender Verkehrsminister der DDR S. $998^{3}$

Weiz, Gerhart Botschafter der Bundesrepublik Deutschland in Djakarta bis 15. Juli 1964; seit 12. September 1964 Generalkonsul in Sao Paulo S. $421^{17}$, 995

Wendland, York Alexander Freiherr von Botschafter der Bundesrepublik Deutschland in Saigon bis 15. August 1964; seit 7. Dezember 1964 Botschafter in Dakar S. $515^{8}$

Wendt, Erich Staatssekretär und Erster Stellvertretender Minister im Mini- 
sterium für Kultur der DDR S. $3^{1}, 6,91$, 129-131, 2924, 309, 409 f., 851 f., 989, 991 , $1021,1022^{33+34}, 1068,1071^{7}$

Wentker, Hermann Legationsrat im Referat "Wiedervereinigung" des Auswärtigen Amts S. $196^{27}, 1419^{11}, 1483^{1}$

Werner, Rudolf Mitglied des Deutschen Bundestages (CDU) und stellvertretender Vorsitzender des Ausschusses für Entwicklungshilfe S. 1298

Werner, Günther F. Leiter des Referats "Sozialrecht und Sozialpolitik" im Auswärtigen Amt S. $1421^{2}, 1422^{6}$

Werner, Pierre Ministerpräsident und seit 21. Juli 1964 Außenminister des Großherzogtums Luxemburg S.912f.

Wessel, Gerhard Vertreter der Bundesrepublik Deutschland im Ständigen Militärausschuß der NATO in Washington S. 509

Westrick, Ludger Staatssekretär bzw. seit 15. Juni 1964 Bundesminister, Chef des Bundeskanzleramtes Dok. 278 und S. 3-7, 19, 23, 27, 31, 33-35, $49^{1+2}, 86^{4}$, $125^{5}, 191 \mathrm{f}$., 196, 21914, 341, 35924, 380, 382 , 396, $411 \mathrm{f}$., $416 \mathrm{f}$., $423^{26}, 480,496$, $511^{12}, 527^{7}, 540,555,566,568,574,643$, $680^{3}, 738^{2}, 777^{2}, 787,792,797,811-814$, 816 f., $819,821^{18}, 869,879,896,903,943^{4}$, $965^{12}, 968,987^{15}, 1004,1006-1009,1011 \mathrm{f}$., $1017,1124,1130-1132,1134,1142^{5}$, 1199 f., $1235,1236^{6}, 1237,1245^{9}, 1256^{6}$, 1273 f., $1275,1388,1457^{2}, 1488,1491$, $1517,1525-1527,1566^{10}$

Weyer, Willi Innenminister des Landes Nordrhein-Westfalen S. 986

Wheeler, Earle G. Stabschef der amerikanischen Landstreitkräfte S. $1285^{1}$

White, Eric Wyndham Exekutivsekretär des GATT in Genf S.512f.

Wicker, Tom Mitarbeiter der Zeitung "The New York Times" S. $1571^{5}$

Wickert, Erwin Leiter des Referats „Politische und sozialökonomische Fragen des Ostblocks" im Auswärtigen Amt S. $50^{6}, 457^{1}$

Wieck, Hans-Georg Legationsrat I. Klasse an der Botschaft der Bundes- republik Deutschland in Washington Dok. 142

Wiesenthal, Simon Leiter des Jüdischen Dokumentationszentrums in Wien S. $1133^{17}$

Williams, G. Mennen Abteilungsleiter im amerikanischen Außenministerium (Assistant Secretary of State for African Affairs) S. 319

Wilson, Archibald Duncan Unterstaatssekretär im britischen Außenministerium (Assistant Under-Secretary of State) S. 1301

Wilson, Harold Vorsitzender der Labour Party; seit 16. Oktober 1964 Premierminister des Vereinigten Königreichs von Großbritannien und Nordirland Dok. 83 und S. 20, 134 $14,156,281,325$, $671,673,1173^{4}, 1385$ f., $1388,1389,1391 \mathrm{f}$., $1400-1402,1405,1406 \mathrm{f}$., 1409,1436 , 1443 f., 1453 f., $1485,1491,1495,1497$, $1499^{9}, 1501^{12}, 1506^{21}, 1552,1554^{21}, 1563$, 1574,1576

Winckler, Jean-Claude Leiter der Mission der Französischen Republik in Berlin S. $1483^{3}, 1484^{5}$

Wingstrand, John David Erster Sekretär in der Politischen Abteilung des schwedischen Außenministeriums S. 324

Winzer, Otto Staatssekretär und Erster Stellvertretender Minister für Auswärtige Angelegenheiten der DDR S. $443,971^{1}$

Wischnewski, Hans-Jürgen Mitglied des Deutschen Bundestages (SPD) S. 908 f., $1165^{7}$

Wolff, Rudolf Legationsrat I. Klasse und Vertreter des Leiters im Referat „Sowjetunion“ des Auswärtigen Amts S. $73^{3}, 171^{2}, 386^{18}$

Wolff von Amerongen, Otto Mitinhaber der Firma Otto Wolff in Köln, Vorsitzender des „Ostausschusses der Deutschen Wirtschaft" in Köln S. 228 ${ }^{12}, 586$

Wollenweber, Karl Gustav Leiter des Referats „Friedensregelung, Beendigung des Besatzungsregimes, Stationierung ausländischer Truppen, Auslands- 
schulden, Auslandsvermögen" im Auswärtigen Amt S. $104^{14}$

Woratz, Gerhard Leiter der Abteilung III im Bundesministerium für Wirtschaft S. $424^{2}, 1137$ f., $1140^{16}$

Wormser, Olivier Abteilungsleiter im französischen Außenministerium (Directeur des affaires économiques et financières) Dok. 97, 207, 273 und S. $244^{3}, 272 \mathrm{f} ., 575,612,615^{2}, 806,1187 \mathrm{f}$., $1360,1446,1448$

Woroschilow, Klimentij Jefremowitsch 1953-1960 Vorsitzender des Präsidiums des Obersten Sowjet der Union der Sozialistischen Sowjetrepubliken S. 662

Wurzel, Heinz Günter Korrespondent der Deutschen Presse-Agentur (DPA) in Moskau bis zur Ausweisung am 18. April 1964 S. $1212^{11}$

Wyszynski, Stefan Kardinal Erzbischof von Gnesen und Warschau, Primas von Polen S. 463, $1357^{1}$

Yates, David Peet britischer Stadtkommandant in Berlin bis September 1964 S. 3, 6, 93

Yorck von Wartenburg, Paul Graf Konsul der Bundesrepublik Deutschland in Lyon bis 24. Februar 1964; seit 24. April 1964 Leiter der Handelsvertretung in Bukarest S. 926, $927^{5+6}, 1421 \mathrm{f}$.

Youla, Nabi Botschafter der Republik Guinea in Bonn S. 1175

Young, Wayland, 2. Baron Kennet Mitglied des Verteidigungsausschusses der Parlamentarischen Versammlung der WEU in London S. 1413

Zaim, Achmed Botschafter der Republik Zypern in Bonn bis Juli 1964 S. $1368^{13}$

Zak, Vladimir Mitarbeiter im tschechoslowakischen Außenministerium S. 1061

Zapp, Carl August Botschafter der Bundesrepublik Deutschland in Caracas bis 21. Juli 1964; seit 23. September 1964 Botschafter in Algier S. $947^{11}$

Zarapkin, Semjon Konstantinowitsch Leiter der Abteilung „Internationale Organisationen" im sowjetischen AuBenministerium S. $1109^{8}$

Zawadzki, Alexander Vorsitzender des Staatsrats der Polnischen Volksrepublik bis zu seinem Tod am 7. August 1964 S. 955

Zech-Nenntwich, Hans-Walter ehemaliger SS-Obersturmführer (wegen Beihilfe zum Mord verurteilt, am 22./23. April 1964 aus der Haft geflohen) S. $664^{16}$

Zinn, Georg-August Ministerpräsident des Landes Hessen S. 314

Zorn, Hermann Regierungsdirektor im Bundesministerium der Finanzen S. $1130^{4}$ 
Sachregister 
Bei der Benutzung des Sachregisters sind folgende Hinweise zu beachten:

- Das Sachregister erfaßt in alphabetischer Reihenfolge Staaten, Organisationen und Institutionen sowie weitere Sachbegriffe.

- Die Untergliederung der Schlagworte „Abkommen und Verträge“, „Gesetze und Verordnungen“, „Konferenzen und Verhandlungen“ sowie "Noten und Memoranden“ folgt der Chronologie.

- Kursiv gedruckte Querverweise erschließen die zwischen den Schlagworten bestehenden Verbindungen.

- Bezieht sich ein Sachbegriff auf ein Dokument als Ganzes, so ist die Dokumentennummer angegeben. Dies ermöglicht auch einen schnellen Zugriff auf das Dokumentenverzeichnis im Band I.

- Beim Nachweis einzelner Seiten beziehen sich hochgestellte Ziffern auf Fußnoten.

- Verweise über die Beziehungen zweier Staaten zueinander finden sich bei dem in der Schlagwortfolge alphabetisch zuerst aufgeführten Staat. So werden beispielsweise die Fundstellen zu den französisch-algerischen Beziehungen unter dem Schlagwort „Algerien“ und dort unter „Frankreich“ genannt.

- Die bilateralen Beziehungen der Bundesrepublik Deutschland werden allerdings stets unter dem Schlagwort des jeweils fremden Staates erfaßt. Entsprechendes gilt für das Verhältnis der Bundesrepublik Deutschland zu übernationalen Organisationen wie etwa der NATO.

- In einigen Fällen wird unmittelbar hinter dem Schlagwort zu einem Staat ein eigenes Schlagwort wie „Frankreich-Bundesrepublik Deutschland“ oder „USA-Bundesrepublik Deutschland“ gebildet, um eine zusätzliche Untergliederung möglich zu machen.

- Band I reicht von Dokument 1 bis 179 bzw. von Seite 3 bis 712 und Band II von Dokument 180 bis 402 bzw. von Seite 713 bis 1580 . 
Abkommen und Verträge

Abkommen und Verträge

- Auslieferungsabkommen vom 9. 7. 1869 zwischen Frankreich und der Schweiz S. 218

- Friedensvertrag von Brest-Litowsk vom 3. 3.1918

S. $17^{5}, 176$

- Friedensvertrag von Bukarest vom 7. 5 . 1918

S. $17^{5}$

- Versailler Vertrag vom 28. 6. 1919 S. 338

- Vertrag von Rapallo vom 16. 4. 1922 zwischen dem Deutschen Reich und der Russischen Sozialistischen Föderativen Sowjetrepublik S. 1004

- Abkommen vom 10.2. 1925 zwischen der Republik Polen und dem Heiligen Stuhl S. 960

- Verträge von Locarno vom 16. 10.1925 S. $1011^{41}$

- Konkordat vom 14. 6. 1929 zwischen dem Freistaat Preußen und dem Heiligen Stuhl

S. $959 \mathrm{f}$.

- Konkordat vom 20. 7. 1933 zwischen dem Deutschen Reich und dem Heiligen Stuhl

S. 959-961

- Abkommen vom 29. 9. 1938 zwischen dem Deutschen Reich, Großbritannien, Frankreich und Italien über die Abtretung sudetendeutscher Gebiete an Deutschland siehe: Münchener Abkommen

- Nichtangriffsvertrag vom 23. 8. 1939 zwischen dem Deutschen Reich und der UdSSR („Hitler-Stalin-Pakt“)

S. 882

- Kommuniqué vom 2. 8. 1945 über die Konferenz von Potsdam siehe: Potsdamer Abkommen

- Brüsseler Abkommen vom 17. 3. 1948 zwischen der Französischen Republik, dem Vereinigten Königreich von Großbritannien und Nordirland, dem Königreich Belgien, dem Königreich der Niederlande und dem Großherzogtum
Luxemburg

S. 928

- Nordatlantik-Vertrag vom 4.4.1949 siehe: NATO

- Vertrag vom 18. 4. 1951 über die Gründung der Europäischen Gemeinschaft für Kohle und Stahl siehe außerdem: $E G K S$

S. $912^{8}$

- Abkommen vom 20. 9. 1951 über den Handel zwischen den Währungsgebieten der Deutschen Mark (DM-West) und den Währungsgebieten der Deutschen Mark der Deutschen Notenbank (DM-Ost)

siehe außerdem: Interzonenhandel

S. $309^{21}$

- Vertrag vom 26. 5. 1952 über die Beziehungen zwischen der Bundesrepublik Deutschland und den Drei Mächten (Deutschland-Vertrag)

S. $357^{14}, 358,435,578,614,758,760,770$, $973,1026,1533$

- Vertrag vom 26. 5. 1952 über die Europäische Verteidigungsgemeinschaft (EVG)

S. $759^{13}$

- Abkommen vom 10.9. 1952 zwischen der Bundesrepublik Deutschland und dem Staat Israel über die Wiedergutmachung (Luxemburger Abkommen) S. $270,352^{6}, 1182,1243^{6}, 1334^{10}$

- Verteidigungsabkommen vom 26. 9. 1953 zwischen Spanien und den USA S. 619

- Schlußakte der Indochina-Konferenz vom 21. 7. 1954

S. 622, 645, 921

- Pariser Verträge vom 23.10. 1954 S. $88,1193,1430$

- Österreichischer Staatsvertrag vom 15. 5.1955

S. $11^{11}, 530$

- Vertrag vom 20. 9. 1955 über die Beziehungen zwischen der DDR und der UdSSR

S. 686 
- Vertrag vom 10. 3. 1956 zwischen der Bundesrepublik Deutschland und der Föderativen Volksrepublik Jugoslawien über wirtschaftliche Zusammenarbeit S. 368,472

- Vereinbarung vom 19.10.1956 zwischen dem Kaiserreich Japan und der UdSSR über die Beendigung des Kriegszustandes

S. 564

- Vertrag vom 27. 10. 1956 zwischen der Bundesrepublik Deutschland und der Französischen Republik zur Regelung der Saarfrage (Saarabkommen) S. $11^{6}, 440$

- Abkommen vom 20. 11. 1956 zwischen der Französischen Republik und den USA über Zusammenarbeit zur friedlichen Nutzung von Kernenergie S. 1180

- Vertrag vom 25. 3. 1957 zur Gründung der Europäischen Wirtschaftsgemein. schaft (EWG) siehe: Römische Verträge

- Vertrag vom 25. 3. 1957 zur Gründung der Europäischen Atomgemeinschaft (EURATOM) siehe: Römische Verträge

- Protokoll vom 25. 11. 1957 zwischen der Französischen Republik, der Italienischen Republik und der Bundesrepublik Deutschland über Rüstungszusammenarbeit

\section{S. $1173^{6}$}

- Vereinbarung vom 8. 4. 1958 zwischen der Bundesrepublik Deutschland und der UdSSR über die Repatriierung von Deutschen aus der UdSSR

S. 65,700

- Kulturabkommen vom 18. 4. $1958 \mathrm{zwi}$ schen der Bundesrepublik Deutschland und dem Vereinigten Königreich von Großbritannien und Nordirland S. 62

- Abkommen vom 25.4. 1958 zwischen der Bundesrepublik Deutschland und der UdSSR über Allgemeine Fragen des Handels und der Seeschiffahrt S. $65,107,438^{7}, 1211^{10}$
- Abkommen vom 25. 4. 1958 zwischen der Bundesrepublik Deutschland und der UdSSR über den Waren- und Zahlungsverkehr
S. $438^{7}$

- Genfer Konvention vom 29. 4. 1958 über den Festlandsockel in der Nordsee

S. 23 f., 264

- Abkommen vom 22. 12. 1958 zwischen der Bundesrepublik Deutschland und dem Königreich Dänemark über den Warenverkehr

$$
\text { S. } 868^{1}
$$

- Abkommen vom 27. 12. 1958 zwischen der VAR und der UdSSR über technische Hilfe S. $458^{11}$

- Zypern-Abkommen vom 19. 2.1959 S. 320

- Internationales Antarktis-Abkommen vom 1.12.1959 S. $183^{8}$

- Bündnisvertrag vom 7. 7. 1960 zwischen Zypern, dem Königreich Griechenland und der Republik Türkei
S. 234

- Garantievertrag vom 7. 7. 1960 über die Unabhängigkeit Zyperns

S. 234

- Logistisches Rahmenabkommen vom 25. 10. 1960 zwischen der Bundesrepublik Deutschland und der Französischen Republik

$$
\text { S. } 1371^{12}
$$

- Abkommen vom 31. 12. 1960 zwischen der Bundesrepublik Deutschland und der UdSSR über den Waren- und Zahlungsverkehr

$$
\text { S. } 107
$$

- Erklärung der algerischen und der französischen Delegation vom 18. 3. 1962 zum Abschluß der Waffenstillstandsverhandlungen (Abkommen von Evian) S. $931^{15}$

- Erklärung und Protokoll vom 23. 7. 1962 über die Neutralität von Laos (Genfer Laos-Abkommen)

S. 581, 645 
- Internationales Kaffee-Übereinkommen vom 28. 9. 1962 S. 446

- Kommuniqué und gemeinsame Erklärung des Präsidenten Kennedy und des Premierministers Macmillan vom 21. 12. 1962 (Nassau-Abkommen) siehe: $M L F$

- Vertrag vom 22. 1. 1963 zwischen der Bundesrepublik Deutschland und der Französischen Republik über die deutsch-französische Zusammenarbeit (Deutsch-französischer Vertrag) siehe: Frankreich-Bundesrepublik

- Handelsabkommen vom 1. 2. 1963 zwischen der Französischen Republik und der UdSSR

S. $272,805,844$

- Protokoll vom 7. 3. 1963 zwischen der Bundesrepublik Deutschland und der Volksrepublik Polen über den Handelsund Seeschiffahrtsverkehr siehe auBerdem: Polen-Bundesrepublik S. $375^{2}$

- Vereinbarung vom 7. 3. 1963 zwischen der Bundesrepublik Deutschland und der Volksrepublik Polen über die Errichtung einer Handelsvertretung in Warschau siehe außerdem: Polen-Bundesrepublik S. 56, 328, 730

- Wiener Konsularkonvention vom 24. 4. 1963

S. 437, 707

- Abkommen vom 5. 7. 1963 zwischen der Bundesrepublik Deutschland und der Französischen Republik über die Errichtung eines Deutsch-Französischen Jugendwerks

siehe außerdem: Frankreich-Bundesrepublik

S. $250^{17}$

- Abkommen vom 16. 7. 1963 zwischen dem Kaiserreich Äthiopien und Kenia über Zusammenarbeit und gegenseitige Hilfe

S. 84

- Vertrag vom 5. 8. 1963 über das Verbot von Kernwaffenversuchen in der At- mosphäre, im Weltraum und unter Wasser siehe: Teststopp-Abkommen

- Vereinbarung vom 7. 9. 1963 zwischen der Bundesrepublik Deutschland und der Sozialistischen Föderativen Republik Jugoslawien über die Entschädigung für die Opfer von Menschenversuchen

siehe außerdem: Jugoslawien-Bundesrepublik

S. $367^{3}, 473$

- Assoziierungsabkommen vom 12. 9. 1963 zwischen der EWG und der Republik Türkei

S. $236^{18}, 1303^{14}$

- Handelsabkommen vom 14. 10. 1963 zwischen der EWG und dem Kaiserreich Iran

S. 127

- Protokoll vom 17. 10. 1963 zwischen der Bundesrepublik Deutschland und der Volksrepublik Rumänien über den Austausch von Handelsvertretungen S. $56,328,730$

- Abkommen vom 10. 11. 1963 zwischen der Bundesrepublik Deutschland und der Volksrepublik Ungarn über den Waren- und Zahlungsverkehr und über die Errichtung von Handelsvertretungen S. 56,298 f., $328,730,1062^{6}$

- Protokoll vom 17.12.1963 über die Ausgabe von Passierscheinen an Einwohner von Berlin (West) zum Besuch von Verwandten in Ost-Berlin (Passierschein-Vereinbarung) siehe: Passierschein-Gespräche

- Handelsabkommen vom 4. 2. 1964 zwischen der Italienischen Republik und der UdSSR

S. $1122^{43}$

- Handelsabkommen vom 10. 2. 1964 zwischen dem Kaiserreich Japan und der UdSSR

S. 1211

- Kulturabkommen vom 20. 2. 1964 zwischen der DDR und der Republik Indien

S. 311 
- Abkommen vom 27. 2. 1964 zwischen dem Königreich Dänemark und der UdSSR über die Regelung der gegenseitigen finanziellen, vermögensrechtlichen und sonstigen Ansprüche in der Lettischen, der Litauischen und der Estnischen Sowjetrepublik sowie den westlichen Bezirken der Ukrainischen und der Weißrussischen Sowjetrepublik und dem Kaliningrader Bezirk der Russischen Sozialistischen Föderativen Sowjetrepublik

S. 475

- Abkommen vom 6. 3. 1964 zwischen der Bundesrepublik Deutschland und der Volksrepublik Bulgarien über den Waren- und Zahlungsverkehr und die Errichtung von Handelsvertretungen S. $298-300,730,1062^{6}$

- Sozialabkommen vom 30. 4. 1964 zwischen der Bundesrepublik Deutschland und der Republik Türkei

S. $117^{19}$

- Abkommen vom 17. 5. 1964 zwischen der DDR und der Republik Sansibar über Freundschaft und gegenseitige Unterstützung

S. $854^{24}$

- Handelsabkommen vom 6. 6. $1964 \mathrm{zwi}$ schen der EWG und dem Staat Israel S. $128^{12}, 734$

- Abkommen vom 9. 6. 1964 zwischen der Bundesrepublik Deutschland und dem Vereinigten Königreich von Großbritannien und Nordirland über die Entschädigung von Opfern aus der Zeit des Nationalsozialismus

S. 840

- Vertrag vom 12.6. 1964 zwischen der UdSSR und der DDR über Freundschaft, gegenseitigen Beistand und $\mathrm{Zu}$. sammenarbeit siehe: Freundschaftsvertrag

- Kulturabkommen vom 19. 6. 1964 zwischen der Französischen Republik und der Sozialistischen Föderativen Republik Jugoslawien

S. 1466

- Zusatzvereinbarung vom 16. 7. 1964 zwischen der Bundesrepublik Deutschland und der Sozialistischen Föderativen Republik Jugoslawien zum Abkommen vom 11. 6. 1952 über den Warenverkehr S. $995^{15}, 1001,1003$

- Abkommen vom 28. 7. 1964 zwischen der Bundesrepublik Deutschland und der Vereinigten Republik von Tanganjika und Sansibar über Ausbildungs- und Ausrüstungshilfe

S. $957^{4}, 979$

- Vereinbarung vom 14. 8. 1964 zwischen der Bundesrepublik Deutschland und der DDR über den Wiederaufbau der Saale-Brücke bei Hirschberg S. $1022^{33}$

- Handels- und Kulturabkommen vom 19. 9. 1964 zwischen der Republik Dahome und der DDR

S. 1150

- Abkommen vom 19.9. 1964 zwischen der Republik Dahome und der DDR über die Errichtung von Handelsmissionen S. 1150,1203

- Protokoll vom 24. 9. 1964 über die Ausgabe von Passierscheinen an Einwohner von Berlin (West) zum Besuch von Verwandten in Ost-Berlin (2. Passierschein-Vereinbarung)

siehe: Passierschein-Gespräche

- Abkommen vom 24.9. 1964 zwischen der Bundesrepublik Deutschland und Malawi über Kapitalhilfe

S. $967^{3}$

- Abkommen vom 3.10.1964 zwischen der Bundesrepublik Deutschland und der Demokratischen Volksstaatlichen Republik Algerien über Kapitalhilfe S. $947^{12}$

- Vereinbarung vom 15. 10. 1964 zwischen der Bundesrepublik Deutschland und der Republik Indien über den Schutz von Kapitalanlagen

S. 313

- Handelsabkommen vom 30. 10. 1964 zwischen der Französischen Republik und der UdSSR

S. $221^{21}, 805,1122,1211$ 
- Handelsvereinbarung vom 7. 11. 1964 zwischen der DDR und der Republik Zypern

S. $1366 \mathrm{f} ., 1414,1416$

- Kulturabkommen vom 11. 1. 1965 zwischen der Französischen Republik und der Volksrepublik Rumänien S. 1466

- Kulturabkommen vom 16. 10. 1966 zwischen der Französischen Republik und der Volksrepublik Bulgarien

S. 1466

- Vertrag vom 19.12.1966 über die friedliche Erforschung und Nutzung des Weltraums

S. 1280

\section{Abrüstung und Rüstungskontrolle \\ siehe außerdem: \\ Atomwaffen \\ Belgien \\ Blockfreie Staaten \\ $D D R$ \\ Frankreich \\ Gewaltverzicht \\ Gomulka-Plan \\ Großbritannien \\ Indien \\ Irland \\ Italien \\ NATO \\ Nichtangriffsabkommen \\ Niederlande \\ Teststopp-Abkommen \\ UdSSR \\ UNO \\ USA \\ Volksrepublik China \\ - 18-Mächte-Abrüstungskommission}

Dok. 303 und S. 37, 58 f., 73, 182, 186, $202,298,318,466,553,694,938,941^{12}$, $1045 \mathrm{f} ., 1052$

- Baruch-Plan vom 14. 6. 1946 zur Kontrolle der Atomenergie

S. 552

- Bodenbeobachtungsposten

Dok. 30, 31 und S. 37, 57-60, 77, 199203, 233 f., $267,329,466^{39}, 465,516,553$, $695,940,1206$

- Bundesrepublik Deutschland

Dok. 43, 120, 173, 356 und S. 14 f., 52 ,
57-61, 77 f., 116,157 f., 184-187, 233 f., $267,295-298,329,435,466-469,490$, 516 f., 551-554, 569, 577, 600, 841, 865$867,890^{19}, 938-941,1045-1051,1205-$ $1210,1294-1296,1401,1519,1521,1524 \mathrm{f}$., $1527,1554,1563-1565$

- „Einfrieren“ von strategischen Kernwaffenträgern (,freeze"-Plan)

Dok. 38 und S. 363, 507-509, 516 f., 552, $600,602,694,1391^{3}$

- entmilitarisierte Zonen

S. 1519

- europäische Sicherheitskonferenz S. 1562-1565

- „heißer Draht“ zwischen Moskau und Washington

S. 1337,1410

- Internationale Atomenergie-Organisation: Kontrollen

Dok. 331

- Kernwaffen im Weltraum

S. 183

- kernwaffenfreie Zonen S. 57 f., 183, 1073

- Nichtangriffserklärungen zwischen NATO und Warschauer Pakt

S. $35^{3}, 285,695$

- Nichtverbreitung von Kernwaffen

Dok. 39, 253 und S. 37, 91, 155, 329, 466 f., $551,577,695$ f., $841,890^{19}, 939,982$, $1052,1055,1073,1082,1099,1109,1111$, $1204,1293,1295$ f., $1307,1319,1324,1332$, $1391,1455,1506,1508,1511,1514,1552-$ $1554,1570,1574,1577$

- Produktionsverbot von spaltbarem Material für militärische Zwecke

S. $183,694,939$

- Rapacki-Plan

S. $296,490,866,1562-1564$

- Rüstungsausgaben S. $78,184,568,695,1518,1520 \mathrm{f}$.

- Sondierungsgespräche vom 27. 9. bis 4. 10.1963

S. $58^{29}, 1494^{5}$

- Truppenstärken

S. 568 f., 1392 
- Verhinderung von Überraschungsangriffen

S. 199-201

- Vernichtung von Kernwaffen S. 1204

- Zerstörung veralteter Bomber S. $695,841,939$

Aden

S. 83, 932

AEG (Allgemeine Elektrizitätsgesellschaft) siehe: Wirtschaftsunternehmen

Ägypten siehe: VAR

Äthiopien S. 971,1208

- Ausrüstungshilfe S. 105,191

- DDR S. 1060

- Kenia S. 84

Algerien siehe außerdem: Arabische Staaten

S. $100,241,537,956,1298$

- Bundesrepublik Deutschland Dok. 215, 224 und S. 732 f., 1122, $1580^{7}$

- DDR

S. 732 f., 740,908 f., $947,1122^{35}$

- Entwicklungshilfe S. 995

- EWG S. 908-910, 946

- Frankreich S. 71,732 f., 889,909 f., 931,945 f., $947^{12}$

- UdSSR S. 619,733

- Volksrepublik China S. $619,733,1374$

Allgemeine Zeitung (Mainz) S. $1255^{3}, 1262^{25}$

Allgemeines Zoll- und Handelsabkommen siehe: GATT

Arabische Staaten siehe außerdem: Algerien DDR Großbritannien Irak

Iran Israel Jemen Jordanien

Kuwait Marokko Saudi-Arabien Syrien Tunesien UdSSR

USA

VAR

- Boykottklausel gegen Israel S. 963

- Bundesrepublik Deutschland Dok. 315 und S. 272, 352, 366, 382, $397^{12}$, $398,416,567,653,670,711$ f., 907, 1215, 1227-1229, 1236, 1334, 1480-1482, 1557 ${ }^{3}$, 1558

- Entwicklungshilfe

S. $1183 \mathrm{f}$., 1247

Arbeiderbladet (Oslo)

S. $1520^{8}$

Argentinien

S. 1050

- Bundesrepublik Deutschland S. $354^{9}, 616$

Astronauten-Bergungsabkommen

- All-Staaten-Klausel S. $1277-1280,1386$

- Bundesrepublik Deutschland S. $1277-1280$

Atomwaffen siehe außerdem: Großbritannien Indien Japan $M L F$ Polen Tschechoslowakei UdSSR-Bundesrepublik Volksrepublik China 
- europäische Atomstreitmacht S. 554, 768, 791, 835, 1174, 1508, 1552 f.

- Verzicht der Bundesrepublik Deutschland auf $A B C$-Waffen S. $88,137,154,173$ f., 178 f., $187,297,637$, $681,1047 \mathrm{f}$., 1169, 1450, 1510, 1514

\section{Ausrüstungshilfe} siehe außerdem: Äthiopien

Guinea

Mali

Tanganjika

USA-Bundesrepublik

Verteidigungshilfe

Dok. 18, 41 und S. 271, 1166, 1283, 1517

Australien
S. 66

- Bundesrepublik Deutschland Dok. 245 und S. $863^{4}$

- GATT

S. 513

- Republik Vietnam S. $1013 f$.

- USA

S. 655

\section{Baltimore Sun}

S. $261,304^{23}, 1571$

Bank für Internationalen Zahlungsausgleich

S. $479 \mathrm{f}$.

Bank of International Development S. 1121

\section{Belgien}

S. 354, 1537, 1575

- Abrüstung und Rüstungskontrolle S. 490

- Bundesrepublik Deutschland Dok. 112, 197, 198 und S. 496, $837 \mathrm{f}$.

- europäische politische Union S. $80-82,487 \mathrm{f}$., $710^{5}, 736,753,809,814$, 822-829, 831-837, 1006f., 1027, 1029, $1350,1425,1438$

- europäisches Parlament S. 274

- EWG

S. $235,418 f ., 824,911$ f., 914,1223
- Frankreich

S. $836,1223^{37}, 1496$

- Großbritannien

S. $1495 \mathrm{f}$.

- Kongo

S. 537, 968 f., 1496

- MLF

S. $451,489,692$ f., $830,837,1054,1056$, $1286,1495 \mathrm{f}$., 1508

- NATO

S. $534,836^{21}, 930$

- Parteien

S. 489

- Spanien

S. 418f.

- Temporary Travel Documents S. 406

- USA S. $968^{6}, 1496$

- VAR

S. 421

- Wahlen

S. 830

\section{Berlin}

siehe außerdem:

Berlin-Klausel

$D D R$

Deutsche Frage

Frankreich-Bundesrepublik

Großbritannien-Bundesrepublik

Passierschein-Gespräche

UdSSR-Bundesrepublik

USA-Bundesrepublik

Dok. 366 und S. 16, 87, 440

- Allied Travel Office S. $360^{32}, 405$

- Alliierte Kommandantur S. $3,4^{6}, 6,93,675,1275-1277,1485$

- alliierte Truppen

S. 51, 1057, 1171

- „Berlin-Ultimatum“ der UdSSR vom 27.11. 1958

S. $858^{5}, 931,1317$

- Besatzungsstatut für Berlin S. 1171 
- Bindungen an die Bundesrepublik Dok. 64, 82, 323 und S. $21^{12}, 276$ f., 327 , 550f., 675, 679, 842, 852, 993, 1057 f., 1071

- Bundeskabinett in Berlin Dok. 267

- Bundestag in Berlin S. 276, 1101

- „contingency planning“ S. $86^{3}$

- Drei-Staaten-Theorie S. $50,294,303,307,408,858,990$ f., 1127 , 1171,1433

- „Freie Stadt“ S. $40^{3}, 90,171^{5}, 177^{18}, 326,684 \mathrm{f}$.

- Freizügigkeit innerhalb Berlins S. 4 f., $6^{10}, 21,328$ f., 408,434

- informelle Vier-Mächte-Kontakte Dok. 379

- Internationale Zugangsbehörde S. $35^{3}, 434,436,442,547,550$

- Kontakte technischen Charakters zwischen Berlin (West) und Ost-Berlin S. 5, 92, 94, 293 f., 307 f., 315, 327, 1069

- Mauer in Berlin S. $4^{6}, 21,40^{3}, 90,92,171^{5}, 294,335,405 f$., $882,1318,1527,1538$

- NATO S. $930 \mathrm{f}$.

- Regierender Bürgermeister S. 21, 276, 1021

- Senat

S. $3-6,7^{11}, 21,93,128,130-132,171^{2+5}$, $196^{27}, 197,268^{11}, 276^{7}, 292^{3+5+6}, 293 \mathrm{f}$., $304,306^{6+8}, 308^{20}, 309$ f., $327,335^{17}, 359$, 384,409 f., 985, 991, 1069, 1071, 1138, 1420,1485

- Sondierungsgespräche 1961-1963 S. $317,522,1494^{5}, 1530$

- UNO S. 1171

- Verbindungswege nach Berlin S. $37,70,73^{3}, 93,171$ f., $277,548,727,842$, $851,1171,1530$

- Vier-Mächte-Verantwortung S. 293, 675, 1483-1485, 1530
- Westmächte

S. 4-6, 171f., 675, 1022

Berlin-Klausel

siehe:

Bulgarien-Bundesrepublik

Ostblock-Staaten

Teststopp-Abkommen

Tschechoslowakei-Bundesrepublik

Volksrepublik China-Bundesrepublik

Berner Union

S. $192^{11}, 249,1578$

Bild am Sonntag (Hamburg)

S. $1488^{16}$

Bild-Zeitung (Hamburg)

S. $1250,1255,1266^{7}$

Birma

S. $319,1202,1204,1208$

Blockfreie Staaten

siehe außerdem:

DDR

UdSSR

S. 1279

- Abrüstung und Rüstungskontrolle S. $1046,1048 \mathrm{f}$.

- Bundesrepublik Deutschland S. 799-802, 1050, 1127 f., 1196, 1248

- MLF

S. $1048 \mathrm{f} ., 1052,1082,1109$

Boeing Airplane siehe: Wirtschaftsunternehmen

Bölkow GmbH siehe: Wirtschaftsunternehmen

Bolivien

S. 563

Bonner Vierergruppe

S. $277^{8+10}, 1275^{4}, 1483-1485$

Brasilien

S. $322,347,354,563,1050,1208$

- Bundesrepublik Deutschland S. $445 \mathrm{f}$., $616 \mathrm{f}$.

- UdSSR

S. 901

Bulgarien siehe außerdem: Bulgarien-Bundesrepublik

S. 1208 
Bundesverband der Deutschen Industrie

- DDR

S. 1019,1060

- Frankreich

S. 1466

- Griechenland S. 158

\section{Bulgarien-Bundesrepublik Deutsch-} land

- Berlin (West) in Abkommen (BerlinKlausel)

S. 298 f., 362

- Handelsabkommen S. 298

- Handelsvertretungen

Dok. 62 und S. 56, 328, 362

\section{Bund der Vertriebenen}

S. $1288 \mathrm{f}$.

Bundeskabinett

Dok. 128 und S. $24,170^{10}, 181,270$ f., 275 , $313,343,346,396^{6}, 397^{12}, 495,506,698$, $782^{18}, 798,854,862,869$ f., $870^{10}, 987$, $1009,1141,1165,1166^{16}, 1196,1217$, $1228^{11}, 1242,1274^{7}, 1394,1491^{41}, 1509$, $1566^{9+10}, 1579,1580^{7}$

- Staatssekretärausschuß für Europafragen

Dok. 33 und S. 1361

\section{Bundeskanzleramt}

S. $3-5,125^{5}, 196^{27}, 396,417^{38}, 669,958$, 1137-1141, 1485

Bundesminister der Finanzen

S. $102^{3}, 166-168,343^{8}, 344,346,504 \mathrm{f}$., $538,840,1115,1165,1166^{16}$

\section{Bundesminister der Justiz}

S. $103,397,669 \mathrm{f}$.

\section{Bundesminister der Verteidigung}

S. $101-106,169^{7}, 180,185,190,191^{4}, 200^{6}$, 202 f., 278 f., 350, 393, 453, 505 f., 509, 540, $604,669,711$ f., 840, 877, 957, 1011, $1012^{49}, 1040,1076,1164-1166,1168$, $1176^{7}, 1207,1209,1302^{11}, 1320 \mathrm{f} ., 1373^{9}$, $1446^{3}, 1448^{9}, 1559,1565$

Bundesminister des Innern S. $396^{6}, 397,669$ f., $1228^{11}$

Bundesminister für Ernährung, Landwirtschaft und Forsten

S. $166-168,300,1114^{13}$
Bundesminister für Familien- und Jugendfragen

S. $1316^{23}$

Bundesminister für gesamtdeutsche Fragen

S. $410,985,987,989^{22}, 1139-1141,1485$

Bundesminister für das Post- und Fernmeldewesen

S. 3f., 840,987

Bundesminister für Verkehr

S. $987,1509^{31}$

Bundesminister für Wirtschaft

S. $23^{2}, 166-168,445-447,500,669,927$, $987,989^{22}, 1065,1137-1140$

Bundesminister für wirtschaftliche $\mathrm{Zu}$ sammenarbeit

S. $8^{8}$

Bundesminister für wissenschaftliche

Forschung

S. 669,1123

Bundesnachrichtendienst

S. 1422

Bundesrat

S. $240^{13}, 1221$

Bundestag siehe außerdem: Berlin

S. $27,31,74^{10}, 151^{10}, 176,219,289^{47}, 306$, $333^{5}, 353,359,379,396^{6}, 397,429,440$, $698,749,751,985,992,1092,1098^{25}$, $1124^{4}, 1134,1188,1221,1228,1229^{17}$, $1240,1244,1247,1270^{15}, 1276,1282 \mathrm{f}$., $1300,1335,1350,1377,1402,1409,1445$, 1515-1517

- Ältestenrat

S. 1281

- Ausschuß für gesamtdeutsche und Berliner Fragen

S. 308

- Ausschuß für Wiedergutmachung S. 1130

- Auswärtiger Ausschuß

S. $216^{3}, 238,268^{12}, 510,610,737$

- Haushaltsausschuß

S. $8^{8}, 270 \mathrm{f}$.

Bundesverband der Deutschen Industrie (BDI)

S. 1267 
Bundesverband deutsch-israelischer

Studiengruppen

$$
\text { S. } 271
$$

Bundesverteidigungsrat

S. $101^{1}, 105$ f., 190 f., $540^{2}, 1046^{10}, 1104$ $1106,1165,1260$

\section{Bundeswehr}

S. 103 f., $169^{7}, 174,269^{2}, 336-338,362$, 450,505 f., $540^{2}, 711,790,796$ f., 929,969 , $1056,1302^{11}, 1304^{18}, 1371,1446 \mathrm{f}$., 1509 , $1518,1520-1523,1525,1527,1536 \mathrm{f}$., 1546 , $1558^{6}, 1559$

\section{CDU (Christlich-Demokratische Union}

Deutschlands)

S. $150-152,276^{5}, 306,510,750,756,808$, $821,959,1091,1112,1182,1257,1266$, $1300,1329,1383,1409,1412$

Ceylon

- Bundesrepublik Deutschland

Dok. 191 und S. $267^{8}, 287$ f., 358,363 , $853,861,1195 \mathrm{f}$.

- DDR

S. $267,287 f$ f., $312^{7}, 358,461,688,798 f$., 802 f., $996,1196^{6}$

- Entwicklungshilfe

Dok. 299 und S. 797-802

Chile

S. $354,616,618$

China

siehe:

Republik China

Volksrepublik China

Christlich-Demokratische Union

Deutschlands

siehe: $C D U$

Christlich-Soziale Union siehe: $C S U$

COCOM (Coordinating Committee for

East-West Trade Policy)

S. 635

\section{COMECON}

siehe: $R G W$

Commonwealth of Nations

S. $34,66,72,127,206,725,996,1311$

Communauté française

S. $389,1121^{33}$
Coordinating Committee for East-West

Trade Policy siehe: COCOM

ØSSR (そeskoslovenská Socialistická

Republika)

siehe: Tschechoslowakei

CSU (Christlich-Soziale Union)

S. $276^{5}, 808,812,1300$

Dänemark

S. 645

- Bundesrepublik Deutschland Dok. 108 und S. $24^{5}, 265,868^{1}$

- EWG

S. 30,119

- MLF

S. 1575

- NATO

S. 930

- Temporary Travel Documents S. 360,406

- UdSSR S. $289,476,749$

- UNO

S. 583

- Volksrepublik China S. 546

Dahome

- Bundesrepublik Deutschland Dok. 282

- DDR S. 1150-1153, $1202 \mathrm{f}$.

DDR (Deutsche Demokratische Republik) siehe außerdem:

Algerien

Bulgarien

Ceylon

Dahome

Deutsche Frage

Freundschaftsvertrag

Interzonenhandel

S. 146,1385

- Abrüstung und Rüstungskontrolle S. 202, 938-941

- Anerkennung

Dok. 202 und S. 59, 88-90, 159, 203, 214, $223,296^{4}, 297,303,312^{9}, 326^{16}, 336,355$, 
$357,365,470,473 \mathrm{f} ., 688,691,741,781$, 798f., 850, 853, 856, 971, 999, 1020, 1126$1128,1145,1151,1156 \mathrm{f} ., 1202,1209,1238$, $1277 \mathrm{f}$., 1318, 1414, 1417, $1481 \mathrm{f}$., $1555 \mathrm{f}$, $1557^{3}$

- Arabische Staaten S. $351^{3}, 1183$ f., $1238,1247,1557^{3}$

- Berlin

S. $3^{2}, 4,21$ f., $40^{3}, 50^{10}, 91,129-131,171$, 276, 362, 409, 606, 687, $1100 \mathrm{f}$, 1527

- Bevölkerung

S. 845-850, 899 f., 902 f., 991 f., 1022, 1382 , $1529,1532,1569$

- Blockfreie Staaten

Dok. 275 und S. 357, 688, 994, 1202 f.

- Bundesrepublik Deutschland S. 76, 302, 528 f., 847 f., 1532

- Entwicklungshilfe Dok. 231 und S. $689 \mathrm{f}$.

- Frankreich S. $97,214^{48}, 220,222$ f., 254, 261, 359, $1123,1578-1580$

- Freie Deutsche Jugend (FDJ) S. 781

- Freikauf politischer Häftlinge durch die Bundesrepublik

Dok. 285, 300

- Ghana

S. 461, 498f., 857, 966, 971, 1151, 1202

- Guinea

S. 498, 1151

- Indien

S. 311,1126

- Jemen

S. 161, $163 \mathrm{f}$.

- Jugoslawien S. $312^{7}, 327,364,368,471-474,731$ f., 741 , $994^{9}, 1001-1003$

- Kambodscha S. 624

- Kasernierte Volkspolizei S. 1194

- Kredite westlicher Staaten $\mathrm{S} .1578 \mathrm{f}$.

- Kuba S. 857
- Leipziger Messe

Dok. 322

- Malawi

S. 966

- Mali

S. 498

- NATO

S. 299

- Ostblock-Staaten

S. 1539 f., 1563 f., $1568 \mathrm{f}$.

- Polen

S. 76, $376 \mathrm{f} ., 1019$

- Reisen von Rentnern in die Bundesrepublik

S. $1140 \mathrm{f}$

- Rumänien

S. 1019

- Sansibar S. $188,189^{7-10}, 267,327,358,498,503 \mathrm{f}$., $854,957,958^{9}, 966$

- Sozialistische Einheitspartei Deutschlands (SED)

S. $362,847,1539$

- Tanganjika

S. $188^{3}, 503,504^{6}, 958$

- Teilnahme an internationalen Abkommen

Dok. 221, 324 und S. $1563 \mathrm{f}$.

- Teststopp-Abkommen S. 88, $90 \mathrm{f}$., 372, 1016, $1036 \mathrm{f}$.

- Tschechoslowakei S. 1018, $1464 \mathrm{f}$.

- UdSSR

S. 53,55 f., $93,172,200,215,223,549$, $639 \mathrm{f} ., 660 \mathrm{f} ., 663,742,898,902,1074$, $1209,1269,1539$

- Ungarn

S. 1019

- UNO

S. 88,461 f., 564,732 f., $740,1002,1126-$ $1129,1192,1202,1386$

- USA

S. 1578

- VAR

S. $160-165,459,498,998-1000,1126$, $1145,1183,1238,1334^{11}, 1555 f$. 
- Verjährung nationalsozialistischer Gewaltverbrechen

S. 1132

- Visumspflicht S. 172

- Volksrepublik China S. 543f., 588, 608, 1023, 1190

- Wiederaufbau der Saale-Brücke S. $988,1139 \mathrm{f}$.

- Zwangsumtausch S. 1418

- Zypern S. 1414-1417

Demokratische Republik Vietnam

- Frankreich S. 211,319

- Laos S. 645

- USA S. 515, 621, $1013^{5}$

- Volksrepublik China S. $622 \mathrm{f}$.

- Zypern S. $1366-1368$

Demokratische Volksrepublik Korea S. 1375

Der Spiegel (Hamburg) S. $22^{15}, 131^{19}, 147^{34}, 197^{29}, 217^{9}, 306^{5}$, $511^{12}, 568^{18}, 652^{9}, 1059^{16}, 1441 \mathrm{f}$.

\section{Deutsche Demokratische Republik} siehe: $D D R$

Deutsche Forschungsgemeinschaft S. 408

Deutsche Frage und Wiedervereinigung siehe außerdem:

Berlin

$D D R$

Frankreich-Bundesrepublik Großbritannien-Bundesrepublik Italien-Bundesrepublik Jugoslawien-Bundesrepublik Polen-Bundesrepublik Selbstbestimmungsrecht UdSSR-Bundesrepublik UNO USA-Bundesrepublik

Dok. 4, 57, 201, 239, 241, 302, 387 und
S. $159,469,534$ f., $543,545,587$ f., 634 , 637, 802, 930, 952-954, 971, 992 f., 999, $1144,1150,1152,1196 \mathrm{f} ., 1240,1245,1247$, $1284,1292,1340,1415,1538$

- Anerkennung des Status quo S. 266, 268, 695, 1015 f., 1207, 1353

- Berliner Erklärung der drei Westmächte und der Bundesrepublik vom 29. 7. 1957

S. 523,578

- Besatzungsstatut S. 9

- „Burgfriedensplan“ vom 6. Juni 1962 S. $386^{16}$

- Deutschland-Initiative vom 3. 1. /10. 4. 1964

Dok. 3, 10, 53, 101, 124, 126 und S. 39, 50-55, 74-77, 94 f., 213, 233, 276, 355-358, 365 , 432f., $447 \mathrm{f}$., $457,464-467,485^{3}$, $486 \mathrm{f}$., $489,491 \mathrm{f}$., $511,517,545,566,613 \mathrm{f}$., $646 \mathrm{f} ., 678-680,728,739,1038$

- "draft principles" vom April 1962

S. 35, 37, 41, 434, 442, 492, 532

- Eden-Plan vom 29.1. 1954 S. 523

- Friedensvertrag mit beiden deutschen Staaten: Entwurf der UdSSR vom 10. 1. 1959

S. 88 f., 177 f., $326,476,486,902$

- Friedensvertrag mit Deutschland

Dok. 213 und S. 12, 175, 177, 614, 628, $686,901,954,964,1106$ f., 1530

- gemischte Fachkommissionen S. 984-986

- Genfer Direktive vom 23. 7. 1955 S. 662

- gesamtdeutsche Wahlen S. $12,38,51$ f., $335,434,440$ f., 627,660 , 662 f., $905,1170,1253,1434,1539$

- Grenzen

Dok. 274 und S. 86-89, 337, 339, 441 f., $476,578,686$ f., $953,964,1028$ f., 1106 f., $1108^{7}, 1530,1533,1568 \mathrm{f}$.

- Herter-Plan vom 14. 5. 1959 S. $10^{2}, 11^{7}, 37,54^{18}, 94,267,357,439,492$, $517,523,531,905,984$

- humanitäre Kommissionen S. $13,52,77,94,441$ f., 1385 
- Konföderation zwischen der Bundesrepublik Deutschland und der DDR S. $50^{10}, 664,902,984,1127,1432^{2}, 1433$

- Kontaktstelle für innerdeutsche Beziehungen

S. 985-988

- Kuratorium Unteilbares Deutschland: Vorschlag vom 30.9.1963

S. $10^{1+2}, 440^{6}$

- Militärmissionen

S. $58 \mathrm{f} ., 201$

- Oder-Neiße-Linie

Dok. 328 und S. $14,87,356,434,486$, 1074, 1568

- Ostgebiete des Deutschen Reiches unter fremder Verwaltung

S. 53 f., $544^{11}, 960,1357 \mathrm{f}$.

- politische Amnestie

S. $13,52,441$

- revidierter westlicher Friedensplan vom September 1961

S. 984

- separater Friedensvertrag mit der DDR S. 522, 727, 742

- ständiger Rat der Vier Mächte

S. $12,38,51-53,77,94,157,356,433$, 440 f., $519,523,525,531-533,841,842^{32}$, 852,1384 f., $1414,1419,1437,1455$, $1468 \mathrm{f} ., 1493 \mathrm{f}$., $1528 \mathrm{f} ., 1531 \mathrm{f}$.

- Vier-Mächte-Verantwortung

S. $11,53,74^{10}, 87,97,178^{20}, 355,358$, 443 f., $530,532,662,681,695,898,1384$, $1437,1468,1493,1523,1526,1529,1563 \mathrm{f}$.

- Volksabstimmung S. 11 f., 51 f., 77, 441 f., 605

- Vorschlag der drei Westmächte vom 27. 10. 1955 zur Wiedervereinigung und europäischen Sicherheit

S. 466,523

- Vorschlag des Auswärtigen Amts vom 13. 8. 63 zur Lösung des DeutschlandProblems S. $10^{2}, 37,75,269,464,984$ f., 1037 f.

- „Wandel durch Annäherung “ S. $303,985 \mathrm{f}$.

- Zwei-Staaten-Theorie S. $40^{3}, 53^{15}, 87,90,177$ f., $257,312,367$, $369,383 \mathrm{f}$., 422, 442, 498, 564, 627, 630,
660 f., 663,684 f., $690,732,741,858,880$, $950,995,1127,1171,1433$ f., 1468,1525 , $1527,1531 \mathrm{f}$.

Deutsche Zeitung mit Wirtschaftszeitung (Köln)

S. 359

\section{Deutscher Bauernverband}

S. 289

Deutsch-französischer Vertrag vom 22.

Januar 1963

siehe: Frankreich-Bundesrepublik

Deutsch-Französisches Jugendwerk siehe: Frankreich-Bundesrepublik

Die Welt (Hamburg)

S. $74,78^{24}, 197^{29}, 306^{7}, 713^{3}, 760^{18}, 792$, $871^{5}, 884,1010^{36}, 1025^{2}, 1026^{7}, 1041^{3}$, $1059^{15}, 1083^{14}, 1085^{6}, 1086-1088,1122^{35}$, $1140^{17}, 1141^{18}, 1141^{3}, 1286^{4}, 1329^{26}$, $1406^{4}, 1516^{8}, 1556^{5}$

Die Zeit (Hamburg)

S. 986

EAG

siehe: EURATOM

Ecuador

S. 354,1050

EFTA (European Free Trade Association)

siehe außerdem:

$E W G$

Großbritannien

OEEC

Österreich

Schweden

S. $45,48,79,134,833$

- Bundesrepublik Deutschland

S. 230,1257

EGKS (Europäische Gemeinschaft für Kohle und Stahl/Montanunion) siehe außerdem: Schweden

S. $80,119,145^{23}, 290,913,1337$

- Bundesrepublik Deutschland

S. 331

- EGKS-Vertrag: Artikel 98 S. 1349

- Hohe Behörde

S. $286^{33}, 287,290^{50}, 331$ 
- Lateinamerika

S. 1121

Elfenbeinküste

S. 563

Entwicklungshilfe
siehe außerdem:
Algerien
Arabische Staaten
Ceylon
DDR
Frankreich-Bundesrepublik
Ghana
Großbritannien-Bundesrepublik
Indien
Italien-Bundesrepublik
Lateinamerika
USA-Bundesrepublik
Zypern

S. $8,516,538,590-592,656,689 \mathrm{f} ., 854 \mathrm{f}$., 858-861, 966 f., $996,1152,1460$ f.

EURATOM (Europäische Atomgemeinschaft) siehe außerdem:

Frankreich

Römische Verträge

- Bundesrepublik Deutschland

S. 1179f., 1294-1296

- EURATOM-Kommission

S. $145^{23}, 1177-1181,1186$

- Sicherheitskontrolle

S. 1177-1181, 1294-1296

Europäische Freihandelsassoziation siehe: EFTA

Europäische politische Union siehe außerdem:

Belgien

Frankreich

Großbritannien

Italien

Luxemburg

Niederlande

Polen

Portugal

Spanien

Tschechoslowakei

S. $205,481,484,1163,1169,1373$

- beratendes kommunitäres Organ

S. 1092,1094 f., 1102 f., 1189, 1250, 1347-
1349, 1428f., 1431, 1451, 1472

- Bundesrepublik Deutschland Dok. 22, 178, 193, 268, 368 und S. 25 f., 29 f., 45-48, 67-69, 79-82, 133-143, 148, $166-168$, 207 f., 214,237 , 255f., 281 f., 284-286, 290, 324-326, 482, $487 \mathrm{f}$., $635 \mathrm{f}$., $713,715,717,719-723,735,738$ f., $750-$ $762,769-776,783,789,792,812,814-816$, 818-835, 885, 890, 893, 923, 973f., 1007, $1027,1090-1097,1103,1116,1136,1187$, $1189, \quad 1224-1226,1233 \mathrm{f} ., 1313-1315$, $1326 \mathrm{f} ., 1345-1350,1359,1390 \mathrm{f} ., 1412 \mathrm{f}$., 1438f., 1451-1453, 1470-1473, 1479

- Cattani-Kommission

S. $709 \mathrm{f}$.

- Fouchet-Pläne

S. $27^{10}, 68,79,81,134,735,759,791,806^{3}$, 816,819 f., $822,825-828,831$ f., 835 , $1006^{17}, 1347-1349,1438,1451,1471 \mathrm{f}$.

- Monnet-Plan

S. 819

- Politische Kommission

S. $814^{11}, 827$ f., 831 f., $1006^{17}, 1426$ f., 1451

Europäische Verteidigungsgemein-

schaft

siehe: $E V G$

Europäische Wirtschaftsgemeinschaft siehe: $E W G$

Europäischer Gerichtshof

S. $127^{10}, 289 \mathrm{f} ., 913,1179$

Europäisches Parlament

siehe außerdem:

Belgien

Frankreich

Niederlande

S. 115 f., 139, 143, 281, 284, 287, 404, 828 f., 911 f., $1116^{2}, 1347,1426$ f., 1429

- Budgetrecht

S. $481-483,1117$

- Bundesrepublik Deutschland S. 274 f., 1094 f., 1097 f., 1117 f.

- Direktwahl

Dok. 56 und S. 286, 1341, 1425

- Sitzverlegung nach Luxemburg S. $913 \mathrm{f}$., $1117^{11}, 1118^{12}$

Europäisches Währungsabkommen S. 117 


\section{Europarat}

siehe außerdem: Italien

S. $285,326,1368$

- Arbeitssprachen

S. 1350 f., 1457

- Bundesrepublik Deutschland

S. $1350 \mathrm{f}$.

EVG (Europäische Verteidigungsgemeinschaft)

S. $69,759,1054,1486^{5}$

EWG (Europäische Wirtschaftsgemeinschaft)

siehe außerdem:

Algerien

Belgien

Dänemark

Frankreich

GATT

Großbritannien

Israel

Italien

Kanada

Kenia

Luxemburg

Niederlande

Norwegen

Österreich

Polen

Republik China

Römische Verträge

Schweden

Schweiz

Spanien

Tanganjika

Türkei

USA

S. 79,81 f., $256,388,829,1103,1337,1459$

- Abschöpfungssystem

\section{S. $747^{42}$}

- Arbeitsprogramm für 1964

S. 235

- Assoziierung afrikanischer Staaten S. 778, 969f., 1121, 1152

- Assoziierungsverhandlungen

S. $126 \mathrm{f}$., 403, 418-420, 632, $1120 \mathrm{f}$.

- Bundesrepublik Deutschland

Dok. 24, 90, 110, 205 und S. 66 f., 127, $141,143-146,230-232,235,286$ f., 289, $298^{4}, 379,570$ f., $631-633,636$ f., $745,747-$
749,758 f., $769,774,810$ f., $874-876,1027$, 1094, 1096-1098, 1112-1121, 1161 f., 1180, $1187 \mathrm{f}$., $1199 \mathrm{f}$., $1224-1226,1233 \mathrm{f}$., $1249 \mathrm{f}$., $1256 \mathrm{f}$., 1266, 1289f., 1310-1314, $1326 \mathrm{f}$., 1350, 1359-1362, 1390f., 1394-1396, 1445, $1455,1473,1490$

- EFTA

S. 66 f., 204,281 f., 284 f., 324-326, $330^{44}$, $402,572,635,815,1097,1116^{2}, 1117,1120$

- Europäischer Entwicklungsfonds S. 251, 778

- europäisches Patentrecht

Dok. 156 und S. 1181

- EWG-Kommission S. $66-68,125,127,138,144^{20}, 379,390$, $479-485$, 513f., 558, 570f., 826, 1094, 1113 f., 1118, 1120, 1161, 1200, 1225, 1256, 1289,1311 f., 1348,1360

- Finanzverordnung S. 1470

- Freizügigkeit von Arbeitskräften in der EWG

S. $145 \mathrm{f}$.

- Fusion der Exekutiven

Dok. 216 und S. 118, 139, 142 f., 145, 284, $286,404,481-483,821,1097$ f., $1116^{2}$, $1118,1425^{9}$

- Getreidepreise (Mansholt-Plan)

Dok. 272, 287, 347, 358 und S. 66, 118, 288 f., 378 f., 403, 481-483, 488, 571, 610$612,624,636 \mathrm{f}$., $747 \mathrm{f}$., $792,810 \mathrm{f}$., $836^{21}$, $838,874-876,893,1097,1117-1119,1180$, $1187,1199 \mathrm{f} ., 1223-1226,1233^{7}, 1234$, 1249 f., $1255^{4}, 1256-1258,1265$ f., 1289 f., $1310,1312,1326-1328,1350,1372,1390 \mathrm{f}$., $1413,1437,1445,1455$ f., 1470,1490

- Handelspolitik S. 481 f., 484

- Landwirtschaftspolitik S. $140^{4}, 248,260$ f., $282,403,481,513$, $748 \mathrm{f}$., $808,875 \mathrm{f} ., 1113,1187^{4}, 1188$, 1233 f., $1257 \mathrm{f}$., $1290,1312,1346,1455 \mathrm{f}$., 1470,1473

- Marktordnungen S. 747 f., 868-870, 1258, 1266, 1290

- Mehrheitsentscheidungen S. 46, 68, 1113f., 1496

- Ostblock-Staaten S. $220,298^{4}, 1094,1097,1122,1396$ 
- Sozialpolitik

S. $118,231,235,484$

- Steuerharmonisierung

S. $118,231,481$ f., $484,1361,1396,1437^{11}$, 1455,1473

- Verkehrspolitik

S. 481,484

- Währungsunion S. 390 f., 479,1096 f., $1116^{2}, 1117$

- Zollkontingente für Drittländer S. 127

- Zolltarif

S. $66,127,195,403,480-482,484,570$, $745,817,1116$ f., $1311,1361,1396,1437^{11}$

FDP (Freie Demokratische Partei)

S. $55,75,276^{5}, 355$ f., $985-987,1182,1289$, 1390

Ferrostaal AG siehe: Wirtschaftsunternehmen

Festlandsockel

Dok. 6,52 und S. 417, 745f.

Fiat siehe: Wirtschaftsunternehmen

Financial Times (London) S. 1567

Finnland S. 749

- Bundesrepublik Deutschland S. 165

- GATT S. $1120^{23}$

- UNO S. 347,583

„flexible response“ siehe: NATO

Forces aériennes Françaises (Paris)

S. 1054

Fouchet-Pläne siehe: Europäische politische Union

Frankfurter Allgemeine Zeitung S. $27^{9}, 81^{39}, 148^{2}, 160^{2}, 187^{10}, 188^{4}, 192^{3}$, $197^{30}, 216^{6}, 222^{4}, 270^{3}, 276^{5}, 277^{11}, 284^{27}$, $304^{26}, 334^{9}, 341^{34}, 353^{5}, 359,361^{39}, 364^{55}$, $511^{12}, 538^{2}, 551^{4}, 606^{6}, 713^{3}, 745^{37}, 747$, $793^{14}, 821,871^{5}, 872^{7}, 896^{3}, 986^{10}, 1029^{22}$, $1041^{3}, 1059^{15}+16,1104^{1}, 1105^{4}, 1123^{47}$
$1131^{8}, 1132^{11}, 1133^{19}, 1157^{1}, 1187^{4}, 1256^{7}$, $1272^{16}, 1286^{4}, 1486^{5}, 1516^{5}$

\section{Frankfurter Rundschau}

S. $1215^{2}$

Frankreich

siehe außerdem:

Algerien

Bulgarien

DDR

Demokratische Republik Vietnam

Frankreich-Bundesrepublik

Dok. 218, 342 und S. 563, 568

- Abrüstung und Rüstungskontrolle S. $184,317 \mathrm{f}$., $362^{46}, 363,365,552-554$, $866,1204,1207$ f., $1210^{27}, 1295$ f.

- Afrikanische Staaten S. 252, 319

- EURATOM Dok. 294

- europäische Atomstreitmacht S. 775, 885, 893, 1264, 1339, 1343 f., 1398, 1450,1536

- europäische politische Union Dok. 7, 194 und S. $29 \mathrm{f}$., 46, 79-82, 135$138,141-143,206,210,215,237,256$, 284 f., 290 f., $580,714,716,719-723,736$ f., 741f., 751-761, 768-775, 784f., 788-793, 814 f., 818, 823-826, 828f., 831-835, 885 f., $893,917-919,923,1006,1029,1031,1116$, $1186 \mathrm{f} ., 1189,1233-1235,1250,1260 \mathrm{f}$., $1290,1327,1336,1339-1341,1345-1350$, $1397,1409,1412,1425,1427,1438$ f., 1445 , $1449-1453,1470-1473,1477,1490,1536$

- europäisches Parlament S. 274, 1117, 1341

- europäisches Patentrecht S. $632 \mathrm{f}$.

- EWG

Dok. 329 und S. $25^{1+2}, 26,135,193,229$ $231,322,612,716,753$ f., $757,764,769$, $792,874-877,885,912,920,923,1116-$ $1121,1187 \mathrm{f}$., $1223-1226,1233 \mathrm{f}$., $1257 \mathrm{f}$., 1265 f., 1312, 1340, 1346, 1470, 1473, 1490, 1496

- Force de frappe

S. $28,47,70$ f., $110^{6}, 137,154,184,195 \mathrm{f}$., $244^{3}, 246,258,283,302,317$ f., 325, 374, $389,429,636 \mathrm{f} ., 655,718,762,765,775$, 790 f., 834 f., 885,887 f., $890^{19}, 893,920-$ 
$923,933,1033,1040,1080,1109,1220$, $1258-1261,1271,1295$ f., 1321 f., 1325 , $1330,1344,1362,1370,1398,1410 \mathrm{f}$, $1435^{2}, 1453,1474,1477,1487,1492$, $1507 \mathrm{f}, \mathrm{s} 36,1542,1545$

- GATT

S. $195,230,260,282,322,1119 f ., 1188^{10}$, $1223 \mathrm{f} ., 1312,1359$

- Griechenland

S. $493 \mathrm{f}$.

- Großbritannien

Dok. 389 und S. 68, 78, 135, 138, 193, 209, 401, 767, 792, 820, 832f., 891, 924, $1033,1040^{3}, 1053,1077,1085,1088 \mathrm{f}$., 1264, 1314

- Indochina: Neutralisierung S. 205, 211-213, 257-259, 319, 325, 537, 581,620 f., 646, 682, 763, 793, 921, 974, $1032 \mathrm{f}$

- Israel

S. 271, 733f., 1298, 1377

- Italien

S. 136, 138, 142, 209 f., 1067, $1452^{9}$

- Jugoslawien

S. 731, 1466

- Kambodscha S. $44,921 \mathrm{f}$.

- Kuba S. $192,227,229,263,288,655$

- Landwirtschaftspolitik S. 612,1340

- Laos

S. 581,922

- Lateinamerika

S. 241 f., 259,322 f., 389,426 f., 581,617 , 779 f., 920

- Mexiko

S. $413^{15+18}, 426$

- MLF

Dok. 343, 350, 374 und S. $110^{6}, 121,123$, $154,194,283,301 \mathrm{f} ., 374,375^{4}, 536,554$, $762,819 \mathrm{f}, 839,885,887,891,1033$, $1053 \mathrm{f} ., 1080,1109,1149,1161,1180$, $1181^{19}, 1185 \mathrm{f} ., 1189,1199,1219 \mathrm{f} ., 1223-$ 1226, 1234 f., 1258-1260, 1263, 1265, 1300 , 1314 f., 1323, 1326 f., 1331 f., 1362-1364, $1372 \mathrm{f} ., \quad 1389 \mathrm{f}$., $1397 \mathrm{f}$., $1401 \mathrm{f} ., 1411 \mathrm{f}$., 1435 f., $1439,1452^{9}, 1474-1477,1479$,
1486-1488, 1490, 1492, 1494-1496, $1503 \mathrm{f}$., 1507 f., 1521,1535 f., $1543-1545,1550$, $1570,1572,1574 \mathrm{f}$

- Nationalrat des Widerstandes (CNR) S. $241^{14}$

- NATO

Dok. 117 und S. 47, 70 f., 134 f., 138, 142, $193 \mathrm{f} ., 208,210,247,256,281,291,316 f$., $322,325,489,536 \mathrm{f}$., $580,717 \mathrm{f}$., 737, 744, 759, 764 f., 790 f., 795, 819-821, 824, 834 f., $837,885-887,899^{10}, 919,932-937,1006$, 1080, 1085-1089, 1104f., 1263-1265, 1323, $1336,1363,1371,1406,1435^{2}, 1475,1496$, 1536

- OAS (Organisation de l'Armée Secrète) S. 31, 238, 241

- Ostblock-Staaten

Dok. 227 und S. 20, 64, 100, $227 \mathrm{f}$., $249 \mathrm{f}$., $361,886,1028,1336,1340,1342,1465 \mathrm{f}$.

- Ost-West-Gespräche S. $317 \mathrm{f}$.

- Parteien

S. 100 f., 222 f., 1353

- Polen

S. $362 \mathrm{f} ., 955 \mathrm{f}$.

- Republik China

S. 43, 98, 194, 319, 365, 612f., 1190

- Republik Korea

S. 223

- Republik Vietnam S. $44 f$., $318 f$., 413 f., 763, 893, 922

- Rumänien S. 729, 926, 955 f., 1020, 1466

- Schweiz S. 218

- Spanien S. 418, $618 \mathrm{f}$.

- strategische Konzeption S. $71,1167 f$., 1314, 1475

- Temporary Travel Documents S. 1058

- Teststopp-Abkommen S. $225 \mathrm{f} ., 318,810$

- Tschechoslowakei S. 956, 1354, 1370, 1464-1466

- Türkei

S. 236 
- UdSSR

S. $20,33,57,95,99,192,196,209,220 f$., 227 f., $249,258,262,272$ f., 320 f., 360 f., $530,545,608-610,761,804-806,843 \mathrm{f}$, $888,891,955,973,1004,1008,1122$, 1224 f., $1268-1271,1341$ f., 1351, 1488, 1526

- USA

Dok. 66 und S. 23, 28 f., 34, 44, 96-98, 112-114, 136-138, 193, 195, 208f., 212, $262,374,390$ f., $413 \mathrm{f}$., $466,621,623,655$, 680 f., $716,718 \mathrm{f}$., 764, 767, 788-791, $794 \mathrm{f}$, 812 f., $819,832,835$ f., $885,887,890,892$, 915, $917 \mathrm{f} ., 924,925^{35}, 932-934,943,974^{13}$, $1006,1030 \mathrm{f}$., $1032,1085-1088,1190 \mathrm{f}$., $1210^{27}, 1219^{10}, 1220,1225,1258$ f., 1261 , $1336 \mathrm{f} ., 1339-1341,1398,1412,1449 \mathrm{f}$., $1477,1487 \mathrm{f}$., $1490-1492,1496,1541 \mathrm{f}$., 1545

- VAR

S. $415,420,734,1298$

- Volksrepublik China

S. $42 \mathrm{f} ., 85,96-100,113,116^{10}, 136-138$, $192,198,205,210-212,214$ f., 223-226, 228,257 f., $281,286,318-321,325,364$ f., $414,530,545$ f., $581,612,646,655,721$, $793,809,820,887,919$ f., $933,974^{13}, 1024$, 1190,1192

- Wahlen

S. 230

- WEU

S. 400 f., 1311

- Wirtschaft

S. 387 f., 478, 571, 745 f., 811

- Zypern

S. $234,259,320,793^{16}$

Frankreich-Bundesrepublik Deutschland

Dok. 8, 11, 44, 45, 46, 47, 48, 49, 51, 75, $133,141,153,154,180,181,182,183,184$, $185,186,187,188,200,210,225,234,244$, $248,249,273,296,297,301,309,311,316$, $318,320,321,351,355,359,364,377,402$ und S. 14, 25-27, 46 f., 68, 140, 154, 272$274,315^{2}, 323,392,401,469,501$ f., 541, $626,636,680$ f., 787-793, 804-806, 808$811,817-819,832,834 \mathrm{f}$., $910,916,926 \mathrm{f}$., 936, 946, 1054, 1057-1060, $1066 \mathrm{f}$., $1103 \mathrm{f}$., $1161,1194,1207,1209,1219^{10}, 1280,1300$,
$1314 \mathrm{f} ., 1326 \mathrm{f} ., 1342-1344,1403,1406$, $1412,1449 \mathrm{f}$., $1459 \mathrm{f} ., 1490 \mathrm{f}$.

- Air-Union-Projekt

S. 1123

- Berlin

S. 5 f., $226,256,1022$ f., 1100 f., 1276 , 1418-1420

- Deutsch-französischer Vertrag vom 22.1. 1963

S. $26,42,110-112,133,136$ f., 192,216 , $226^{18}, 254$ f., $262,281,322$ f., $325,361,377$, 389,713 f., 720 f., $723,736,739,743,750$ f., $753-758,760-762,769,774,784,793$, $807-810,814,816,820$ f., 891, 918, 923$925,947,949,973 f ., 1005,1007,1010$, 1030-1033, 1050, 1109, 1189, 1191, 1234, $1290,1311,1336,1346,1362,1370,1428$, $1447,1474,1579$

- Deutsch-Französisches Jugendwerk S. 250f., 254, 721, 780-782, 786, 1010

- Deutsche Frage und Wiedervereinigung Dok. 113 und S. 90-97, 193, 213-215, $256,318,321,355-360,365,436,442-445$, 448, 465 f., 521, 525, 613 f., 684 f., 698 f., $724,727,739-742,761,771$ f., 887 f., 891 , $973,996,1026$ f., 1033, 1229, 1371, 1384, 1468 f., $1495,1528^{4}, 1530,1532,1533^{22}$, 1542

- Entwicklungshilfe: Kooperation Dok. 97 und S. 242-244, 251-253, 260, 581, 618, 762, 778 f., 886, 920, 1011, 1121

- „Fall Argoud“

Dok. 87 und S. 30-32, 216-220, 238-241, 610,889

- Farbfernsehen S. 253 f., 787

- Informationsaustausch S. 253 f., $785-787$

- Konsultationen Dok. 17, 50, 207, 247, 344 und S. 710 $783,787,810,823,974,1030$ f., 1149,1249 , 1579

- militärische Zusammenarbeit

Dok. 251, 260, 319, 373 und S. 245-248, 254, 742-744, 768, 796f., 809, 885 f., $890^{19}$, $892,919,944$ f., 1011 f., $1030,1187,1229$, $1261,1371,1373,1391$ 
- nukleare Zusammenarbeit Dok. 292 und S. 575, 768, 885, 887, 944 f., $1050,1411,1487,1492,1511$

- Oder-Neiße-Linie

Dok. 222 und S. 442, 886, 891, 919, 949, 955f., 973, 1026-1028, $1033 \mathrm{f}$.

- Städtepartnerschaften S. $1010 f$.

- Streitkräfte in der Bundesrepublik S. 70, 239, 956

- Währungsunion Dok. 85, 109

- wirtschaftliche Zusammenarbeit S. $248-250,744-749,777-780,1123 \mathrm{f}$., $1267,1298 \mathrm{f} ., 1491 \mathrm{f}$.

- Zusammenarbeit in Bildung und Forschung

S. $782 \mathrm{f}$.

\section{Freie Demokratische Partei siehe: FDP}

Freundschaftsvertrag vom 12. 6. 1964 zwischen der UdSSR und der DDR

Dok. 170 und S. 62912, 639f., 644, 646, $651,657,659,663,672$ f., 713,724 f., 727 , $731,732^{53}, 739,741 \mathrm{f} ., 767,842,848,898$, 953 f., $1018,1127,1172,1275^{3}, 1532$

- westliche Reaktion Dok. 166, 167, 175 und S. 725, 728 f., 740, 891

\section{Friedensvertrag mit Deutschland siehe: Deutsche Frage}

GATT (General Agreement on Tariffs
and Trade)
siehe außerdem:
Australien
EWG
Finnland
Frankreich
Großbritannien
Italien
Kanada
Niederlande
Polen
Südafrika
USA
- Bundesrepublik Deutschland
S. 66, 193, 195, 330, 1118f.

- Dillon-Runde S. $484^{18}$

- Kennedy-Runde

Dok. 122 und S. $19^{3}, 48,66$ f., 81 f., 118 , $127,140,193,195,205,227,229$ f., 232 , $235,248,260$ f., 281 f., 284 f., 288, 301, 322 , $330,378,402$ f., $480-484,488,515,558^{14}$, $570-572,611,636,715,745,748 \mathrm{f}$., 792, $811,817,821,836^{21}, 838,874-876,1097$, 1112 f., $1117-1120$, $1161 \mathrm{f} ., 1188,1223-$ $1226,1233^{7}, 1250,1290,1311$ f., 1327 , $1359-1361,1396,1425,1437,1455$, $1456^{24}, 1473$

- Zolldisparitäten

S. 513,1120

Gebrüder Junghans AG siehe: Wirtschaftsunternehmen

General-Anzeiger (Bonn)

S. $170^{1}, 270$

\section{Gesetze und Verordnungen}

- Reichswahlgesetz vom 6. 3. 1924

S. 12,440

- Grundgesetz vom 23. 5. 1949

S. 11, 219, 1057, 1237, 1276 f., 1283, 1516

- Gesetz vom 22. 8. 1950 über die Notaufnahme von Deutschen in das Bundesgebiet

S. 129

- Bundeswahlgesetz vom 7.5. 1956 S. $1276 \mathrm{f}$

- Gesetz vom 27. 7. 1957 gegen Wettbewerbsbeschränkungen (Kartellgesetz) S. 153

- Verordnung vom 18. 12. 1962 über die Ausfuhr von Großrohren (Röhrenembargo)

siehe außerdem: UdSSR-Bundesrepublik

S. 109

- Gesetz vom 16. 11. 1964 zur Änderung des Einkommensteuergesetzes, des Spar-Prämiengesetzes und anderer Gesetze (Steueränderungsgesetz 1964)

S. $778^{4}$

- Gesetz vom 17. 3. 1965 zur Regelung der Verbindlichkeiten nationalsozialisti- 
scher Einrichtungen und der Rechtsverhältnisse an deren Vermögen

S. $198^{36}$

- Zweites Gesetz vom 14. 9. 1965 zur Änderung des Bundesentschädigungsgesetzes

S. $1130 \mathrm{f}$

Gewaltverzicht in territorialen Streitfragen

S. $14,579,1047$

- Vorschlag der UdSSR vom 31.12.1963 S. 73 f., 86-89, 95, 176, 178f., 333, 339

Ghana siehe außerdem: $D D R$

S. 84 f., 858

- Bundesrepublik Deutschland

Dok. 116, 233 und S. 967, 995

- Entwicklungshilfe

S. 499 f., $972^{4}$

- UdSSR

S. 498

Gomulka-Plan vom 29. Februar 1964 siehe außerdem: Abrüstung

Dok. 61, 204 und S. 285, 329, 362 f., 490 , $553,1206,1294-1296,1562 \mathrm{f}$.

Griechenland siehe außerdem:

Bulgarien

Frankreich

OECD

S. 354,568

- Bundesrepublik Deutschland

S. $169,299,494,1368$

- Großbritannien

S. 494

- Italien

S. 493

- MLF

S. 451,1056

- NATO

S. 122, 975-977

- Niederlande

S. $493 \mathrm{f}$.

- Türkei

S. $181,932,977$
- Verteidigungshilfe

Dok. 114 und S. 102, 977

- Zypern: Enosis

S. 169,234 f., $495^{9}, 794,818,1254,1301$ f., 1329,1364 f., 1368

GroBbritannien

siehe außerdem:

Belgien

Frankreich

Griechenland

Großbritannien-Bundesrepublik

S. 563

- Abrüstung und Rüstungskontrolle

S. 58, 184, 1206, 1208f., 1293f., 1296, 1307, 1319, $1391 \mathrm{f}$., 1401, 1552-1554, 1570, 1574

- Afrikanische Staaten

S. 980

- Arabische Staaten

S. 567, 1328

- Atomwaffen

S. $933,1259,1321$ f., 1407

- EFTA

S. 326, 1311

- europäische politische Union

S. $26,27^{10}, 29,34,46,69,79-82,119,133$, 135 f., 138, 140-143, 206, 209, 214, 256, 280-282, 285, 290, 301, 325 f., 487 f., 710 , $751-754,757,760,771,828 f$., 833 f., 918, $922,1007^{19}, 1029,1050,1092,1095 \mathrm{f}$., 1103 f., 1141 f., $1313-1315,1345^{7}, 1430 \mathrm{f}$., $1444 \mathrm{f} ., 1451 \mathrm{f}$.

- europäisches Patentrecht S. $632,674,1123$

- EWG

S. 29 f., $45,47-49,68 f$., $81,110^{6}, 111,119$, 127,134 f., 139, 142, 193, 206, 283, 324, $390,402,483,571$ f., 631 f., $767,807,815$, $820,829^{22}, 834,889,1033,1088,1096$, $1313,1315,1345^{7}$

- GATT

S. 66 f., 1311

- Indonesien

S. $82 \mathrm{f}$.

- Israel

S. 1377

- Italien

S. $142,1213^{1}$ 
Großbritannien-Bundesrepublik Deutschland

- Konservative Partei

S. $34,48,134$ f., 205 f., $281,833,1173^{4}$, $1495,1501,1511$

- Kuba

S. $227,288,654$

- Labour Party

S. $34,48,134$ f., $155,156^{21}, 206$ f., 281,560 , $673^{17}, 750,829,833$ f., 891 f., 1099, 1132 , $1206,1331,1392,1444,1454,1495,1548$

- Malaysia

S. 82 f., 209, 213, 682

- MLF

Dok. 146, 305 und S. 48, 71 f., $124^{15}, 142$, $154-156,214,374,375^{4}, 429,450-453$, $489,560,674,691-693,838-840,982^{6}$, $1052 \mathrm{f}$., $1056,1079,1098 \mathrm{f}$., $1110,1147 \mathrm{f}$., 1156, 1218 f., 1221, 1249, 1285-1287, 1301, $1305,1309,1326^{8}, 1329-1333,1352,1363$, 1372,1385 f., $1388 \mathrm{f}$., $1392^{5}, 1393,1394^{8}$, 1399-1402, 1405, 1407, 1409, 1411 f., 1436 , $1443-1445,1453 \mathrm{f} ., 1486,1495 \mathrm{f} ., 1499$ 1508, 1510-1514, 1520f., 1535, 1541, 1543-1555, 1567, 1570, 1574-1576

- NATO

S. 560,813 f., $933,1086,1401,1406,1445$

- Ostblock-Staaten S. 7 f., 32,64 f., $227,361,1319$ f.

- Polen S. 1563

- strategische Konzeption S. $1167 \mathrm{f}$.

- Temporary Travel Documents S. 406

- Türkei S. 1303

- UdSSR

S. $8,20,56$ f., 64 f., $73,78,97,209,273$, 609 f., $671,673^{17}, 805,840-842,844$, $1052 \mathrm{f} ., 1122,1211,1269,1316 \mathrm{f} ., 1352$, $1443,1493,1498,1506^{21}, 1510,1526,1530$

- Unterhaus S. $64,1401,1409,1443 \mathrm{f} ., 1495,1510$

- USA S. $209,262,435,655,1218$ f., 1256,1259 , $1286,1326,1403,1405,1408,1436,1488$, 1499-1501, 1567, 1574-1576

- VAR

S. 415,420
- Volksrepublik China S. $42,85,99,546$

- Währungskrise S. 1399, 1404 f., 1407, 1436, 1488

- Wahlen S. $47 \mathrm{f}$., $81 \mathrm{f}$., $134 \mathrm{f}$., $138,141,155,193$, 206 f., $256,280-282,301,326,428,443$, $451,511,529,548,560,580,674,710,714$, $736,815,821$ f., $829,833,837-839,891$, $1056,1091,1095,1173^{4}, 1220,1324,1329$, 1405

- WEU

Dok. 89 und S. $26,142,838,1095,1117$, 1311-1315, 1451

- Zahlungsbilanz S. 9,496

- Zypern

S. 83, 169 f., 209, 347, 1302, 1365

\section{Großbritannien-Bundesrepublik}

Deutschland

Dok. 2, 12, 13, 14, 15, 137, 165, 199, 334, $335,336,362,372,381,382,383$ und S. 168-170, 205, 265, 344, 392, 399-401, $593 \mathrm{f}$., $604,844,1053,1057-1060,1123,1165$, $1173-1175,1194,1221,1257,1296,1330$, 1363, 1399-1402, 1409, 1412

- Berlin

S. 5 f., $380,685,1100$ f., $1276,1418-1420$, 1513

- Deutsche Frage und Wiedervereinigung Dok. 99 und S. 50-55, 74-78, 442-445, 464-466, 491 f., 519 f., 524 f., $530,532,673$, $996,1038,1309 \mathrm{f} ., 1493 \mathrm{f} ., 1528^{4}, 1530-$ 1532

- Devisenausgleich

Dok. 115, 145, 190, 208 und S. $7^{1}, 8 \mathrm{f}$., 61 f., 810, 840, 1318f., 1446, 1509, 1566

- Entwicklungshilfe: Koordinierung S. 72,1319

- Jugendaustausch S. 1316,1497

- Kulturbeziehungen S. 62,85

- Truppenstationierung S. 247, $758 \mathrm{f}$.

- Wiedergutmachung S. 573 
Guinea

siehe außerdem:

$D D R$

S. 732

- Ausrüstungshilfe

S. 103,979 f., 1175 f., 1377

- Bundesrepublik Deutschland Dok. 293

- UdSSR

S. 1176

Haaretz (Tel Aviv)

S. 271

\section{Hallstein-Doktrin}

Dok. 171 und S. $94,214^{48}, 225,287 \mathrm{f}$. 327 f., 338-340, 351, 384, 459, 465, 732 2 , $799,853,1482$

Heiliger Stuhl

S. 462-464, 1058

- Bundesrepublik Deutschland Dok. 229, 346

- Diözesangrenzen S. $1357 \mathrm{f}$.

- Polen S. 463,960

- Temporary Travel Documents S. 1058

- UdSSR S. 463

Hermes-Bürgschaften S. $926,946^{5}, 962^{3}, 1195$ f., 1297,1335 , $1416 \mathrm{f}$.

Herter-Plan vom 14. Mai 1959 siehe: Deutsche Frage

\section{Hochtief AG} siehe: Wirtschaftsunternehmen

\section{Hongkong}
S. 252

\section{Indien}

siehe außerdem: $D D R$

S. 858, 1144, 1204, 1208, 1511, 1540

- Abrüstung und Rüstungskontrolle S. $982^{2}, 1048-1050,1051^{20}, 1052^{10}$

- Afrikanische Staaten S. 980
- Atomwaffen

S. 1449

- Bundesrepublik Deutschland Dok. 65 und S. $1048^{15}$

- Entwicklungshilfe S. $313,567,799$

- MLF

S. $982^{2}$

- UdSSR

S. 1353

- Volksrepublik China S. 647,980

Indonesien siehe außerdem: Großbritannien

S. $213,224,542,859,949,1026,1028$

- Bundesrepublik Deutschland S. 83,995

- Malaysia S. 82 f., 980

- Niederlande S. $537^{18}, 931$

- USA S. 83

Interamerikanische Bank S. $426 \mathrm{f}$.

International Council of Scientific Unions S. 406

Internationale Atomenergie-Organisation siehe: Abrüstung

Internationaler Währungsfonds S. $117,390,479,557-561,571,1356$

Internationales Olympisches Komitee S. $781 \mathrm{f}$.

Interzonenhandel

Dok. 96 und S. 21, 91, 197, 308, 327, 409, $548,851,1579$

- Arbeitsgemeinschaft Interzonenhandel S. $1273^{3+4}$

- Düngemittel-Lieferungen der Bundesrepublik Deutschland an die DDR S. 988

- Interministerieller Ausschuß Dok. 278 
- Kredite der Bundesrepublik Deutschland an die DDR

S. $13,52,425,1140$

- Leopold-Behrendt-Gespräche S. 424

- Swing

S. $1139 \mathrm{f}$.

- Treuhandstelle S. $5^{8}, 92,129,309$ f., 410,986 f., $989^{22}$, 1138

\section{Irak \\ siehe außerdem: \\ Arabische Staaten \\ S. 1050}

\section{Iran}

siehe außerdem:

Arabische Staaten

S. $127,645,1050$

\section{Irland}

- Abrüstung und Rüstungskontrolle S. $186^{4}, 1045-1047$

- UNO

S. 347,583

Island

S. 1058

\section{Israel}

siehe außerdem:

Frankreich

Großbritannien

Israel-Bundesrepublik

- Ableitung des Jordanwassers S. $395,422,567$

- Afrikanische Staaten S. 980

- Arabische Staaten S. $422,567,650,774,1242,1377$ f., 1481 , 1556

- EWG

S. $126 \mathrm{f} ., 396,734$

- Italien S. 653,656

- Jordanien S. 670

- Jugoslawien S. 1334
- Knesseth

S. $1133,1236,1240$

- Syrien

S. 1328

- UdSSR

S. 1334

- UNO

S. 1378

- USA

S. $416,567,734,1238,1377,1534$

- VAR

S. $165,459,670,1377 \mathrm{f}$.

Israel-Bundesrepublik Deutschland

Dok. 25, 83, 88, 230, 276, 312 und S. 162 , $164,423,999,1297 \mathrm{f}$.

- Aktion „Geschäftsfreund"

Dok. 76 und S. 396 f., 734 f., 962, 1246

- Ausbildungshilfe

S. $270^{5}, 1166,1228,1246$

- Boykott deutscher Firmen S. $962 f$.

- diplomatische Beziehungen

Dok. 73 und S. $160^{4}, 398 f$., 415 f., 459 , $907 \mathrm{f}$., $1183 \mathrm{f}$., $1216,1229,1244,1246 \mathrm{f}$., $1282,1328,1334,1376,1480 \mathrm{f}$., 1515 , $1516^{5}, 1555,1556^{5}, 1557^{3}, 1558$

- Handelsvertretungen S. 1228,1246 f., 1282 f., $1334,1480,1556$

- Oder-Neiße-Linie S. 963

- Rüstungsfachleute aus der Bundesrepublik in der VAR

Dok. 214, 313 und S. 396-398, 422, 460, $964 \mathrm{f} ., 1133 \mathrm{f}$., $1183,1216,1228,1236 \mathrm{f}$., $1243,1246^{11}, 1328$

- Sonderprojekt „Frank./Kol.“

Dok. 289, 396

- Verjährung nationalsozialistischer Gewaltverbrechen

S. 1131-1133

- Waffenlieferungen

Dok. 54, 138, 151, 179, 306, 308, 314, 388, 395 und S. 103, 190, 396, 398, 567 f., 653, $656,659,670,694^{2}, 962,1236 \mathrm{f} ., 1244-$ $1246,1282 \mathrm{f} ., 1328,1333,1356^{2}, 1480 \mathrm{f}$.

- Wiedergutmachung S. $198,649,653,1130 f$. 
- Wirtschaftshilfe Dok. 295 und S. $1356^{2}$

- Wissenschaftler aus der Bundesrepublik in Israel S. 1237,1378

Italien siehe außerdem:

Frankreich

Großbritannien

Israel

Italien-Bundesrepublik

S. $591,750,1208$

- Abrüstung und Rüstungskontrolle S. $60 \mathrm{f}$.

- Europarat S. $1350 \mathrm{f}$.

- europäische politische Union S. 33 f., $80,82,120,135$ f., 138-143, 206 f., $237^{4}, 281,325,736,756,809,814,824$, 826 f., 832,1006 f., 1067, 1424-1432, 1438, 1451-1453

- EWG

S. $139,144-146,235,418 f$ f., 559,869 f., $1114,1361,1455 \mathrm{f}$.

- GATT

S. 195,261

- Jugoslawien

S. 158

- MLF

Dok. 283 und S. 120-124, 142, $154 \mathrm{f}$, 195 f., 214, 283, 429, 451, 489, 560, 1054, $1056,1079,1089^{4}, 1090,1098,1110$ f., $1156,1163^{4}, 1214^{8}, 1222,1291 \mathrm{f} ., 1393$, $1401,1444,1453-1455,1478,1488,1536$, $1550,1574-1576$

- NATO

S. $140,142,813$ f., 1067, 1086, 1452

- Österreich

S. $1120^{26}, 1456$

- Parteien S. $121,134,141,143,149-152,195,207$, $283,325,1353,1453$

- Spanien S. 147,418 f., 620

- Temporary Travel Documents S. 406,1058

- UdSSR

S. 805,844
- UNO

S. 345,564

USA

S. 139, 141 f., 154, 558-560

- VAR

S. 421

- Währungsprobleme

S. 558-560, 571

Italien-Bundesrepublik Deutschland

Dok. 27, 28, 29, 223, 257, 265, 271, 375 und S. 25, 121-124, 195 f., 206 f., 1213 f., $1291 \mathrm{f} ., 1393$

- Deutsche Frage und Wiedervereinigung S. 140,1455

- Entwicklungshilfe: Kooperation S. $144 \mathrm{f}$.

- italienische Arbeitnehmer in der Bundesrepublik Deutschland

S. 145 f., 148, 151 f.

- Kulturbeziehungen

S. $143 \mathrm{f}$.

- Wirtschaftsbeziehungen

S. 144 f., 147 f., 152

Izvestija (Moskau)
S. $214^{47}, 329^{37}, 1009^{29}$

Japan

S. 99

Atomwaffen

S. 1204, 1449

- Bundesrepublik Deutschland

Dok. 203 und S. 589 ${ }^{15}, 590$

- Republik Korea

S. 1458 f., 1461

- UdSSR

S. 564,805

- UNO

S. 564

Jemen

siehe außerdem:

Arabische Staaten

$D D R$

- Bundesrepublik Deutschland

S. 162

- VAR

S. $162,1238,1481$ 


Jerusalem Post
S. 271,670
Jordanien
siehe außerdem:
Arabische Staaten
Israel
S. $103,670,1482$
Jugoslawien
$\quad$ siehe außerdem:
DDR
Frankreich
Israel
Italien
Jugoslawien-Bundesrepublik
- UdSSR
S. 471,731 f., 900
- UNO
S. 1002
- USA
S. 470

Jugoslawien-Bundesrepublik Deutschland Dok. 107 und S. 448, 731 f., 740 f., 1021

- Deutsche Frage und Wiedervereinigung Dok. 77, 243 und S. 470, 472-474, $995 \mathrm{f}$.

- diplomatische Beziehungen S. $327,363,368,470^{4}, 472,853,860$

- Kroatische Emigrantenorganisationen S. 364, 368-370, 474

- Kulturbeziehungen S. 472,474

- Wiedergutmachung S. $363^{52}, 367-369,470^{4}, 472$ f., 1002,1467

- Wirtschaftsbeziehungen S. 363 f., 368 f., $472-474,689,995,1467$

- „Wohlverhaltensklausel“ S. 1001

\section{Kambodscha} siehe außerdem: $D D R$ Frankreich

S. 211 f., $257,319,622,624,858$

\section{Kamerun}

S. $778 f$.

\section{Kanada}

S. $66,119,798,1208,1537$
- Bundesrepublik Deutschland Dok. 157 und S. 724 f.

- EWG S. 636

- GATT S. 513

- MLF S. 637

- NATO S. 534 f., 930

- Schweden S. 635

- Türkei S. 635

- UdSSR S. 635

- UNO S. $347,583,642$

- Volksrepublik China S. 724

\section{Kenia} siehe außerdem: Äthiopien

S. 84 f., 1387

- EWG S. 403,1121

- Somalia S. 84

Kennedy-Runde siehe: GATT

Klöckner-Humboldt-Deutz AG siehe: Wirtschaftsunternehmen

Kölner Rundschau am Sonntag S. $1033^{12}$

Kolumbien S. 446

Kommunistische Partei Deutschlands siehe: $K P D$

Konferenzen und Verhandlungen

- Konferenz der Staats- und Regierungschefs Großbritanniens, der USA und der UdSSR vom 4. bis 11.2. 1945 in Jalta S. 210, 917

- Konferenz der Staats- und Regierungschefs Großbritanniens, der USA und der 
UdSSR vom 17. 7. bis 2. 8. 1945 in Pots- - Tagung des NATO-Ministerrats vom 22. dam
S. $1251^{4}$
S. 937

bis 24. 5. 1963 in Ottawa

- Indochina-Konferenz vom 26. 4. bis 21. 7. - Tagung des WEU-Ministerrats am 25./ 1954 in Genf

S. 212,922

26. 10. 1963 in Den Haag

S. 400

- Neun-Mächte Konferenz vom 28. 9. bis - Tagung des NATO-Ministerrats am 16./ 3. 10. 1954 in London S. $69^{33}, 137^{27}, 179^{24}, 935$ 17. 12. 1963 in Paris

S. 51

- Konferenz der afroasiatischen Staaten vom 18. bis 24. 4. 1955 in Bandung S. 313

- Konferenz der Staats- und Regierungschefs der Vier Mächte vom 18. bis 23.7 . 1955 in Genf

S. $1170 \mathrm{f}$.

- Zypernkonferenz vom 17. bis 19. 2. 1959 in London S. $234^{9}$

Konferenz der Staats- und Regierungschefs der arabischen Staaten vom 13. bis 16. 1. 1964 in Kairo

S. $421 \mathrm{f}$

Konferenz vom 15. 1. bis 8. 2. 1964 in London zur Lösung des Zypern-Konflikts

S. $115,169^{5}$

- Außenministerkonferenz der Vier Mächte vom 13. 5. bis 20. 6. und vom - Bilderberg-Konferenz vom 20. bis 22. 3. 13. 7. bis 5. 8. 1959 in Genf S. 53,355 1964 in Williamsburg S. 263

- Tagung der Regierungschefs der EWGStaaten am 10./11. 2. 1961 in Paris S. $206^{17}$

- Tagung der Signatarstaaten des GATT vom 24. 2. bis 20.3.1964 in Genf

Laos-Konferenz vom 14. 5. 1961 bis 23.7. 1962 in Genf S. $211^{37}$

- Tagung der Regierungschefs der EWGStaaten am 18. 7.1961 in Bonn S. $206^{17}$

Botschafterkonferenz der blockfreien Staaten vom 23. bis 28. 3. 1964 in Colombo

S. $312,357,994^{7}$

- UNO-Konferenz für Handel und Entwicklung vom 23. 3. bis 16. 6. 1964 in Genf (Welthandelskonferenz)

Dok. 144 und S. 146, 365, 378, 446, 499 f., $572,648 \mathrm{f} ., 715,722,778 \mathrm{f}$.

- Tagung des Interamerikanischen Wirt- - Konferenz am 10. 4. 1964 in Djakarta schafts- und Sozialrats vom 5 . bis 17.8 . 1961 in Punta del Este S. 242 zur Vorbereitung einer afroasiatischen Konferenz S. $421^{17}$

- Gründungskonferenz der Blockfreien - Ministerratstagung der SEATO vom 13. Staaten vom 1. bis 6.9.1961 in Belgrad S. 312 f., $471 \mathrm{f}$., $474,1002,1415^{8}$ bis 15.4.1964 in Manila S. $491^{4}$

- Tagung des NATO-Ministerrats vom 13. - Tagung des WEU-Ministerrats am 16./ bis 15. 12.1962 in Paris S. 75 17. 4. 1964 in Brüssel S. $399,401,423,430,436$

- Tagung des EWG-Ministerrats am 28./ - Tagung der assoziierten afrikanischen 29. 1. 1963 in Brüssel S. $48^{1}$ Staaten vom 20. bis 27. 4. 1964 in Paris S. 252

- Ministerkonferenz der GATT-Vertrags- - Tagung des Ministerrats der CENTO am partner vom 16. bis 21. 5. 1963 in Genf S. 49 28./29. 4. 1964 in Washington S. 432 
- Tagung der Internationalen Kaffeeorganisation im April 1964 in London S. $446 \mathrm{f}$.

- Ministertagung des Ausschusses für Handelsverhandlungen im Rahmen des GATT (Kennedy-Runde) vom 4. bis 6. 5 . 1964 in Genf

S. 411

- Tagung des NATO-Ministerrats vom 12. bis 14. 5. 1964 in Den Haag

Dok. 127 und S. 269, 525, 551, 624, 737, $739,930,935,1435$

- Konferenz der Regierungschefs der Kongo Commonwealth-Staaten vom 8. bis 15.7 . 1964 in London

S. 996

- Tagung des WEU-Ministerrats am 16./ 17. 7.1964

S. $1134 \mathrm{f}$.

- Konferenz der Staats- und Regierungschefs der Organisation der Afrikanischen Einheit vom 17. bis 21. 7. 1964 in Kairo

S. $457,725,729,732,740,993,1144^{6}, 1201$

- Tagung der Interparlamentarischen Union vom 20. bis 28. 8. 1964 in Kopenhagen

S. $997,1196^{6}$

- Europäische Rektorenkonferenz vom 2. bis 8.9.1964 in Göttingen

S. 1010

- Konferenz der Staats- und Regierungschefs der arabischen Staaten vom 5. bis 11.9.1964 in Alexandria

S. $421,457,993$

- Pugwash-Konferenz für Wissenschaft und Weltangelegenheiten vom 13. bis 19. 9. 1964 in Karlsbad

S. 1206

- Konferenz der blockfreien Staaten vom 5. bis 10 . Oktober 1964 in Kairo

S. $355,357,368,382,415,421 \mathrm{f}$., $446,457 \mathrm{f}$., $499,649,653,688,725,800 \mathrm{f}$., 994, 997, $1000-1002,1049 \mathrm{f}$., $1126 \mathrm{f} ., 1129,1142$, $1144 \mathrm{f} ., 1150,1153^{11}, 1196^{6}, 1201,1203$, $1245,1284,1415^{8}$

- Tagung des EWG-Ministerrats am 14./ 15. 12.1964 in Brüssel

S. $1396^{18}$
Tagung des NATO-Ministerrats vom 15. bis 17. 12.1964 in Paris

S. 1364,1497

- Konferenz der Regierungschefs der Arabischen Liga vom 9. bis 12. 1. 1965 in Kairo

S. 1482

- Konferenz der Staats- und Regierungschefs der Organisation der Afrikanischen Einheit vom 21. bis 26. 10. 1965 in Accra

S. 1379

\section{siehe außerdem: Belgien}

- Bundesrepublik Deutschland S. $562,968-970$

- Kongo-Krise

S. 345

- UNO

S. 583

- USA

S. $968-970$

- Volksrepublik China S. 968

Korea

siehe:

Demokratische Volksrepublik Korea

Republik Korea

KPD (Kommunistische Partei Deutschlands)

S. $150,664 \mathrm{f}$.

\section{Kuba}

siehe außerdem:

$D D R$

Frankreich

Großbritannien

S. $32,224,690$

- Bundesrepublik Deutschland S. $19,193,229,263,288,327,516,653,853$, 860

- Kuba-Krise von 1962

S. $90^{2}, 318,322,468,537,601,718,924$, 931, 1382, 1475

- Niederlande

S. 288

- Spanien

S. 19 
- UdSSR

S. 243,549

- USA

S. $19^{4}, 21,204,208,227,522,529,549,645$

Kuratorium Unteilbares Deutschland siehe: Deutsche Frage

Kuwait

siehe außerdem:

Arabische Staaten

S. 1356

Laos

siehe außerdem:

Demokratische Republik Vietnam

Frankreich

S. 211 f., $257,319,549,622,683,932$

- USA

S. $581,621,623$

- Volksrepublik China

S. 414,646

Lateinamerika siehe außerdem:

EGKS

Frankreich

USA

WEU

S. $252 f ., 413$

- Bundesrepublik Deutschland Dok. 102 und S. 241 f., 259

- Entwicklungshilfe

S. 322 f., 617

- kernwaffenfreie Zone S. 1402

Le Monde (Paris) S. $318^{14}, 443,885,1008^{7+8}, 1025^{2}, 1029^{22}$, $1034,1327^{14}, 1435^{2}, 1487^{13}$

Libanon

S. $931,1164^{4}, 1378$

Liberia

S. 971

Luxemburg

- Bundesrepublik Deutschland S. $286^{33}$

- europäische politische Union S. $736,814,824,832,1438$

- EWG

S. 286f., 912-914
Madagaskar

S. 103,1050

Malawi

siehe außerdem: $D D R$

S. $854^{25}, 967$

Malaysia

siehe außerdem:

Großbritannien

Indonesien

S. $224,258,319,516,563,932,1013$

\section{Mali}

siehe außerdem: DDR

S. 732, 1202

- Ausrüstungshilfe

S. $105^{19}, 106,191$

Marokko

siehe außerdem:

Arabische Staaten

S. 563, 1050

- Bundesrepublik Deutschland

Dok. 378

- Spanien

S. 619

- VAR

S. 1481

"massive retaliation"

siehe: NATO

Mexiko

siehe außerdem:

Frankreich

S. $194,322,1048 \mathrm{f} ., 1208$

Militärhilfe

siehe:

Ausrüstungshilfe

Verteidigungshilfe

MLF (Multilateral Force)

siehe außerdem:

Atomwaffen

Belgien

Blockfreie Staaten

Dänemark

Frankreich

Griechenland

Großbritannien

Indien

Italien

Kanada

Niederlande 
Norwegen

UdSSR

\section{USA}

Dok. 238 und S. 28, 184-186, 297, 636, $721,808,812,933,1209,1354,1562$

- „Atlantic Nuclear Force“ (ANF)

Dok. 393 und S. 1306, 1332, 1495, 1499 1508, 1511-1514, 1535f., 1570, 1572, $1576 \mathrm{f}$.

- Bundesrepublik Deutschland

Dok. 79, 104, 254, 261, 262, 263, 327, 354, 357, 384 und S. $47 \mathrm{f}$., $71 \mathrm{f}$., 111, 121-124, $137,154-156,174,176-178,187,195 \mathrm{f}$. 246, 256, 284, 301f., 323, 329, 411, $428 \mathrm{f}$., $467,489,554,576^{3}, 594,602,637,652 \mathrm{f}$. $693,695 \mathrm{f}$, $762,768,830,834,837,839$, $841,888,890,937 \mathrm{f} ., 982^{6}, 1033,1046 \mathrm{f}$. $1050,1089^{4}, 1090,1098-1100,1104,1109$ $1111,1147-1149,1154,1163,1174^{9}, 1180$, $1185 \mathrm{f} ., 1189,1199,1211,1213 \mathrm{f} ., 1219$ $1222,1234^{13}, 1235,1249,1256 \mathrm{f}$., $1259 \mathrm{f}$., 1263-1265, 1291f., 1300, 1304-1309, 1315, 1322, 1324-1327, 1329-1333, 1362, 1390, $1392^{5}, \quad 1400-1403,1408 \mathrm{f} ., \quad 1411-1414$, $1435 \mathrm{f}$., $1443 \mathrm{f}$., $1449 \mathrm{f}$., $1454 \mathrm{f}$., $1474-1479$, 1485-1492, 1494, 1500, 1502-1508, 1510 $1513,1519-1526,1536,1541-1543,1545-$ $1555,1574-1576$

- Demonstrationsschiff S. $142,300,450$

- Einsatzregelung

S. 71, 283, 982f., 1047, 1055, 1079, 10894, $1090,1111,1154 \mathrm{f}$., $1185 \mathrm{f}$., 1258f., $1306 \mathrm{f}$., $1330-1332,1388^{4}, 1412,1450,1476,1489$, 1495, 1499 f., 1504, 1547, 1550 f., 1555

- Europäisierungsklausel

Dok. 23, 288, 330 und S. 451, 1110f., $1149,1156^{7}, 1185 \mathrm{f}$., $1189,1306,1323 \mathrm{f}$. $1331 \mathrm{f}, \mathrm{1343}, 1389,1393,1450,1552$

- Finanzierung

S. $451-453,1046,1089^{4}, 1502,1548$

- gemischte Besatzungen

S. $1306,1363,1372,1388^{4}, 1393,1400$, $1443,1454,1488,1500,1503,1505,1507 \mathrm{f}$. $1512,1541,1544-1546,1550,1555,1577$

- MLF-Arbeitsgruppe

Dok. 284 und $S .48^{12}, 72,121,123 f$., 429 , $449-456,691-693,838^{10}, 1051,1053^{15}$, 1082,1148 f., 1400 f., $1545-1553$
- MLF-Charta

S. $1148 f$., 1155 f., 1163

- Nassau-Abkommen

S. $453,767,918,922,1309^{18}, 1388^{4}, 1406$, 1513

- NATO-Anbindung

S. 1078, 1081, 1214, $1286 \mathrm{f} ., 1372,1393$, $1401,1454,1486 \mathrm{f}$., 1504 f., 1549

- politische Kontrolle S. 123 f., 450 f., $454,982,1323,1547-1552$, 1577

Revisionsklausel

S. 1292, 1552

- Struktur

Dok. 172 und S. 452 f., $838^{10}, 839,1053$, 1214, 1219, 1305-1308, 1363, 1393, 1399f., $1414,1436,1454 \mathrm{f}$., $1486,1488,1495$, 1500f., 1503, 1505-1508, 1512, 1544-1547, 1555, 1577

Mongolische Volksrepublik

S. 1128

Montanunion

siehe: $E G K S$

Montecatini Società Generale siehe: Wirtschaftunternehmen

Mosambik siehe außerdem: Portugal

S. 979

Münchener Abkommen vom 29. September 1938

S. $1029,1124^{2}$

- Rechtswirksamkeit

Dok. 147 und S. 579, 730, 1019 f., 10621065, 1354f., 1383, 1463-1465

Multilaterale Atomstreitmacht der

NATO

siehe: $M L F$

Nationalchina siehe: Republik China

National-Zeitung und Soldaten-Zeitung

(München)

S. $1183^{7}, 1281,1288$

NATO (North Atlantic Treaty Organisation)

siehe außerdem:

Belgien

Berlin 
Frankreich

Griechenland

Großbritannien

Italien

Kanada

$M L F$

Nichtangriffsabkommen

Niederlande

Norwegen

Portugal

Tschechoslowakei

Türkei

UdSSR

USA

S. $28,74,87 \mathrm{f}$., $118 \mathrm{f}$., $224,295,326^{16}, 329 \mathrm{f}$., 345, 812, 826, 1093, 1103, 1369 f., $1458 \mathrm{f}$.

- Abrüstung und Rüstungskontrolle S. 58, 199 f., 297, 507-509

- Athener "nuclear guidelines“ S. $124^{15}, 536,936,1321$

- Atlantischer Nuklearrat S. 1321-1323, 1330

- Bericht der "Drei Weisen“ vom 4. 12. 1956 über nicht-militärische Zusammenarbeit

S. 534, 929

- Bundesrepublik Deutschland

Dok. 149, 220, 269, 348 und S. 177 f., 204, $297,323,336-338,340,346,535,633 \mathrm{f}$., 637 f., 717, 744, 762, 764 f., 770, 775 f., 790 , $813,824,888,890,899,969,976,1055 \mathrm{f}$., $1086,1167-1169,1321$ f., 1522

- Dreier-Direktorium S. 291,316 f., $934,1079^{6}, 1080^{6}, 1085-1087$

- Exekutivausschuß S. 813

- „flexible response“ S. $70^{34}, 1105,1168,1262,1263^{6}, 1478$

- "massive retaliation“ S. $70^{34}, 932,1168$

- NATO-Vertrag vom 4. 4. 1949 S. 9,717 f., 770,928 f., 934 f., 1111,1154 , 1324

- Ostblock-Staaten: Kreditpolitik S. $7^{3}, 262$ f., $273^{7}, 635,930$

- politische Konsultationen S. 932

\section{- SACEUR}

S. $71,452^{14}, 600,937,983,1055,1078$, $1081,1214,1286,1325^{5}, 1362,1400-1402$, $1454,1487,1501,1504-1506,1513^{2}, 1514$, $1546,1549 \mathrm{f}$.

- Standing Group

S. 245,937

- strategische Konzeption (MC 100/1)

Dok. 290 und S. 70 f., 934, 937, 1078$1080,1083,1104,1186,1325,1330$ f., 1401 , 1475 f., 1575

- Streitkräfteplanung („Stikker exercise“) S. 452

- Vorwärtsverteidigung

S. $70,502,538,929$ f., 937

Neue Rheinische Zeitung (Köln)

S. 1089

Neue Zürcher Zeitung

S. $732^{48}, 1064^{11}, 1084,1213^{1}, 1254^{16}, 1484$

Neues Deutschland (Ost-Berlin)

S. $161^{5}, 214^{48}, 311^{5}, 850^{11}, 971^{1}, 991^{7}$, $1151^{6}, 1352^{34+35+37}$

Neuseeland

S. $66,513,655$

Nichtangriffsabkommen zwischen

NATO und Warschauer Pakt siehe außerdem: Abrüstung

S. $60,61^{38}, 469,1073,1171,1206,1530$

Niederlande siehe außerdem:

Indonesien

$K u b a$

S. 570,591

- Abrüstung und Rüstungskontrolle S. 285,866

- Bundesrepublik Deutschland

Dok. 59, 266, 279 und S. $24^{5}$, 264 f., 300 f., 496, 631, 1103 f., $1112 \mathrm{f}$.

- europäische politische Union

S. $80-82,207,281$ f., 284 f., 290,300 f., 710 , $736,753,756,809,814,822-824,826-829$, 831 f., 1006 f., 1093-1097, 1104, $1141 \mathrm{f}$., 1234,1438

- europäisches Parlament S. $1097 \mathrm{f}$.

- EWG

S. $145^{23}, 281$ f., $286-289,301,418,631$ f., $911 \mathrm{f} ., 1094,1096-1098,1118,1120$ 


\begin{tabular}{|c|c|}
\hline & $\begin{array}{l}\text { GATT } \\
\text { S. } 301\end{array}$ \\
\hline - & $\begin{array}{l}\text { MLF } \\
\text { S. } 283 \mathrm{f} ., 300 \mathrm{f} ., 692 \mathrm{f} ., 1054,1056,1098- \\
1100,1291,1445^{13}, 1488,1550,1574 \mathrm{f} .\end{array}$ \\
\hline - & $\begin{array}{l}\text { NATO } \\
\text { S. } 291,534\end{array}$ \\
\hline - & $\begin{array}{l}\text { Parteien } \\
\text { S. } 1098 \mathrm{f} \text {. }\end{array}$ \\
\hline - & $\begin{array}{l}\text { Spanien } \\
\text { S. } 418\end{array}$ \\
\hline - & $\begin{array}{l}\text { UdSSR } \\
\text { S. } 1099\end{array}$ \\
\hline - & $\begin{array}{l}\text { USA } \\
\text { S. } 1100\end{array}$ \\
\hline - & $\begin{array}{l}\text { Volksrepublik China } \\
\text { S. } 42,546\end{array}$ \\
\hline - & $\begin{array}{l}\text { WEU } \\
\text { S. } 838,1134 \mathrm{f} .\end{array}$ \\
\hline - & $\begin{array}{l}\text { Zypern } \\
\text { S. } 291\end{array}$ \\
\hline & ger \\
\hline
\end{tabular}

Nigeria

S. 403, 1048 f., 1120, 1208

Nordatlantikpakt-Organisation siehe: NATO

Nord et Sud Aviation siehe: Wirtschaftsunternehmen

Nordvietnam siehe: Demokratische Republik Vietnam

\section{Norwegen}

S. 563, 591

- EWG

S. 30

- MLF

S. $1520^{8}, 1575$

- NATO

S. $\mathbf{5 3 4 ,} 930$

- Spanien

S. 621

- Temporary Travel Documents S. $405 \mathrm{f}$.

- UdSSR

S. 749
- UNO

S. 583

- Volksrepublik China

S. 546

Noten und Memoranden

- Note der UdSSR vom 23. 10. 1954 an die Drei Mächte zur Einberufung einer AuBenministerkonferenz der Vier Mächte S. $177^{19}$

- Note der UdSSR vom 27. 11. 1958 an die Westmächte („Berlin-Ultimatum“) siehe: Berlin

- Memorandum der UdSSR vom 17. 2. 1961 an die Bundesrepublik Deutschland zur Deutschland- und Berlin-Frage S. 385

- Memorandum der UdSSR vom 27. 12. 1961 an die Bundesrepublik Deutschland zur Deutschland- und Berlin-Frage S. 627

- Memorandum der Bundesrepublik Deutschland vom 21. 2. 1962 an die UdSSR zur Deutschland- und BerlinFrage

S. $626 \mathrm{f}$.

- Protestnote der Föderativen Volksrepublik Jugoslawien vom 30.11. 1962 an die Bundesrepublik Deutschland gegen das Attentat auf das Gebäude der Abteilung für die Wahrnehmung jugoslawischer Interessen in der ehemaligen jugoslawischen Botschaft in Bonn

S. $364^{55}$

- Noten der Bundesrepublik Deutschland vom 11. 3. 1963 an die Föderative Volksrepublik Jugoslawien über Fragen der Wiedergutmachung und die Entschädigung für Opfer von Menschenversuchen sowie Wirtschaftsbeziehungen

S. 473

- Noten der UdSSR vom 8. 4. 1963 an die USA, das Vereinigte Königreich von Großbritannien und Nordirland und die Bundesrepublik Deutschland zur MLF S. $284^{24}, 577$

- Note der Bundesrepublik Deutschland vom 10. 5. 1963 an die UdSSR zur Repatriierung Deutscher aus der UdSSR

S. 700 
- Noten der USA, des Vereinigten Königreichs von Großbritannien und Nordirland sowie der Bundesrepublik Deutschland vom 18. 5. 1963 an die UdSSR zur MLF

S. 577

- Note der Bundesrepublik Deutschland vom 6. 1. 1964 an die Französische Republik zum „Fall Argoud“

S. $30 \mathrm{f}, 216$

- Note der Französischen Republik vom 30. 1. 1964 an die Bundesrepublik Deutschland zum „Fall Argoud“ S. $31^{20}, 217 \mathrm{f}$.

- Aide-mémoire der Bundesrepublik Deutschland vom 1.5. 1964 an die Volksrepublik Polen zum Gomulka-Plan S. 865

- Note der ČSSR vom 12. 5. 1964 an die NATO-Staaten zur MLF

Dok. 140

- Aide-mémoire der Französischen Republik, des Vereinigten Königreichs von Großbritannien und Nordirland sowie der USA vom 12. 6. 1964 an die UdSSR zum Freundschaftsvertrag zwischen der UdSSR und der DDR

S. 651,679

- Aide-mémoire der Bundesrepublik Deutschland vom 13. 6. 1964 an die UdSSR zum Stand der deutsch-sowjetischen Beziehungen

S. 879, 894 f., 951

- Aide-mémoire der Volksrepublik Polen vom 16. 6. 1964 an die Bundesrepublik Deutschland zum Gomulka-Plan S. $865 \mathrm{f}$.

- Note der UdSSR vom 25. 6. 1964 an die Französische Republik, das Vereinigte Königreich von Großbritannien und Nordirland sowie die USA gegen die Einberufung der Bundesversammlung nach Berlin (West)

S. 742

- Note der UdSSR vom 11. 7. 1964 an die Bundesrepublik Deutschland zur MLF S. $891^{20}, 1193$

- Aide-mémoire der UdSSR vom 27. 7. 1964 an die Bundesrepublik Deutschlands zum Stand der deutsch-sowjeti- schen Beziehungen

S. 879, 894, 951

- Aide-mémoire der Französischen Republik vom 17. 8. 1964 an die Bundesrepublik Deutschland zum Stand der deutsch-französischen Beziehungen

S. 972-974

- Note der Bundesrepublik Deutschland vom 2. 9. 1964 an die UdSSR zur MLF

S. $1193 \mathrm{f}$.

- Memorandum der DDR vom 4.9.1964 an die Teilnehmer der Konferenz der blockfreien Staaten

S. 1126-1129

- Memorandum der USA vom 9.9.1964 an die Bundesrepublik Deutschland zur Aufnahme einer Berlin-Klausel in die Ratifizierungsurkunden zum TeststoppAbkommen

S. 1035, 1037

- Note der Bundesrepublik Deutschland vom 11. 9. 1964 an die UdSSR zum „Fall Schwirkmann"

S. 1041

Oder-Neiße-Linie

siehe:

Deutsche Frage

Frankreich-Bundesrepublik

Israel-Bundesrepublik

Polen-Bundesrepublik

OECD (Organization for Economic Cooperation and Development)

S. 479, 571, 649

- Griechenland-Konsortium

S. 494,567

- Türkei-Konsortium

S. $117,232,236,779,1303,1541$

Österreich

siehe außerdem: Italien

S. 1540,1563

- Bundesrepublik Deutschland

Dok. 174 und S. 1120

- EFTA

S. $697,1456^{28}$

EWG

S. $119,126^{5}, 403,697,1120,1456$ 
- UdSSR

S. 108

Organisation für wirtschaftliche Zusammenarbeit und Entwicklung siehe: $O E C D$

Ostausschuß der deutschen Wirtschaft S. $228^{12}, 341 \mathrm{f} ., 927$

Ostblock-Staaten

siehe außerdem:

EWG

Frankreich

Großbritannien

NATO

Nichtangriffsabkommen

UdSSR

USA

VAR

- Berlin (West) in Abkommen (BerlinKlausel)

S. 55 f., 328, 438, 524, 586, 687, 842, 863

- Bundesrepublik Deutschland

Dok. 226, 391, 400 und S. 8, 14, 16, 55 f., $65,76,93 \mathrm{f}$., $147,288,298^{4}, 302,308,328$, 335 , 340f., 362, 384, 435, 441, 465, 469, $520,524,538,544,548,586,609 \mathrm{f}$., 628 , $644,730,740,852 \mathrm{f}$., $881,886,890,1198$, 1207, 1319 f., 1382 f., 1463

- Entwicklungshilfe S. 689

- Kredite westlicher Staaten

S. 7 f., 147, 227-229, 289, 609, 649, 1140, 1464

- Wiedergutmachung

S. 953

Ostgebiete des Deutschen Reiches unter fremder Verwaltung siehe: Deutsche Frage

Pakistan

S. 567

Panama

S. $204,208,354,414$

Paraguay

- „Fall Mengele“

Dok. 74, 371

Passierschein-Gespräche siehe außerdem: Berlin

Dok. 1, 26, 60, 92, 240 und S. $21 \mathrm{f}$., 36 ,
50 f., 56, 76, 91-94, 171 f., 196 f., 267 f., 287 , 299, 302-304, 306-308, 314f., 326 ${ }^{16}$, $327 \mathrm{f}$., 335 , $358 \mathrm{f}$., $380,383^{6}, 384,424,441,548$, 606, 850f., 853, 986-988, 1038, 1057

- Passierschein-Vereinbarung vom 17. 12.1963

S. $3^{1}, 5,287,409,847^{6}, 852,989$ f., 993 , 1021f., 1068-1071

- Passierschein-Vereinbarung vom 24. 9. 1964

Dok. 258 und S. 1139, 1318

- Unterschriftsformel

S. 990, 992, 1022 f., 1071

Peking Review

S. $96^{27}, 608^{10}$

Peru

S. $354,616,1011$

Philippinen

S. 83

Phoenix-Rheinrohr AG

siehe: Wirtschaftsunternehmen

Polen

siehe außerdem:

DDR

Frankreich

Großbritannien

Heiliger Stuhl

Polen-Bundesrepublik

S. 17, 53, 520, 522, 524, 1208

Abrüstung und Rüstungskontrolle

Dok. 398 und S. 1294

- Atomwaffen

S. 363

- europäische politische Union

S. 816

- EWG

S. 599

- GATT

S. 513

- UdSSR

S. $490,1074,1465$

- USA

S. 1294

Polen-Bundesrepublik Deutschland Dok. 80, 148 und S. 158, 810, 865-867

- Deutsche Frage und Wiedervereinigung S. $1560^{4}$ 
- Handelsvertretung in Warschau S. 1019

- konsularische Beziehungen S. 375 f., 1467

- Nichtangriffsvertrag Dok. 270, 397

- Oder-Neiße-Linie S. $376 f$., $463,490,901,1106,1467,1560^{4}$, $1562 \mathrm{f}$.

- Wirtschaftsbeziehungen S. 56,514

\section{Polyspinners} siehe: Wirtschaftsunternehmen

\section{Portugal}

- Bundesrepublik Deutschland Dok. 237 und S. $1176^{7}$

- europäische politische Union S. $751-755,771,815$

- Kolonialpolitik S. $497,537,931,979$

- NATO S. 534

Potsdamer Abkommen vom 2. August 1945

S. $54,87,337$ f., $367^{2}, 434^{20}, 475^{4}, 476,490$, 665,675 f., 685 f., 880 f., $898,901,973$, $1002^{10}, 1523,1560^{4}$

Pravda (Moskau)
S. $975^{2}, 1353$

Quick (Hamburg)

S. $680,1244^{1}$

Rapacki-Plan siehe: Abrüstung

Renmin Ribao (Peking)

S. 873

Republik China siehe außerdem:

Frankreich

S. $97,223,414,563$,

- EWG

S. 612

- Teststopp-Abkommen

S. 940

- UdSSR

S. 940,1279
- UNO

S. 462

- USA

S. 648

Republik Korea siehe außerdem: Frankreich Japan

- Bundesrepublik Deutschland Dok. 376

- Entwicklungshilfe S. 1458,1460

- USA S. 257, 1459 f.

- VAR S. 1375

Republik Vietnam siehe außerdem: Australien Demokratische Republik Vietnam Frankreich

S. $683,932,1016$

- Bundesrepublik Deutschland

Dok. 129 und S. $448,527^{7}, 535,541,566$ f., $583,623,653$ f., 763, 794, 810, 818, $1013 \mathrm{f}$.

- Neutralisierung

Dok. 130 und S. 45, 211, 224, 318, 413, $448,516,534,763,809$

- USA

S. $44,208,224,257 \mathrm{f}$., $515,522,535,541$, $549,551^{19}, 621-623,645,648,655,657$, $726,741,763,794,818,915^{5}, 921 \mathrm{f}$., $1013 \mathrm{f}$., 1146, 1571, 1573

- Volksrepublik China S. 646

Révolution (Paris)

S. 1024

Révolution africaine (Algier)

S. $732^{52}$

Rheinische Post (Düsseldorf)

S. $896^{2}$

Rheinischer Merkur (Koblenz)

S. 1075

Rhodesien

S. 497 
RIAS (Rundfunk im amerikanischen Sektor/Berlin)
S. 22

Rinascità (Rom)

S. $1353^{38}$

Römische Verträge vom 25. März 1957 siehe außerdem:

EURATOM

$E W G$

S. $26,46,118^{5}, 141,274,390,632,769,923$, $1266,1340,1430$

- EURATOM-Vertrag: Artikel 16 S. 1181

- EURATOM-Vertrag: Artikel 25 S. 1181

- EURATOM-Vertrag: Artikel 52 S. $1295^{12}$

- EURATOM-Vertrag: Artikel 77 S. 1177

- EURATOM-Vertrag: Artikel 79 S. 1178

- EURATOM-Vertrag: Artikel 84 S. $1177^{7}, 1178$

- EURATOM-Vertrag: Artikel 106 S. 1180

- EURATOM-Vertrag: Artikel 205 S. 1349

- EWG-Vertrag S. $67,1188,1224$

- EWG-Vertrag: Artikel 8 S. $119^{7}, 748^{46}, 875^{9}$

- EWG-Vertrag: Artikel 14 S. 1117

- EWG-Vertrag: Artikel 28 S. $1116^{3}$

- EWG-Vertrag: Artikel 39 S. 1113

- EWG-Vertrag: Artikel 110 S. 402,1113

- EWG-Vertrag: Artikel 111 S. 514

- EWG-Vertrag: Artikel 138 S. 1341

- EWG-Vertrag: Artikel 145 S. 282
EWG-Vertrag: Artikel 200 S. $875^{9}, 876^{10}$

- EWG-Vertrag: Artikel 227 S. 908

- EWG-Vertrag: Artikel 237 S. 1349

- Präambel S. $1091^{7}$

Rotes Kreuz

- Deutsches Rotes Kreuz S. $181^{6}, 409$ f., 701, 704 f., 1422

- Internationales Komitee vom Roten Kreuz

S. $13^{17}, 307,410$

Ruhr-Nachrichten (Dortmund) S. $896^{2}$

Ruhr-Stickstoff AG siehe: Wirtschaftsunternehmen

Rumänien siehe außerdem: DDR

Frankreich

Rumänien-Bundesrepublik

S. $742,883,1208,1354$

- UdSSR S. $17^{5}, 528^{6}, 729$

- Volksrepublik China S. 363

Rumänien-Bundesrepublik Deutschland S. 56, 529

- Familienzusammenführung Dok. 367 und S. 598

- Handelsvertretungen S. 1019

- Wirtschaftsbeziehungen Dok. 219

Salzgitter Industriebau AG siehe: Wirtschaftsunternehmen

Sansibar siehe außerdem: $D D R$ Tanganjika S. $84 \mathrm{f} ., 687$

- Bundesrepublik Deutschland Dok. 40 und S. 967 
- UdSSR

S. $392 f$.

Saturday Evening Post (New York)

S. 271

Saudi-Arabien

siehe außerdem:

Arabische Staaten

S. 1481

Schweden

siehe außerdem:

Kanada

S. $469,749,1050,1208,1540,1563$

- Bundesrepublik Deutschland Dok. 67

- EFTA

S. 326

- EGKS

S. 330

- EWG

S. $126^{5}$

- UNO

S. 347,583

Schweiz

siehe außerdem: Frankreich

S. 568, 591, 1563

- Bundesrepublik Deutschland S. 354

- EWG

S. $119,126^{5}, 513$

- UNO

S. $343^{3}, 345$

SEATO (South-East Asia Treaty Organisation)

S. 682

Selbstbestimmungsrecht

S. 10 f., 14, 16 f., $21,53,86,89,95,140,154$ 284 f., 327, 333, 384, 434, 461, 522f., 549, $566,587 \mathrm{f} ., 627,630,641,676,690,696$, $802,880,894,897,899,930,954,1125$, $1129,1152,1284,1364,1415,1458^{4}, 1469$, $1508,1525,1527,1529,1531 \mathrm{f} ., 1533^{22}$, $1538-1540,1564,1568 \mathrm{f}$.

Siemens-Halske AG siehe: Wirtschaftsunternehmen

Silasa siehe: Wirtschaftsunternehmen
Somalia

siehe außerdem: Kenia

S. 103

Sondierungsgespräche

siehe:

Abrüstung

Berlin

Sowexport

siehe: Wirtschaftsunternehmen

Sowjetunion siehe: $U d S S R$

Sozialdemokratische Partei Deutschlands siehe: $S P D$

Spanien siehe außerdem:

Belgien

Frankreich

$K u b a$

Marokko

Niederlande

Norwegen

- Bundesrepublik Deutschland

Dok. 94, 390 und S. 620, 901

- europäische politische Union

S. 751-755, 771, 815

- EWG

S. 146 f., $403,418-420,619$ f., 755

- UdSSR

S. 620,901

- UNO

S. 564

- USA
S. 619

SPD (Sozialdemokratische Partei

Deutschlands)

S. 150 f., $276^{5}, 304,308^{20}, 610,819,985$, $987,1257,1276,1310,1383,1409,1491$, 1516,1537

Stern (Hamburg)

S. $1244^{1}$

Sudan

S. 103 f., 1319, 1375

Sudetendeutscher Rat

S. $1124 \mathrm{f}$.

Südafrika

S. 497 
- Bundesrepublik Deutschlend Dok. 58 und S. 1152 f.

- GATT

S. 513

- UNO

S. 279

Süddeutsche Zeitung (München) S. $398^{14}, 1244^{1}, 1406^{4}$

Südkorea siehe: Republik Korea

Südostasienpakt-Organisation siehe: SEATO

Südvietnam siehe: Republik Vietnam

Suez-Krise von 1956 S. $271,345,420^{4}, 421,562,734,931,1375$, 1377,1481

\section{Syrien}

siehe außerdem:

Arabische Staaten

Israel

S. 1481

Taiwan

siehe: Republik China

Tanganjika

siehe außerdem:

$D D R$

Großbritannien

S. 1387

- Ausrüstungshilfe S. $103,191,392^{4}, 393,957,979-981,1377$

- Bundesrepublik Deutschland Dok. 86, 118, 228 und S. 854, 969

- Entwicklungshilfe S. 957

- EWG S. 403,1121

- Vereinigung mit Sansibar S. $503^{3}, 504$

Techmaschimport siehe: Wirtschaftsunternehmen

Telefunken GmbH siehe: Wirtschaftsunternehmen

Temporary Travel Documents (TTD) siehe außerdem: Belgien
Dänemark

Frankreich

Großbritannien

Heiliger Stuhl

Italien

Kanada

Norwegen

- Beschluß der NATO-Staaten vom 26. August 1961

S. $360^{28}, 405$

- Lockerung der TTD-Sperre

Dok. 91 und S. 360

Teststopp-Abkommen vom 5. August 1963

siehe außerdem:

Abrïstung und Rüstungskontrolle

$D D R$

Frankreich

Republik China

Volksrepublik China

S. $15,38,58,77,91,116,182,208,329,458$, $550,608,845,904^{2}, 939$ f., 1337,1522

- All-Staaten-Klausel

S. $1277-1279,1386$

- Berlin (West) in Abkommen (BerlinKlausel)

Dok. 250 und S. 371-373, 1016

- Bundesrepublik Deutschland: Beitritt S. $225,334,468,760,810,1016,1419$

- Ratifizierung durch die Bundesrepublik Dok. 78 und S. $176^{17}, 510,673$

Thailand

S. $319,516,1050$

- Bundesrepublik Deutschland Dok. 169

- Volksrepublik China S. 683

The New York Herald Tribune S. $262,271,470^{4}$

The New York Times

S. $35^{3}, 42^{2}, 261$ f., $304^{23}, 341^{33}, 670,871^{5}$, $887^{11}, 968^{4}, 1016^{6}, 1084 \mathrm{f} ., 1086^{9}, 1174$, $1205^{9+10}, 1231^{7}, 1286^{4}, 1369^{2}, 1487^{13}$, $1554^{20}, 1571-1573,1575^{16}$

The Spark (Accra)

S. 499

The Sunday Telegraph (London)

S. 982 
The Times (London)

S. $103^{10}, 174^{8}, 801^{15}, 1148,1213$ f., $1215^{2}$ $1365^{15}, 1405^{7}, 1511$

Tschad

S. $778 \mathrm{f}$

Tschechoslowakei siehe außerdem:

$D D R$

Frankreich

Tschechoslowakei-Bundesrepublik

S. 320,563 f., 729, 742, 934, 1021, 1208

- Abrüstung und Rüstungskontrolle S. 577

- Atomwaffen S. 363

- europäische politische Uniom S. 816

- NATO

S. $576 \mathrm{f}$.

- UdSSR

S. 1465

Tschechoslowakei-Bundesrepublik

Deutschland siehe außerdem: Münchener Abkommen S. $158,576-579,1132^{11}$

- Berlin (West) in Abkommen (BerlinKlausel)

S. $438 \mathrm{f}$., 708, 731, 842, $863 \mathrm{f}$., $1019,1061^{5}$, 1062-1065, 1353f., 1383, $1463 \mathrm{f}$.

- diplomatische Beziehungen S. $437,1061,1063$

- Familienzusammenführung S. $597 \mathrm{f}$.

- Grenzen S. $637,901,919,1125,1467,1568$

- Handelsvertragsverhandlungen S. 708, 1019f., 1062-1066, 1354

- Handelsvertretungen Dok. 100, 177, 256 und S. 56, 328, 362, $730,1019,1354,1463 \mathrm{f}$.

- Wiedergutmachung S. $597 \mathrm{f}$.

Türkei

siehe außerdem:

Frankreich

Griechenland

Großbritannien
Kanada

$O E C D$

S. 346,568

- Bundesrepublik Deutschland

Dok. 21, 333 und S. 299, 1034, 1250-1255, 1328

- EWG

S. 236,1303

- Keban-Staudamm

S. 1254,1303

- MLF

S. $451,1056,1253,1301$

- NATO

S. 102, 116, 122, 236, $976 f ., 1251,1364 \mathrm{f}$.

- türkische Arbeitnehmer in der Bundes. republik

S. 117

- UdSSR

Dok. 317 und S. $1301 \mathrm{f}$.

- USA

S. $1302 \mathrm{f}$.

- Verteidigungshilfe

S. $101 \mathrm{f} ., 116,977,1251,1300,1541$

- Wirtschaftshilfe

S. $116 \mathrm{f}$.

- Zypern

S. $115,169,347,794,818,1254,1301 \mathrm{f}$. $1328 \mathrm{f} ., 1365$

Tunesien

siehe außerdem:

Arabische Staaten

S. 1481

UdSSR (Union der Sozialistischen Sowjetrepubliken)

siehe außerdem:

Algerien

Brasilien

Dänemark

$D D R$

Frankreich

Ghana

Großbritannien

Indien

Israel

Italien

Japan

Jugoslawien 
Kanada

Kuba

Niederlande

Norwegen

Österreich

Polen

Republik China

Rumänien

Sansibar

Spanien

Teststopp-Abkommen vom 5. August 1963

Tschechoslowakei

Türkei

UdSSR-Bundesrepublik

S. 17, 32 f., 91 f., 142, 563

- Abrüstung und Rüstungskontrolle

S. $115 \mathrm{f}$., 184, 199, 201-203, $466 \mathrm{f}$., $508 \mathrm{f}$., 568f., 694, 1045-1049, 1072, 1159, $1208 \mathrm{f}$., $1294,1518,1520-1527$

- Afrikanische Staaten

S. 1191

- Blockfreie Staaten

S. 994,1046

- Kommunistische Partei der Sowjetunion (KPdSU)

S. $43^{4}, 1158$

- Kredite westlicher Staaten

Dok. 55, 192 und S. 56f., 63-66, 100, 192 , 196,220 f., 228,249 f., 262,609 f., 634 f., 843-845, 1122, 1269-1271, 1320, 1526

- Mittelstreckenraketen

S. $983,1047,1168,1305,1400,1475,1490$, 1504, 1519-1522, 1527, $1546 \mathrm{f}$.

- MLF

S. $284,329,508$ f., $686,696,891,1045$ 1049,1052 f., 1073, 1099, 1109, 1186, 1211, $1252,1287,1412,1494,1506,1508,1517^{3}$, 1518-1525, 1530

- NATO

S. 600 f., $976,977^{10}$

- Ostblock-Staaten

S. $55,606,646,686 \mathrm{f} ., 742,952-954,1018$, $1028,1317,1353,1381,1538$

- UNO

S. $384,462,564$ f., $1159,1192,1518$

- USA

S. $22,36-38,65,97,154,158,172,202,208$, $317,329,355,412,467 \mathrm{f} ., 507,521,547-$ $550,568,680^{3}, 681,766,772,784$ f., $788 \mathrm{f}$.,
835 f., $888,890,917-919,922$ f., 925,1045 , $1075,1168,1208,1210,1231,1268,1277 \mathrm{f}$., $1336,1380 \mathrm{f}$., $1386^{35}, 1489,1526,1529 \mathrm{f}$.

- VAR

S. $160^{4}, 457-459,573,656,712,996,999$, $1238,1353,1377$

- Volksrepublik China

S. $16,43,50,63,96,99 \mathrm{f} ., 198,211,213-$ $215,258,430,467,488,528-531,543-547$, $564,608,620,648,687,762,890,950,953$, $1023 \mathrm{f} ., 1072,1075,1191 \mathrm{f} ., 1252,1268 \mathrm{f}$., 1271, 1316 f., 1328, 1352 f., 1381 f., 1465

- Weizenlieferungen westlicher Staaten S. $65,108,116,288,334,384,523,634 \mathrm{f}$.

- wirtschaftliche Lage S. 50 f., $56,63,65,108,430,467$ f., 529,609 , $843,1073,1268,1270$ f., 1380

- Zypern S. $169,181,291,320,515,975$ f., 1253 f.

UdSSR-Bundesrepublik Deutschland Dok. 68, 84, 155, 211, 212, 286, 298, 304, 310,386 und S. $16,21,171,303,361$ f., 491, $529,545,607,749,767,888,973,974^{13}$ $1008 \mathrm{f} ., 1209,1267-1271,1556$

- Atomwaffen

Dok. 36 und S. 336-338, 411, 429, 1046 f., $1433,1518-1523,1525,1527$

- Berlin

S. $108,200,292,294,372,438,466,524$, $530,675,684-687,842,894,950,1036$, 1038,1100 f., 1211 f., 1419 f., 1433

- Chruschtschow-Besuch in der Bundesrepublik: Vorbereitungen

Dok. 150, 158, 163, 259 und S. 412, 431, 608, $666 \mathrm{f}$., 672, $903 \mathrm{f}$., $951,1004 \mathrm{f}$., $1009 \mathrm{f}$. $1015,1017 \mathrm{f}$., $1027-1030,1039,1043 \mathrm{f}$. 1055 f., 1082, 1172, 1317 f., 1353, 1382

- Deutsche Frage und Wiedervereinigung Dok. 16, 35, 162, 209, 291, 369 und S. 53, $74 \mathrm{f} ., 77,213,266^{3}, 268,326 \mathrm{f}$., 334-340, 356-358, 383f., 433 f., $443 \mathrm{f}$., 465-467, 469, $486,517,520-524,530-532,605$ f., $627-$ $630,675,684-687,841 \mathrm{f} ., 894,897-899$, $901 \mathrm{f}$., $904^{2}, 905,951,1004,1017 \mathrm{f}$., 1072 $1075,1211,1231,1332,1352,1385,1468 \mathrm{f}$. $1493,1508,1518,1523,1525-1533$

"Fall Schwirkmann"

Dok. 252 und S. 1027 f., 1075 
- Freilassung der Studenten Naumann und Sonntag

S. $706 \mathrm{f} ., 1212$

- Kreditgewährung S. $63-66,108 \mathrm{f} ., 193,196,289,330,1211$, 1271

- Kulturbeziehungen S. 170 f., $530,894,950,1419$ f.

- Repatriierung Dok. 176

- Röhrenembargo S. $109,385,1211$

- Wirtschaftsbeziehungen Dok. 19 und S. 65, 273, 333 f., 385, 412 , $530,629,900,950,1211,1526$

\section{Uganda}
S. $403,1121,1375,1387$

\section{Ungarn}

siehe außerdem:

$D D R$

S. 365,729 f., 883

- Bundesrepublik Deutschland S. 1019

Union der Sozialistischen Sowjetrepubliken siehe: $U d S S R$

UNO (United Nations Organisation)
siehe außerdem:
Berlin
Dänemark
DDR
Finnland
Irland
Israel
Japan
Jugoslawien
Kanada
Kongo
Norwegen
Portugal

Republik China

Schweden

Schweiz

Spanien

Südafrika

UdSSR

Volksrepublik China

S. $83^{54}, 181,969,1046,1049,1052,1055$,
$1082,1099,1110,1183,1204,1208,1253$, 1277-1280, 1539 f., $1562 f$.

- Abrüstung und Rüstungskontrolle

\section{S. 1554}

- Bundesrepublik Deutschland

Dok. 135, 142, 159 und S. 88, 146, 279, 343-346, 348f., 460-462, 592, 762, 1126 , $1128,1192,1207$

- Deutsche Frage und Wiedervereinigung S. $12,441,461,565,641,1531$

- International Development Agency S. $313^{13}$

- Menschenrechtskommission S. $10^{2}$

- ständige Friedenstruppe

S. 642

- UNCTAD

\section{S. $146^{29}$}

- UNESCO
S. $88^{9}, 253$

- UNO-Charta

S. $179^{24}, 285,346,563,641,643,648 \mathrm{f} ., 676$, $954,1128^{5}, 1192^{26}, 1381$

- WHO
S. $88^{9}, 319$

\section{Uruguay}

S. 354

USA (United States of America) siehe außerdem:

Australien

Belgien

Dänemark

Demokratische Republik Vietnam

Frankreich

Großbritannien

Indonesien

Israel

Italien

Jugoslawien

Kongo

Kuba

Laos

Niederlande

Polen

Republik China

Republik Korea

Republik Vietnam

Spanien

Teststopp-Abkommen vom 5. August 1963 
USA-Bundesrepublik Deutschland

Türkei

UdSSR

USA-Bundestepublik

Dok. 264 und S. 563, 1537

- Abrüstung und Rüstungskontrolle S. 38 f., 59 f., $182-187,202$ f., $267,329,363$, $441,466,568$ f., 695, 1045, 1205, 1208, 1293 f., 1296, 1553 f., 1570,1574 f., 1577

- Afrikanische Staaten S. 980, 1387

- Allianz für den Fortschritt S. $242^{22}, 616$

- Arabische Staaten S. 656

- atlantische Partnerschaft S. $111,119,134,154$ f., 302, 374, 402, 480, $657,718,922,1031,1291^{4}, 1347$

- Atomenergie-Gesetz (McMahon Act) S. 318,1045

- Demokratische Partei S. $98^{37}$

- EFTA S. $325 \mathrm{f}$

- europäische Atomstreitmacht S. 1332

- europäische politische Union S. $68 \mathrm{f} ., 1430$

- EWG

Dok. 81 und S. 204f., 325, 515, 817, 1118 f., $1162,1223,1225$ f., 1437

- GATT

S. 67,330

- „Hähnchenkrieg“ mit der EWG S. 655

- Kongreß S. $48^{14}, 114,428,455,654$ f., 794,1079 , $1105^{7}, 1286,1494,1555,1571,1574$

- Lateinamerika S. 208, 212, 242, 259f., 427, 615, 617, 920

- Marshall-Plan (European Recovery Program) S. $499^{20}$

- MLF

Dok. 281, 401 und S. 48, 71, 121, $154 \mathrm{f}$. $302,428 \mathrm{f}$., $450 \mathrm{f}$., $453-456,508,536,658$, 982, 1046 f., 1050 f., 1054-1056, 1078-1084, $1090,1110,1155 \mathrm{f} ., 1185 \mathrm{f} ., 1211,1220-$
1222,1258 f., $1286,1306-1308,1323,1330$ $1333,1389,1398,1400-1402,1408$ f., 1411 , $1436,1444,1449 \mathrm{f} ., 1452^{9}, 1454^{18}, 1477$, 1485-1492, 1494, 1499-1502, 1504-1506, $1512,1536,1541-1543,1545-1555$

\section{NATO}

S. $122,204,246,316 f ., 536,602,776,812$ f., $933,1086,1104 \mathrm{f}, 1322,1325,1575 \mathrm{f}$

- Ostblock-Staaten: Handel und Kredite S. 20

- Republikanische Partei

S. $47,321,655,658$

- Senat

S. 414,510

- strategische Konzeption

S. $1167 \mathrm{f}$., $1259 \mathrm{f} ., 1398,1410,1475$ f.

- Streitkräfte in Europa

S. 137, 195, 536, 765, 887, 1190, 1337, 1408, 1410 f., 1474 f., 1479

- UNO

S. 583

- VAR

S. 415 f., 460,1534

- Volksrepublik China

S. 98, 211 f., 224, 414, 546 f., $565^{19}, 589$, 622-624, $647 \mathrm{f}$., 654, 726, 766, 771f., 784, $788,816,835,863,872,890,1024,1190$, $1192,1204 \mathrm{f}$

- Wahlen

S. $38,47,137,204,209,321,414,428,430$, $454,486,511,524,529,531,548,550,580$, $613,623,647,652,655,658,694,726,741$, $750,790,795,812-814,924,1006$ f., 1015 , $1075,1146,1278^{4}, 1324,1408$

- Zahlungsbilanz

S. $232,468,479,555-558,561$

- Zolltarife

S. 1312

- Zypern

Dok. 71 und S. 793 f., 818

USA-Bundesrepublik Deutschland

Dok. 5, 20, 42, 63, 93, 98, 103, 123, 134, $136,160,161,189,195,196,217,232,246$, $307,338,339,341,353,360,361,363,370$, 380,392 und S. 25-29, 47, 134, 137, 146, 168-170, 186 f., 204 f., 209 f., 213, 255-263, $315^{2}, 323,340,342,344,347-349,392$, 454-456, 470-474, 478f., 507-509, $540 \mathrm{f}$. 
588f., 604, 673, 714 f., $717,750,760,775$ f., $785,886,890,892,973$ f., $1030,1032 \mathrm{f}$., 1035 f., 1051, 1054, 1056-1060, 1072-1076, 1081-1084, 1109-1111, 1146-1149, 1154$1156,1190 \mathrm{f} ., 1209,1257,1260,1269$, 1279 f., 1285-1287, 1296, 1322, 1398, 1447 , 1534-1536

- Ausrüstungshilfe: Koordinierung S. 102

- Berlin

Dok. 132 und S. 5 f., $380,443,465$ f., 1038, 1100 f., $1276 \mathrm{f} ., 1418-1420,1434$

- Deutsche Frage und Wiedervereinigung Dok. 9, 111, 152, 168 und S. 40, 75 f., $78 \mathrm{f}$., $266-268,302-304,355 \mathrm{f}$., 433, 441-445, 448, 464-466, 468, 491f., 519, 522-524, 531 f., 545 f., 548-550, 566, 644-646, 652, 657f., 685-687, 725, 765-767, 772, $788 \mathrm{f}$., $835 \mathrm{f}$., $887 \mathrm{f}$., 996, 1015f., $1037 \mathrm{f}$., $1384 \mathrm{f}$., 1410 f., $1437,1469,1528^{4}, 1529-1533,1543$

- Devisenausgleich

Dok. 119, 125, 399 und S. $7^{1}, 61^{40}, 247$, $417,496,517$ f., 556 f., $566,593,656$ f., 659 , $706,810,877,890^{19}, 1012^{49}, 1371,1373$, 1437

- Entwicklungshilfe: Kooperation S. 242, 260, 567, 573

- Stahlzölle S. $19 \mathrm{f}$.

- Streitkräfte in der Bundesrepublik Deutschland und Berlin

Dok. 72 und S. 247, 281, 496, 505, 517, $526,550,551^{19}, 557,568$ f., $680^{3}, 681,718$ f. 758-760, 767, 956, 1016 f., 1073

US Steel Corporation siehe: Wirtschaftsunternehmen

VAR (Vereinigte Arabische Republik) siehe außerdem:

Arabische Staaten

Belgien

$D D R$

Großbritannien

Israel

Italien

Jemen

Marokko

Republik Korea

UdSSR
USA

S. $572,732,1048$ f., 1052,1208

Ostblock-Staaten

S. 421

VAR-Bundesrepublik Deutschland

Dok. 32, 95, 242, 280, 325, 326, 340, 352, 385 , 394 und S. 415 f., $458-460,649 \mathrm{f}$., $694^{2}, 996,1126,1182-1184,1237$ f., 1247 , 1481

atomare Meerwasser-Entsalzungsanlage Dok. 332 und S. 1283, 1335

Deutsche Frage und Wiedervereinigung S. 1297

- Rüstungsfachleute aus der Bundesrepublik

Dok. 164 und S. 112, 272, 459 f., 712, 1244, $1245^{9}, 1247,1334$ f., 1558

- Waffenlieferungen der Bundesrepublik an Israel

S. $1165^{6}, 1297$ f., $1374^{3}, 1376$ f., 1516,1534 , $1535^{9}$

- Wirtschaftshilfe

Dok. 345 und S. 459 f., 1143, 1238, 1283, $1335,1374^{3}, 1556 \mathrm{f}$.

Vatikan

siehe: Heiliger Stuhl

Venezuela

S. 1050

Vereinigte Arabische Republik siehe: VAR

Vereinigte Staaten von Amerika siehe: USA

Vereinte Nationen siehe: UNO

Verteidigungshilfe siehe außerdem: Griechenland Türkei

S. 858

Vier-Mächte-Verantwortung für

Deutschland als Ganzes siehe: Deutsche Frage

Vietnam

siehe:

Demokratische Republik Vietnam Republik Vietnam 
Voice of America

S. $22^{15}$

Volksrepublik China

siehe außerdem:

Algerien

Dänemark

$D D R$

Demokratische Republik Vietnam

Frankreich

Großbritannien

Indien

Kanada

Kongo

Laos

Niederlande

Norwegen

Republik Vietnam

Rumänien

Thailand

UdSSR

USA

Volksrepublik China-Bundesrepublik

S. $84,638,682$

- Abrüstung und Rüstungskontrolle S. 1204-1206, $1210^{27}$

- Afrikanische Staaten

S. 1191

- Atomwaffen

S. $488,552,1191,1204,1319,1449,1511$, 1554,1575

- Kommunistische Partei Chinas (KPCh) S. $43^{4}, 1023,1252$

- Theorie der "Zwischenzone“

S. 544

- UNO

S. $43,98,214,258,319,365,462,564$, $565^{19}, 648,1192,1204 \mathrm{f}$.

- wirtschaftliche Lage

S. 258

Volksrepublik China-Bundesrepublik

Deutschland

S. $100,193,213,257$ f., $285,511,529 f$., 788 $890^{19}, 973$

- Berlin (West) in Abkommen (BerlinKlausel)

S. 542 f., $545,586-588,612,726,741,864$, 873

- Deutsche Frage und Wiedervereinigung S. $873^{10}, 893$
- diplomatische Beziehungen

S. 1190

- Handelsvertretungen

S. $542^{4}, 543,587,654,726,810,872$

- Kulturabkommen S. $542^{4}, 543,587$

- Warenabkommen

Dok. 69, 131, 143, 206, 236 und S. 612, $648,654,722^{25}, 726$ f., $741,810,863$ f., 893 , 1023 f., 1075

Volkswagenwerk AG

siehe: Wirtschaftsunternehmen

Waffen- und Luftrüstungs-AG

siehe: Wirtschaftsunternehmen

Warschauer-Pakt-Organisation siehe außerdem: Nichtangriffsabkommen

S. $199,202,295,326^{16}, 684$ f., 952,1252

Washingtoner Botschaftergruppe

S. $10^{2}, 41,50-55,74$ f., 77 f., $94,213,233$, $266^{3}, 268,276,355$ f., $358^{21}, 432 \mathrm{f}$., $440 \mathrm{f}$., $444,457,464$ f., 487, 517, 519, 525, 533, $566,647,673,677-680,684-687,698,728$, $729^{30}, 1073^{5}, 1203,1384^{26}, 1385,1543$, 1565

\section{Washington Post}

S. 1571

Weltbank

S. $313^{13}, 559$

Westinghouse Electric siehe: Wirtschaftsunternehmen

WEU (Westeuropäische Union) siehe außerdem:

Frankreich

Großbritannien

Niederlande

S. 25, 69, 87, 118, 301, 751 f., 914, 1347

- Bundesrepublik Deutschland

S. 48, 154, 1135 f., 1194, 1313-1315

- Konsultationen

Dok. 277

Lateinamerika

S. 400

Wiedervereinigung

siehe: Deutsche Frage 
Wirtschaftsunternehmen

- AEG (Allgemeine Elektrizitätsgesellschaft)

S. 962 f., $972^{4}, 1298^{6}$

- Boeing Airplane S. 1491

- Bölkow GmbH S. $1491 \mathrm{f}$.

- Ferrostaal AG S. 1273

- Fiat S. 231

- Gebrüder Junghans AG S. 269,711

- Hochtief AG S. $1298^{6}$

- Klöckner-Humboldt-Deutz AG S. $1195^{2}, 1196^{7}$

- Montecatini Società Generale S. 231

- Nord et Sud Aviation S. $1491^{43}$

- Phoenix-Rheinrohr AG S. $946^{5}$

- Polyspinners S. $1122^{39}$

- Ruhr-Stickstoff AG S. $423 \mathrm{f}$.

- Salzgitter Industriebau AG S. $221^{22}$

- Siemens-Halske AG S. $19,1298^{6}, 1509$

- Silasa S. 19

- Sowexport S. 1483

- Techmaschimport S. $1122^{39}$

- Telefunken GmbH S. $254^{35}, 963^{4+6}$

- US Steel Corporation S. $19^{5}, 20$

- Volkswagenwerk AG S. 153
- Waffen- und Luftrüstungs-AG

S. $173,174^{7}$

- Westinghouse Electric

S. 19

- Zeiss Ikon AG

S. 1309

WHO (World Health Organisation) siehe: $U N O$

\section{Zeiss Ikon AG}

siehe: Wirtschaftsunternehmen

Zwei-Staaten-Theorie siehe: Deutsche Frage

Zypern

siehe außerdem:

DDR

Demokratische Republik Vietnam

Frankreich

Griechenland

Großbritannien

Niederlande

Türkei

UdSSR

USA

S. 537

- Acheson-Plan

S. 1365

- Bundesrepublik Deutschland

Dok. 34, 37, 70, 349, 365 und S. 192, 234, $259,291,348,562,582$ f., 969,976

- Entwicklungshilfe

S. $1367 \mathrm{f} ., 1416 \mathrm{f}$.

- Truppenkontingente aus NATO-Staaten S. 169,180 f., $192^{6}, 234,259,291,320,515$, 583,969

- UNO

S. $515,1301,1365$

- UNO-Friedenstruppe

S. 169, 234, 291, 343-349, 582 f., 641, 976 f.

- Zypern-Konflikt

Dok. 235 und S. 204, 331, 774, 932, 1056, $1364 f$. 


\section{Organisationsplan des Auswärtigen Amts vom Juli 1964}




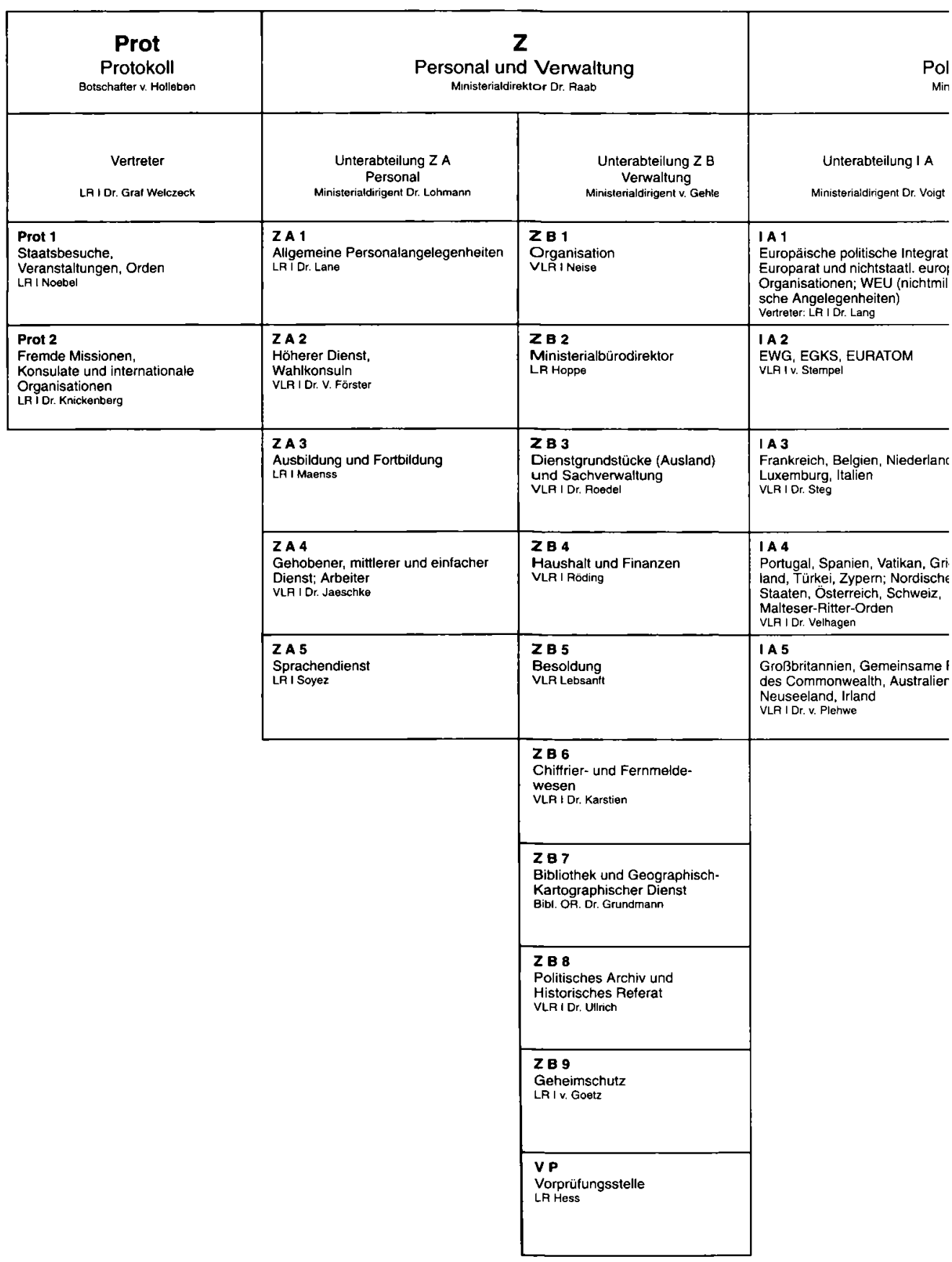




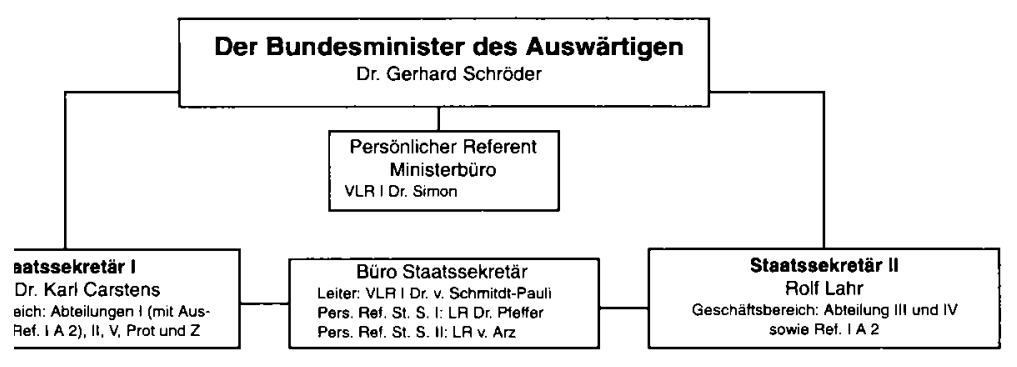

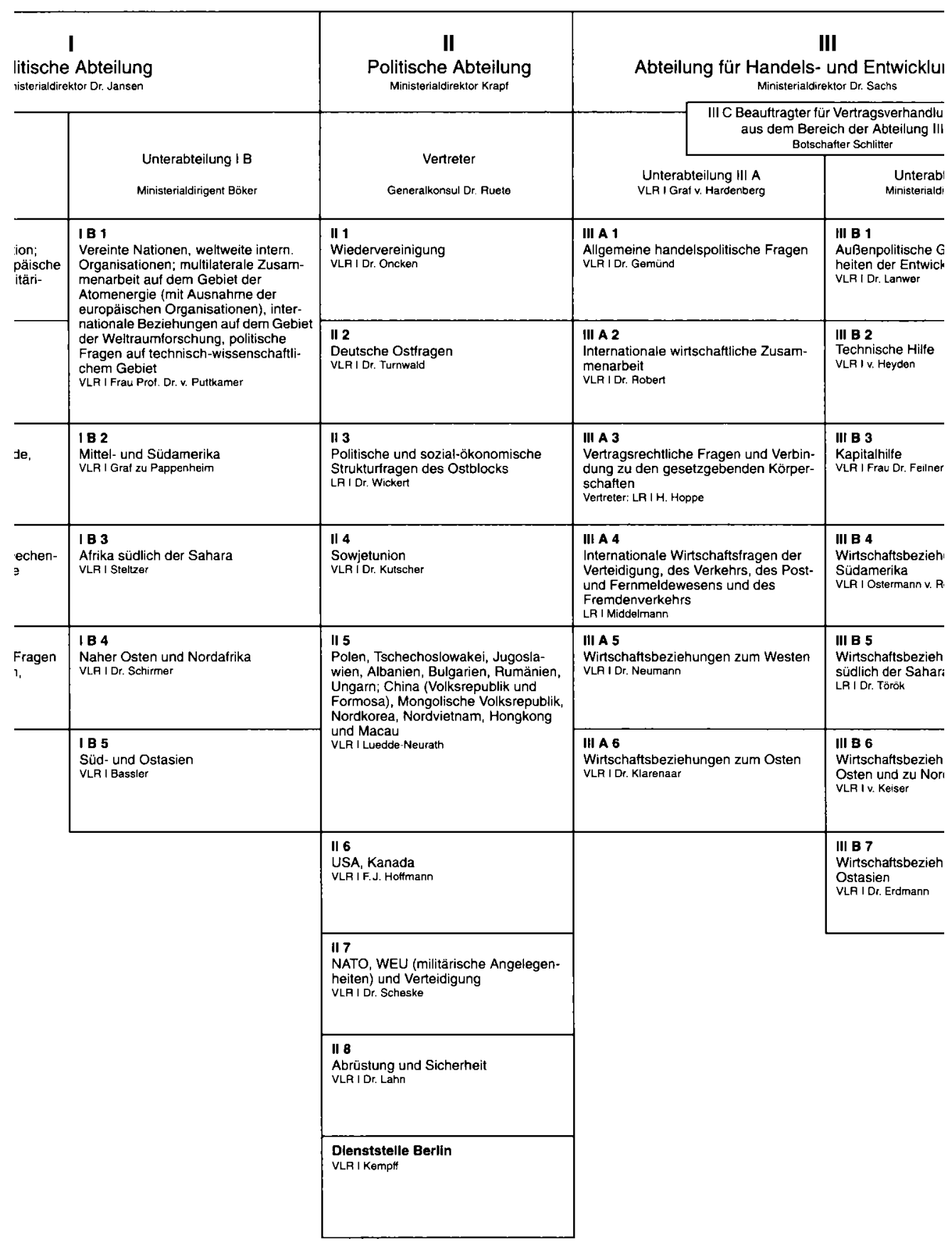




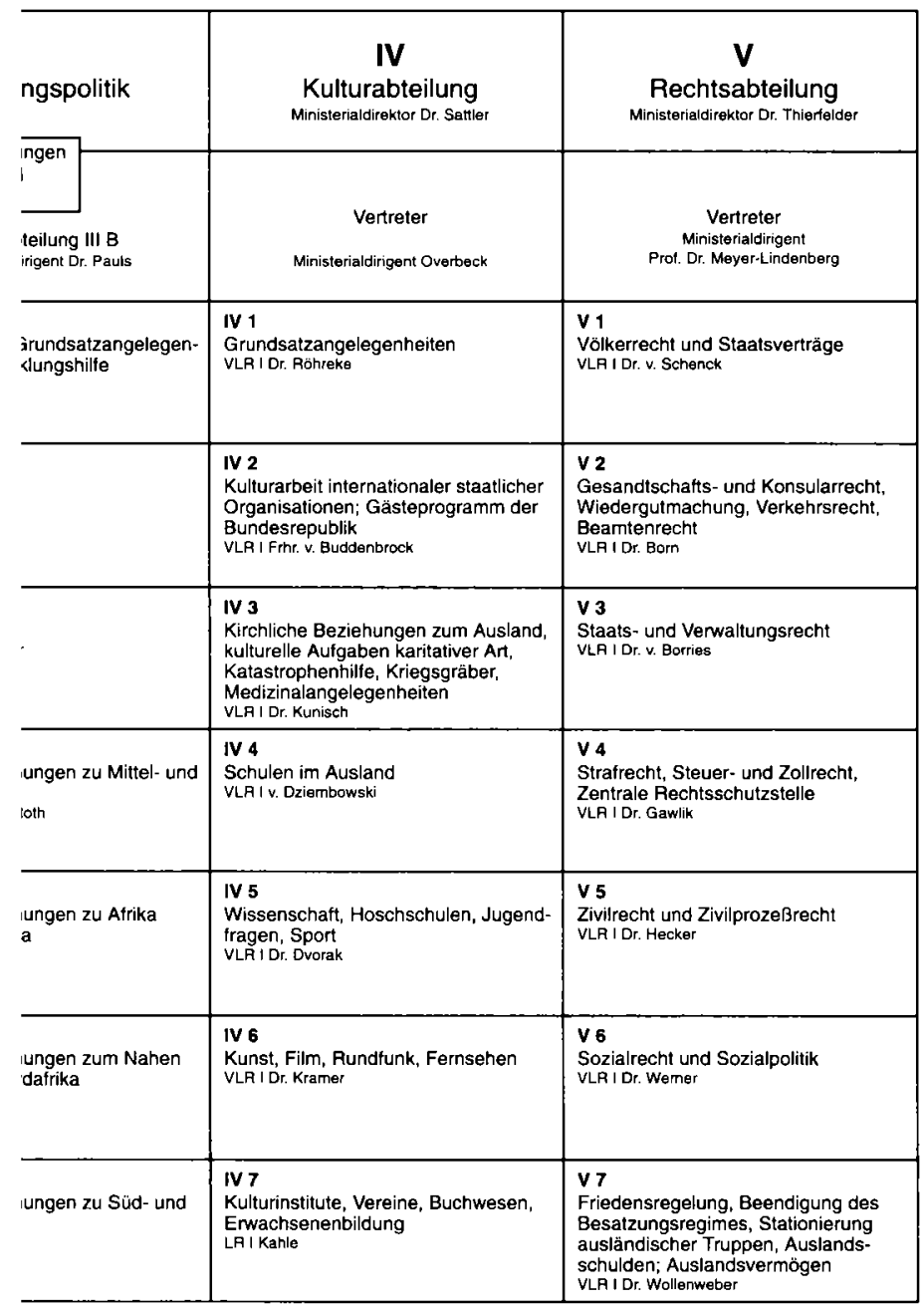

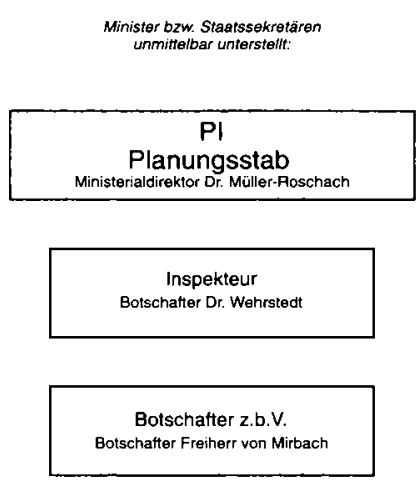

L 1

Parlaments- und Kabinettsrelerat VLF I Balken

\section{2}

Inlandsreterat

VLF I Dr. K. Hoffmann

L 3

Informationsreferat Ausland

LR I Borchardt

\section{4 \\ Pressereferat \\ VLRI Dr. Hille}

